\title{
Essays on Structural Changes, US Business Cycles and Monetary Policy
}

\author{
by
}

\begin{abstract}
Joshua Brault
A thesis submitted to the Faculty of Graduate and Postdoctoral Affairs in partial fulfillment of the requirements for the degree of
\end{abstract}

\author{
Doctor of Philosophy \\ in \\ Economics
}

Department of Economics

Carleton University

Ottawa, Ontario, Canada

(C) 2021

Joshua Brault 


\section{Abstract}

In this thesis I study a major structural change in the US economy, namely, the consequences of the Great Moderation on the US economy and the operation of monetary policy.

My first chapter explores a variety of empirical relationships on lead-lag properties of the US business cycle and how these relationships have changed since the onset of the Great Moderation. We emphasize four major changes in lead-lag properties. Since these relationships serve as a benchmark for many models of the business cycle, we examine if a variety of models can account for these changes. We find that they cannot.

My second chapter provides an explanation for the first property in my first chapter, that the real interest rate switched from negatively leading the US business cycle to positively lagging. The explanation rests on the fact that uncertainty about the current state of the economy has become less severe since the onset of the Great Moderation. This allows policymakers to set monetary policy closer to their rule-based policy prescription under no uncertainty and reduce unintended monetary induced fluctuations.

My third chapter explores business cycle asymmetry prior to and after the Great Moderation. I show that the business cycle has become more asymmetric since the onset of the Great Moderation with booms becoming smaller and busts staying relatively the same. I highlight that this type of asymmetry is consistent with a class of models which feature occasionally binding collateral constraints. 
My fourth chapter is a contribution to New Keynesian (NK) models. In a standard NK model, monetary policy operates through the real interest rate channel. This channel has recently drawn some criticism when the model is extended to include capital accumulation. In this setting it is possible for the real interest rate to fall in response to a positive monetary policy shock, contradicting the intuition of the real interest rate channel. We show that result vanishes when frictions on the flow of investment are present, as in modern NK models. Under this framework the response of the real interest rate is always the same as the monetary policy shock. 
To my Mother, Lesa Helen Brault 


\section{Acknowledgments}

I thank my supervisor, Hashmat Khan, for his support and guidance throughout my PhD. I learned a great amount from him and always enjoyed our collaborations. He has always been supportive and enthusiastic about my work, which made my $\mathrm{PhD}$ a very enjoyable experience. I am looking forward to our future collaborations.

I also thank my thesis committee members Chris Gunn and Lilia Karnizova. They have always provided great feedback on my work and been available for any of my questions. Both of them have always extended opportunities to put a spotlight on my work through presentations and meetings with external speakers, which I always appreciated. I am particularly thankful to Dana Galizia for his input into many of my papers, attending my seminars, and providing feedback. I was a research assistant to Dana for an extended period of time during my $\mathrm{PhD}$ which was very beneficial to me.

I also thank the economics faculty at Carleton University. I have benefited from my interactions with them throughout my $\mathrm{PhD}$ and received feedback from many in my preparation for the job market.

Lastly, I would like to thank all the administrative staff in the Department of Economics throughout my PhD: Dawn Bjornson, Marge Brooks, Kaylen Brzezinski, Rowan Brzezinski, Alison Dailey, Najia Haneefi, Renée Lortie, Sabrina Robineau, and Amanda Wright. They were always extremely helpful whenever I had questions or needed some assistance. This made my life infinitely easier and allowed me to put more focus on my research. 


\section{Contents}

Abstract

Acknowledgements iv

List of Tables $\quad$ ix

List of Figures $\quad$ xii

1 The Shifts in Lead-Lag Properties of the US Business Cycle 1

1.1 Introduction . . . . . . . . . . . . . . . . 1

1.2 Shifts in Lead-Lag Properties . . . . . . . . . . . . . 5

1.2.1 Data . . . . . . . . . . . . . . 6

1.2.2 Real Interest Rates Positively Lag Output . . . . . . . 6

1.2.3 Labour Productivity Negatively Lags Output . . . . . 14

1.2.4 Labour Inputs Negatively Lead Labour Productivity 19

1.2.5 Unemployment Rate Positively Leads Labour Productivity . . . . . . . . . . . . . . . . 21

1.2.6 An informative check . . . . . . . . . . . . 23

1.3 Robustness . . . . . . . . . . . . . . . . . . . . 24

1.3.1 Alternative filters . . . . . . . . . . . . . . . 24

1.3.2 Broader business cycle phase of 8-50 quarters . . . . . 25

1.3.3 Demographic adjusted hours . . . . . . . . . . 26

1.3.4 Standardized variables . . . . . . . . . . 26 
1.3.5 Filtering on subsamples . . . . . . . . . . . 27

1.3.6 Alternative samples . . . . . . . . . . . . . . 27

1.3.7 Parameterization versus model structure . . . . . . 27

1.4 Conclusion . . . . . . . . . . . . . . . . . . . . . . . . . . . 28

2 Monetary policy uncertainty and the cyclicality of interest rates

2.1 Introduction . . . . . . . . . . . . . . . 35

2.2 Empirical investigation into noise . . . . . . . . . . 45

2.2.1 Real-time measurement error . . . . . . . . . . 45

2.2.2 Fed Greenbook forecasts . . . . . . . . . . . . . . . . 48

2.3 Model, Solution, and Estimation . . . . . . . . . . . . 52

2.3.1 Model .................. . . 52

2.3.2 Solution . . . . . . . . . . . . . . . 54

2.3.3 Estimation . . . . . . . . . . . . . 57

2.4 Results and discussion . . . . . . . . . . . . . . 61

2.4.1 Uncertainty and the cyclicality of the nominal and real interest rate . . . . . . . . . . . . . . 63

2.4 .2 Technology shocks . . . . . . . . . . . 73

2.5 Conclusion . . . . . . . . . . . . . . . . . . 75

3 Has the US Business Cycle Become More Asymmetric? 81

3.1 Introduction . . . . . . . . . . . . . . . . 81

3.2 Deepness and Steepness . . . . . . . . . . . . . 83

3.2.1 Detrending ................. . 85

3.2.2 Coefficient of Skewness Test . . . . . . . . . . 86

3.3 Results . . . . . . . . . . . . . . . . . . . . . 88

3.3.1 Sensitivity . . . . . . . . . . . . . 93

3.4 Models With Occasionally Binding Constraints . . . . . . . . 94

3.4.1 A Partial Equilibrium Model With Housing As Collateral 95

3.4.2 General Equilibrium .............. . 99 
3.5 Conclusion . . . . . . . . . . . . . . . . . 100

4 The real interest rate channel is structural in contemporary New-Keynesian models: A Note 105

4.1 Introduction . . . . . . . . . . . . . . . . . . 105

4.2 New-Keynesian Model With Capital . . . . . . . . . . 108

4.2.1 Long-run real interest rates and investment . . . . . . . 111

4.3 Conclusion . . . . . . . . . . . . . . . . . . . . . . 114

$\begin{array}{ll}\text { Appendices } & 118\end{array}$

A Appendix to The Shifts in Lead-Lag Properties of the US Business Cycle 119

A.1 Cross-correlations across filters . . . . . . . . . . . . . . 119

A.2 Standard errors of the cross-correlations . . . . . . . . 119

A.3 Literature studying business cycle cross-correlations . . . . . 120

A.4 Replication codes . . . . . . . . . . . . . . . . . . 121

A.5 Data and Definitions . . . . . . . . . . . . 130

A.6 Alternative definitions of real interest rate . . . . . . . . 131

A.7 Alternative sample periods . . . . . . . . . . . . . . 135

A.8 Extending the definition of the business cycle to 8-50 quarters 135

A.9 Robustness to standardized volatility . . . . . . . . . . 140

A.10 Filtering on subsamples . . . . . . . . . . . . . . 143

A.11 Demographic adjusted productivity . . . . . . . . . . . 143

A.12 Jordá, Schularick, and Taylor (2016) . . . . . . . . . . 146

B Appendix to Monetary policy uncertainty and the cyclicality of interest rates 153

B.1 Proofs of Propositions . . . . . . . . . . . . . . 153

B.2 Derivation of the economic model . . . . . . . . 155

B.2.1 Households . . . . . . . . . . . . . . . . 155

B.2.2 Final goods firms $\ldots \ldots \ldots \ldots \ldots$ 
B.2.3 Intermediate goods firms . . . . . . . . . . . 157

B.2.4 Monetary policy . . . . . . . . . . . . . . . 158

B.2.5 Equilibrium and Log-linearization . . . . . . . . . . 158

B.3 Model setup and solution . . . . . . . . . . . . . . . . . 163

B.3.1 Computing impulse response functions . . . . . . . 166

B.4 Data and Estimation . . . . . . . . . . . . . . 167

B.4.1 Data . . . . . . . . . . . . . . . . 167

B.4.2 Estimation . . . . . . . . . . . . . . . . 168

B.5 Additional results . . . . . . . . . . . . . . . . . 171

C Appendix to Has the US Business Cycle Become More Asymmetric? 173

C.1 Data Sources . . . . . . . . . . . . . . . . . . . . 173

C.2 Bai and Ng (2005) Standard Errors for Sample Skewness . . . 174

C.3 Additional Results . . . . . . . . . . . . . . . . . 175

D Appendix to The real interest rate channel is structural in contemporary New-Keynesian models: A Note 180

D.1 The Model . . . . . . . . . . . . . . . . . . . . . . . . . . . . 180

D.1.1 Households . . . . . . . . . . . . . . . . . . . 180

D.1.2 Intermediate firms . . . . . . . . . . . . . . . 181

D.1.3 Final goods firms . . . . . . . . . . . . . . . 182

D.1.4 Monetary policy rule and market clearing conditions . 183

D.1.5 Solving for the steady state . . . . . . . . . . 183

D.1.6 Log-linearizing the model . . . . . . . . . . . . . 184

D.2 Dynare Codes . . . . . . . . . . . . . . . . . . . 186 


\section{List of Tables}

2.1 Standard deviation of output growth and inflation real-time measurement errors . . . . . . . . . . . . . . 48

2.2 Standard deviation of Greenbook forecast errors in output growth and inflation . . . . . . . . . . . . 51

2.3 Prior and posterior distributions of structural parameters and shock processes . . . . . . . . . . . . . . . . . . 59

2.4 Contemporaneous comovements conditional on a preference

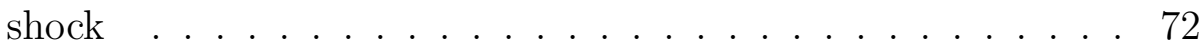

3.1 Average Booms, Busts, Expansions and Contractions _. . . . 89

3.2 Coefficient of skewness test _. . . . . . . . . . . . 91

3.3 Changing Business Cycle Asymmetry _. . . . . . . . . . . 92

3.4 Deepness and steepness from the model _ . . . . . . . . . . 98

3.5 Deepness and Steepness from Guerrieri and Iacoviello (2017) . 100

A.1 Cross-correlations and volatilities using the Hodrick-Prescott filter . . . . . . . . . . . . . . . . . . 122

A.2 Cross-correlations and volatilities using the $h p$ filter (Hamilton

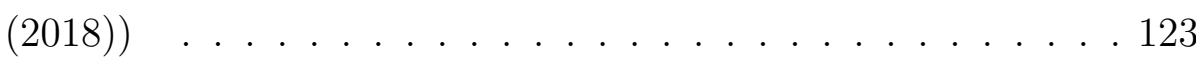

A.3 Cross-correlations and volatilities using the Baxter and King (1999) filter . . . . . . . . . . . . . . . . . 124

A.4 Cross-correlations and volatilities using the Christiano and Fitzgerald (2003) filter . . . . . . . . . . . . . 125 
A.5 Data sources . . . . . . . . . . . . . . . . . . 130

A.6 Cross-correlations using alternative measures of the real interest rate, pre-1985. . . . . . . . . . . . . . . . . 133

A.7 Cross-correlations using alternative measures of the real interest rate, post-1985. . . . . . . . . . . . . . . . . 134

A.8 Cross-correlations and volatilities using Hodrick-Prescott filter, excluding the Great Recession . . . . . . . . . . 136

A.9 Cross-correlations and volatilities using Hodrick-Prescott filter, alternative onset of Great Moderation 1983Q1 . . . . . 137

A.10 Cross-correlations and volatilities using Baxter and King (1999) filter, 8-50 quarters . . . . . . . . . . . . . . . . . 138

A.11 Cross-correlations and volatilities using Christiano and Fitzgerald (2003) filter, 8-50 quarters . . . . . . . . . . . . 139

A.12 Cross-correlations and volatilities using Hodrick-Prescott filter, standardizing entire sample . . . . . . . . . . . . . 141

A.13 Cross-correlations and volatilities using Hodrick-Prescott filter, standardizing each subsample _ . . . . . . . . . . . 142

A.14 Cross-correlations and volatilities using Hodrick-Prescott filter, filtering pre- and post subsamples . . . . . . . . . . . . 144

A.15 Cross-correlations and volatilities using demographic adjusted hours in definition of output per hour . . . . . . . . . . . 145

A.16 Cross-correlations between growth rate of real gdp per capita and leads/lags of real credit per capita. Data from 1948-1984. 146

A.17 Cross-correlations between growth rate of real gdp per capita and leads/lags of real credit per capita. Data from 1985-2013. 147

A.18 Cross-correlations between HP filtered real gdp per capita and leads/lags of HP filtered real credit per capita. Data from 1948-1984. . . . . . . . . . . . . . . . . . . . 147 
A.19 Cross-correlations between HP filtered real gdp per capita and leads/lags of HP filtered real credit per capita. Data from 1985-2013. . . . . . . . . . . . . . . . . . . 148

B.1 Data and model standard deviations . . . . . . . . . 170

B.2 Unconditional variance decomposition . . . . . . . . . . 170

C.1 Data sources . . . . . . . . . . . . . . . . . . . 174

C.2 Ljung-Box test results . . . . . . . . . . . . . . . 175

C.3 Changing business cycle asymmetry: Alternative filters . . . 176

C.4 Changing business cycle asymmetry: Alternative growth rates 176

C.5 3rd central moments: Pre- and post-1984 . . . . . . . 177

C.6 Changing business cycle asymmetry: Pre- and post-1985 . . 178 


\section{List of Figures}

1.1 Cross-correlations between output, the real interest rate, the nominal interest rate, ex-post and ex-ante inflation . . . . 8

1.2 Ex-post and ex-ante real interest rates pre- and post-1985 . . 10

1.3 Cross-correlations between output and real interest rate . . . 12

1.4 Cross-correlations between output and labour productivity . . 16

1.5 Cross-correlations of output with total factor productivity (Fernald (2014)) and wage-interest ratio . . . . . . . . . . 18

1.6 Cross-correlations between labour productivity and labour in-

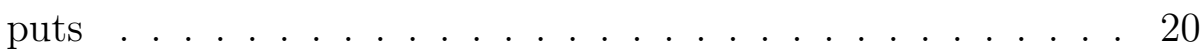

1.7 Cross-correlations between the unemployment rate and labour

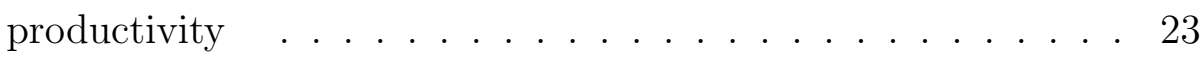

1.8 Cross-correlations between output and residential investment 24

1.9 Cross-correlations from Smets and Wouters (2007) under alternative parameterizations from the post-1985 posterior . . . 28

2.1 Cross-correlogram between output, nominal and real interest

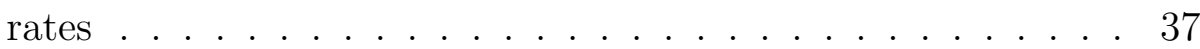

2.2 Real-time measurement error in output growth and inflation . 47

2.3 Greenbook forecast errors in output growth and inflation . . . 50

2.4 Uncertainty and the cyclicality of interest rates counterfactual 62

2.5 Monetary policy shock . . . . . . . . . . . . . 66

2.6 Inflation noise shock . . . . . . . . . . . . . . 68

2.7 Uncertainty and demand shocks _. . . . . . . . . 70 
2.8 Uncertainty and expectations of the state of the economy . . 72

2.9 Uncertainty and technology shocks . . . . . . . . . . . 74

3.1 Steep and Deep Business Cycles (Sichel 1993) . . . . . . . . . 84

3.2 IRF to a $10 \%$ housing price shock . . . . . . . . . . . . 97

4.1 Impulse response functions to a monetary policy shock with investment adjustment costs . . . . . . . . . . . . . . . . . . 109

4.2 Impulse response functions to a monetary policy shock with (small) investment adjustment costs . . . . . . . . . . . . 111

4.3 Impulse response functions to a monetary policy shock in $\mathrm{Ru}$ pert and Šustek (2019) ........... . 112

4.4 Long-run real interest rate and investment in response to a monetary policy shock under alternative adjustment costs . . 113

A.1 Cross-correlations with 1 standard deviation confidence bands 126

A.2 Cross-correlations with 1 standard deviation confidence bands 127

A.3 Cross-correlations with 1 standard deviation confidence bands 128

A.4 Cross-correlations with 1 standard deviation confidence bands 129

B.1 Output noise shock . . . . . . . . . . . . 171 


\section{Chapter 1}

\section{The Shifts in Lead-Lag Properties of the US Business Cycle}

\subsection{Introduction}

Stylized facts and regularities in the cyclical behaviour of macroeconomic aggregates continue to guide contemporary business cycle research. ${ }^{1}$ Models of the business cycle either seek to directly account for these stylized statistical properties or use them as evaluation criteria in determining the suitability of models aimed at studying a variety of topics such as the welfare costs of business cycles, the sources of business cycles, the role of economic policies, or asset prices. In this context, two popular types of comovements characterize aggregate fluctuations. Contemporaneous correlations with output indicating pro-, counter- or acyclicality, and the largest absolute magnitude of cross-correlations with output (or another reference variable) indicating

\footnotetext{
${ }^{1}$ This chapter of my thesis is published in Economic Inquiry. See Brault and Khan (2020) for the published manuscript which is available at https://onlinelibrary.wiley.com/doi/10.1111/ecin.12841.
} 
leads and lags. This latter type of business cycle comovement has been emphasized in the literature since Blanchard and Watson (1986) and Kydland and Prescott (1990). Changes in the economy's structure, institutions, policies, and exogenous shocks can all impinge upon both types of comovements. While the recent business cycle literature has extensively studied shifts in contemporaneous correlations after the onset of the Great Moderation period in the mid-1980s, the shifts in the second type of comovement have either received less attention or have gone unexplored. ${ }^{2}$

The main contributions of our paper are twofold. First, we document shifts in the cross-correlations (also referred to as phase shifts) among macroeconomic variables in the post-World War II US business cycle since the mid-1980s. We focus on the real interest rate- a key intertemporal price in decision-making - and labour market quantities, namely, labour productivity, labour inputs, and the unemployment rate. Our rationale for focusing on these variables is that there exists an established literature emphasizing the leading or lagging properties of these variables over the business cycle which we discuss below. These shifts in the cross-correlations indicating leading or lagging properties are, by definition, larger in absolute magnitude than the contemporaneous correlations reflecting the presence of important empirically relevant mechanisms not captured by contemporaneous comovements alone. Second, we study a variety of contemporary Dynamic Stochastic General Equilibrium (DSGE) models and show that they all produce counterfactual lead-lag patterns relative to US data. Even models that successfully explain the shifts in contemporaneous correlations display counterfactual lead-lag properties. We discuss important challenges for model development and evaluation for future research aimed at improving our understanding of comovement - a central feature of the US business cycle.

We use the Hodrick and Prescott $(1980,1997)$ (HP) filter as a baseline to

\footnotetext{
${ }^{2}$ Shifts in volatility and responses of macroeconomic variables to business cycle shocks have also been studied in the literature but these moments are not the focus of our paper.
} 
obtain the cyclical component of the data. The advantage of using the HP filter is that it facilitates comparisons with the previous literature that has also used the same filter. We then consider the cyclical components based on three alternative filters, namely, Baxter and King (1999), Christiano and Fitzgerald (2003), and Hamilton (2018). The two time periods we consider are 1948-1984 (the pre-1985 period) and 1985-2016 (the post-1985 period). This sample split has been widely studied in the literature in the context of declining volatility and cyclicality of macroeconomic variables associated with the onset of the Great Moderation period. ${ }^{3}$ We summarize the four major lead-lag shifts between the pre- and post-1985 periods as follows:

First, real interest rates positively lag output. Real interest rates display a 'Positive Lagging Property' (PLP). They strongly lag output by three quarters with positive signs. The well known inverted-leading-indicator property of real interest rates documented by King and Watson (1996) has completely vanished. We find a remarkable stability of the evidence for PLP. We show that the PLP of the real interest rate holds for ex-ante and ex-post real rates, for different prices deflators, and for filtered or unfiltered real interest rates. Importantly, we document that the shift from leading to lagging, and the sign switch, has also occurred in the nominal interest rate. Second, labour productivity negatively lags output. Labour productivity has shifted from leading the cycle with a positive sign to lagging with a negative sign. Output per hour lags by four quarters and output per person lags by five quarters. Third, labour inputs negatively lead labour productivity. Total hours worked have shifted from lagging output per hour by three quarters with a positive sign to leading by two quarters with a negative sign. Employment has shifted from lagging output per person by three quarters with a positive sign to leading by four quarters with a negative sign. Fourth, the unemployment rate positively leads labour productivity. The unemployment rate shifted from

\footnotetext{
${ }^{3}$ See, for example, Hall (2007), Stiroh (2009), Galí and Gambetti (2009), Barnichon (2010), Fernald and Wang (2016), Daly et al. (2017), Garin, Pries and Sims (2018), and Galí and van Rens (2020).
} 
negatively lagging output per hour by three quarters and output per person by two quarters to positively leading output per hour by two quarters, and output per person by four quarters.

We conduct extensive checks to establish that these properties are in fact robust post-1985 US business cycle stylized facts. They suggest business cycle comovement of the real interest rate along with labour productivity and labour market variables has experienced a substantial shift in the leadlag properties. Interestingly, such a shift is not present in investment data. For example, the well known property that residential investment leads the US business cycle is also present in the post-1985 data.

In light of the new lead-lag stylized facts listed above, an immediate question is: how do the properties of simulated data from existing Dynamic Stochastic General Equilibrium (DSGE) models compare with their empirical counterparts? We provide a few selected examples. For real interest rate dynamics we consider simulated data from Smets and Wouters (2007), Iacoviello (2005), and Basu and Bundick (2017), respectively. Our rationale is that these models have frictions and shocks that are embedded in a many contemporary DSGE models, and therefore, provide a useful reference point. For labour productivity and labour input dynamics, we consider simulated data from the models in Galí and van Rens (2020) and Garin, Pries and Sims (2018), respectively. Our rationale is that since these models successfully explain the decline in the procyclicality of labour productivity after the mid-1980s, they provide a natural benchmark to determine their intrinsic lead-lag properties relative to the stylized facts reported above. Finally, for the unemployment rate and labour productivity dynamics we consider simulated data from Barnichon (2010). Our rationale is that this model studies the change in the contemporaneous correlation of unemployment and labour productivity after the mid-1980s and, therefore, is well-suited to examine the cross-correlations between the same two variables.

While our rationales for selecting DSGE models are clear, it is important 
to note that none of these models were developed to match cross-correlations. Therefore, if it turns out that a particular model does match the lead-lag pattern, then it would be explaining something it was not designed to and that will reveal the strength of the proposed mechanism. On the other hand, if it turns out that a particular model does not match the lead-lag structure then that would provide important information for researchers toward developing new models to explain the stylized facts we have documented.

As we discuss in detail, our comparative analysis reveals that all the models we consider produce counterfactual lead-lag properties (both qualitatively and quantitatively) relative to their empirical counterparts in the post-1985 data. By extension, we hypothesize that this assessment applies to a wide class of contemporary DSGE models. This finding raises many important challenges and suggests promising areas for future research aimed at understanding business cycle comovement and improving DSGE models, determining consequences for macroeconomic forecasts, and for developing leading indicators for policy analysis.

The rest of this paper is organized as follows. Section 1.2 presents the data and documents the shifts in the lead-lag properties of the real interest rate and the three labour market variables. It also provides a comparison with properties based on simulated data from DSGE models. Section 1.3 assesses the robustness of the properties. Section 1.4 concludes.

\subsection{Shifts in Lead-Lag Properties}

In this section we present the data and the shifts in the lead-lag properties of four macroeconomic series. We also provide a comparison of lead-lag properties when looking through the lens of recent DSGE models. The set of models includes those with a focus on the changes in contemporaneous correlations since the onset of the Great Moderation period in the mid-1980s. 


\subsubsection{Data}

We use quarterly data obtained from the Federal Reserve Bank of St. Louis Economic Database (FRED). ${ }^{4}$ The two samples we consider are 1948Q11984Q4 (pre-1985) and 1985Q1-2016Q4 (post-1985). We employ two different measures of output in the paper, namely, real Gross Domestic Product (GDP) and nonfarm business sector real output, to allow a comparison with the model-based results in the literature.

We perform standard transformations of the variables prior to examining the cross-correlations. Specifically, we take the natural log of all variables (excluding the real interest rates and the unemployment rate). Throughout our analysis, the HP filter smoothing parameter for quarterly data is 1600 . The baseline cyclical data is computed by detrending the entire sample prior to splitting into pre- and post-1985. In the robustness section we document that the results presented herein are not sensitive to detrending each sample independently. We present the main empirical findings on the shifts in crosscorrelation and the lead-lag properties below. ${ }^{5}$

\subsubsection{Real Interest Rates Positively Lag Output}

We define the real interest rate as:

$$
\text { Real interest } \text { rate }_{t}=\left\{\begin{array}{l}
3 \text {-month T-bill } t-\pi_{t+1}^{F}: \text { Ex-ante } \\
3 \text {-month T-bill } t-\pi_{t+1}: \text { Ex-post }
\end{array}\right.
$$

where $\pi_{t+1}^{F}$ and $\pi_{t+1}$ are the one-period-ahead forecast of the inflation rate and the one-period-ahead actual inflation rate, respectively. We use the GDP deflator to construct $\pi_{t+1}$ as the annualized log difference. For $\pi_{t+1}^{F}$ we consider a variety of methods. First, we use an in-sample 3 variable

\footnotetext{
${ }^{4} \mathrm{~A}$ more detailed description of the data is provided in the Appendix.

${ }^{5}$ The Appendix contains tables with the cross-correlations that we discuss in this section.
} 
VAR consisting of inflation, unemployment, and the nominal interest rate to forecast inflation (as in Stock and Watson (1999)). By construction, the in-sample VAR contains future information via the estimated parameters, therefore we also consider recursive and rolling window VARs (with a window length of 40 quarters). Finally, we use consumer price index estimates from the Survey of Professional Forecasters as a measure of expected inflation.

Figure 1.1 shows the cross-correlations between HP filtered output, $Y_{t}$, and leads and lags of the HP filtered real interest rate, denoted as $R_{t}{ }^{6}$ Specifically, $\operatorname{Corr}\left(Y_{t}, R_{t+k}\right): k=\{-5,-4, \ldots, 0, \ldots, 4,5\}$, where a negative $k$ indicates correlations between past real interest rates and current output and a positive $k$ indicates correlations between future real interest rates and current output. The largest correlation in absolute terms determines the lead-lag property of a given series relative to another. This cross-correlation is represented by the solid black dots. ${ }^{7}$

Panel (a) shows that in the pre-1985 period, the ex-post real interest rate was strongly negatively correlated with future output, and was countercyclical. This is the well-known Inverted Leading Indicator Property (ILP) of real interest rates documented by King and Watson (1996). ${ }^{8}$

Panel (b) shows that in the pre-1985 data the nominal interest rate also displayed a strong negative correlation with future output. In sharp contrast, the ILP for both the ex-post real interest rate and nominal interest rate has completely vanished in the post-1985 data. The real interest rate lags output by three quarters with a positive sign and the nominal interest rate lags output by one quarter with a positive sign. The real interest rate in the post-1985 data is also strongly procyclical. We refer to this shift in business

\footnotetext{
${ }^{6}$ The results are nearly identical if we do not filter the real interest rate. These are shown in the Appendix.

${ }^{7}$ All leads and lags discussed in the paper are statistically significant against the null hypothesis $H_{0}: \rho_{i, j}=0$.

${ }^{8}$ Similar properties of interest rates dynamics are documented in Fiorito and Kollintzas (1994) (Table 3), Chari, Christiano and Eichenbaum (1995) (Figure 3), Beaudry and Guay (1996) (Table 2), and Stock and Watson (1999) (Table 2).
} 


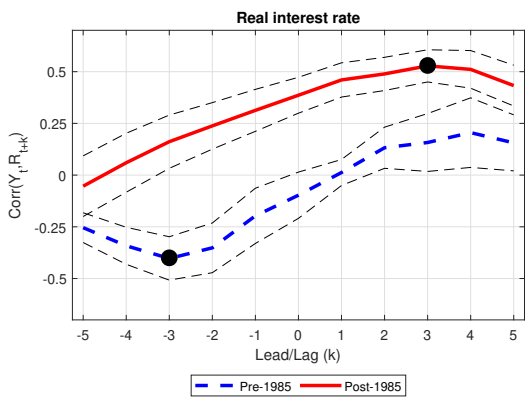

(a)

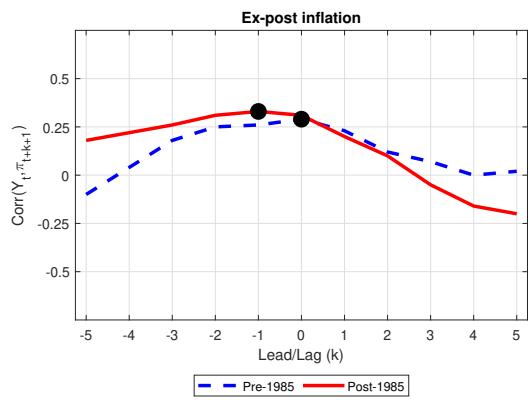

(c)

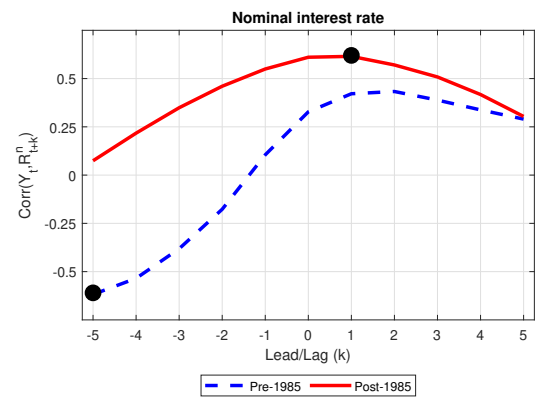

(b)

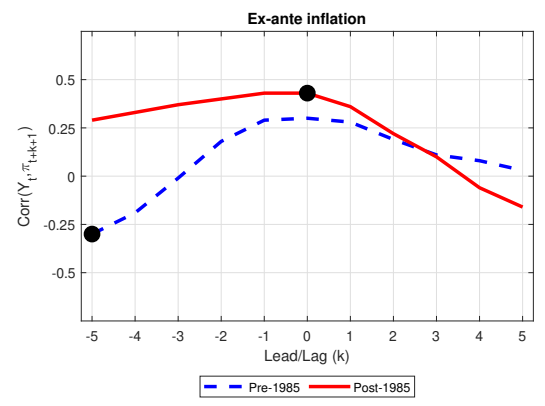

(d)

Figure 1.1: Cross-correlations between output, the real interest rate, the nominal interest rate, ex-post and ex-ante inflation

Note: Ex-post and ex-ante inflation measures are at time $t+1$. Ex-post and ex-ante inflation are generated from the GDP deflator, the ex-ante measure is based on in-sample VAR forecasts. The black dashed bands represent one standard deviation confidence bands computed using GMM. For more information on computing standard errors, see the Appendix. 
cycle dynamics of the real interest rate as the 'Positive Lagging Property' (PLP).

Panels (c) and (d) show the cross-correlation between output and one period ahead ex-post and ex-ante inflation. The cross-correlation properties of the ex-post inflation rate remain relatively unchanged while the crosscorrelation for ex-ante inflation has become positively correlated with future output. These findings may suggest that changes in the conduct of monetary policy is likely to be central in understanding the shifts in real interest rate dynamics.

We now provide further evidence that this switch from ILP to PLP is a robust stylized fact of the post-1985 real interest rate dynamics. The PLP of real interest rates also exists in the 1985I-2007IV sample, the Great Moderation period. This evidence (as shown in Table A.8 in the Appendix) indicates that PLP is not driven by the zero-lower-bound on the federal funds rate reached in the aftermath of the Great Recession in the US. Furthermore, the findings are also robust to alternative measures of the real interest rate such as alternative price indexes for inflation (CPI, PCE, Core CPI), using the federal funds rate as the measure of the nominal interest rate, and estimates of the nominal interest rate in the absence of the zero-lower-bound from $\mathrm{Wu}$ and Xia (2016) (as shown in Tables A.6 and A.7 in the Appendix). ${ }^{9}$

We now examine real interest rate-output dynamics through the lens of a variety of DSGE models and compare it with the evidence. In this context, our approach follows King and Watson (1996) who also presented a variety of models that were all unable to account for the ILP. This has been a long-standing puzzle in the literature. While this property was attributed

\footnotetext{
${ }^{9}$ Figure 1.2 establishes that the various sources of instability noted in Dotsey, Lantz and Scholl (2003) are not present in the post-1985 data. Thus, we conclude that the post-1985 data are consistent on the cyclical relationship between real interest rates and output, and represent a key stylized fact of business cycles. Mertens (2010) finds that real interest rates exhibit a leading indicator property conditional on the technology shock but with a positive sign. However, the post-1985 data show the PLP property suggesting that technology shocks alone cannot account for it.
} 


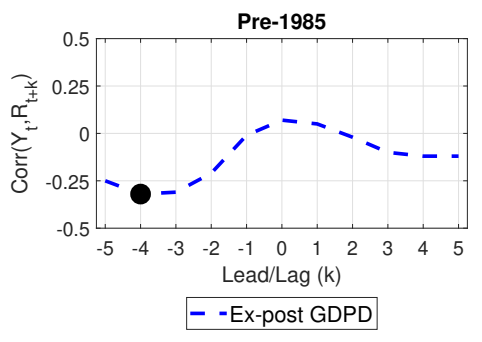

(a)

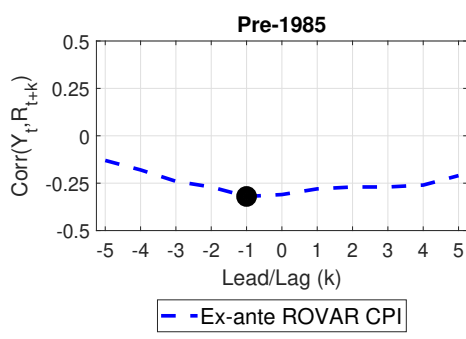

(c)

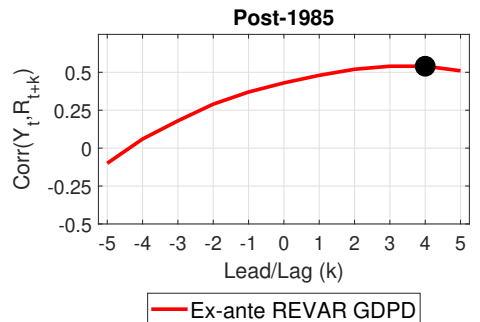

(e)

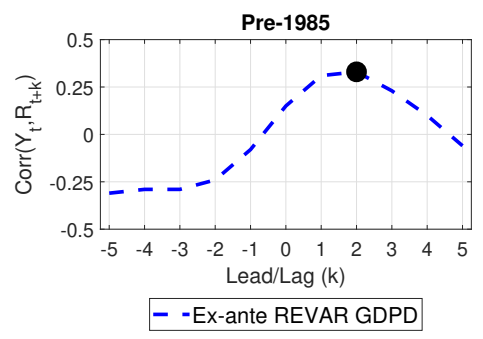

(b)

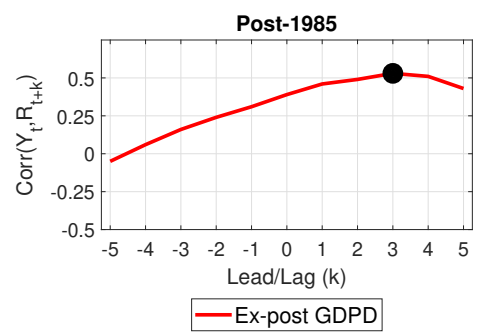

(d)

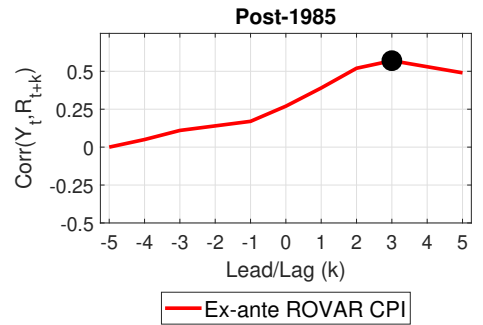

(f)

Figure 1.2: Ex-post and ex-ante real interest rates pre- and post-1985

Note: Ex-ante REVAR real interest rate is computed using estimates of expected inflation from the recursive VAR. Ex-ante ROVAR real interest rate is computed using estimates of expected inflation from the rolling VAR. The rolling window is set to 40 quarters. Pre1985 cross-correlations are computed on data from 1956III:1984IV to avoid small sample VAR estimates. 
to monetary shocks, Boldrin, Christiano and Fisher (2001) presented a technology shock driven two-sector real business cycle model with consumption habits and limited labour mobility that accounted for the ILP. Recently, Pintus, Wen and Xing (2017) present a model, building on Kiyotaki and Moore (1997), in which self-fulfilling belief shocks redistribute income away from lenders to borrowers during booms. Although their objective is to provide a theoretical rationale for the ILP, they do not provide a quantitative comparison of model-based cross-correlations with those in the data. However, the post-1985 evidence we document poses a new challenge to the research aimed at explaining ILP since it no longer exists in the data. Business cycle dynamics of real interest rates are characterized by PLP. ${ }^{10}$

The right panel of Figure 1.3 shows the cross-correlation based on the simulated data from a standard Real Business Cycle (RBC) model. ${ }^{11}$ Interestingly, the procyclicality of real interest rates in the post-1985 data is, at least qualitatively, consistent with that based on this simulated data. While it is known that the model does not produce any lead-lag pattern between the real interest rate and output, the purpose of showing it here provides a useful perspective. The same challenge that the RBC model faced in matching ILP applies to matching PLP in the post-1985 data. Moreover, the mechanisms discussed in Boldrin, Christiano and Fisher (2001) and Pintus, Wen and Xing (2017) produce ILP, and therefore, by construction, cannot explain the PLP of real interest rates.

To investigate the real interest rate-output cross-correlations based on DSGE models developed more recently, we consider three models which have structural features - frictions and shocks - that are embedded in many contemporary DSGE models. These are Smets and Wouters (2007), Iacoviello (2005), and Basu and Bundick (2017). ${ }^{12}$ The bottom row in Figure 1.3

\footnotetext{
${ }^{10}$ Pintus, Wen and Xing (2018) study global financial linkages and the comovement of economic activity across countries. Their model, however, produces countercyclical real interest rate which runs counter to the the procyclical real rate in the the post-1985 data.

${ }^{11}$ We consider a frictionless version of the RBC model (See Cooley and Hansen (1995)).

${ }^{12}$ In the Appendix we provide links to replication codes for each of the models discussed.
} 


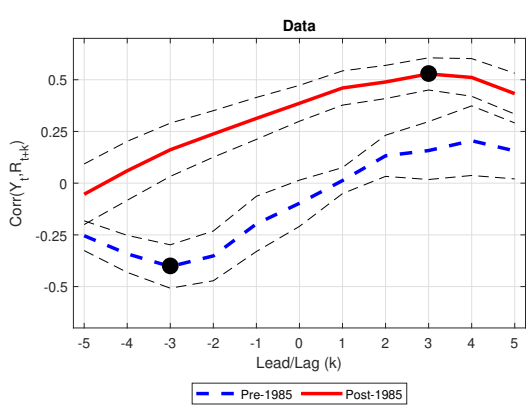

(a)

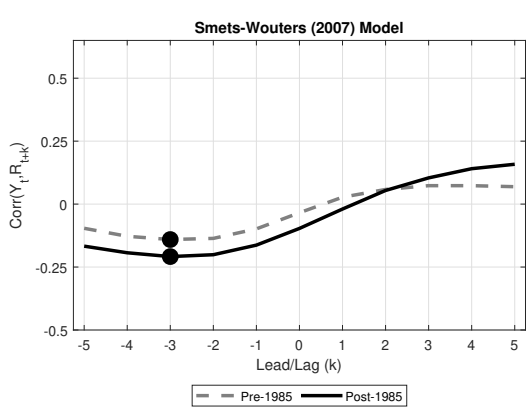

(c)

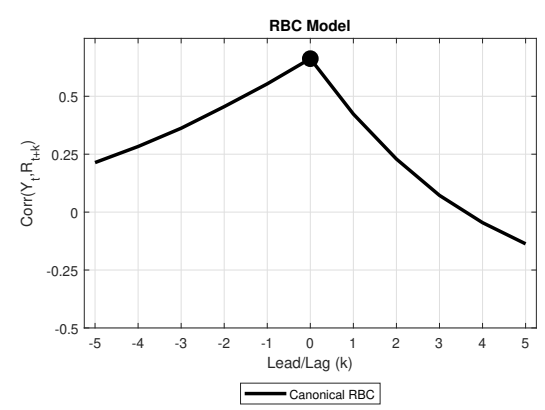

(b)

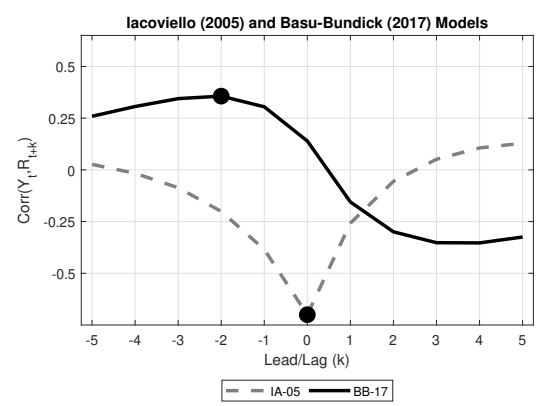

(d)

Figure 1.3: Cross-correlations between output and real interest rate

Note: $k$ denotes the number of leads (negative values) or lags (positive values) between real interest rate and output, $Y_{t}$. The correlations at the black dashed line represent the contemporaneous correlations. Black solid circles denote the largest cross- or contemporaneous correlation that occurs at the $k$ th lead/lag, $\max \mid\left\{\operatorname{Corr}\left(Y_{t}, R_{t+k}\right), k=\right.$ $-5,-4, \ldots, 0, \ldots, 4,5\} \mid$. Both actual and model-simulated output and real interest rates are HP filtered. For Smets and Wouters (2007) we estimate the pre-1985 model on data spanning from 1966I:1984IV and the post-1985 on data spanning from 1985I:2007IV. The black dashed bands represent one standard deviation confidence bands computed using GMM. 
shows the cross-correlations based on data simulated from these models, respectively.

Panel (c) shows the cross-correlations based on the simulated data from the Smets and Wouters (2007) model estimated for 1966I:1984IV and 1985I:2007IV. It is perhaps not well recognized that the Smets and Wouters (2007) model did in fact generate ILP. The presence of consumption habits, a mechanism explored in Boldrin, Christiano and Fisher (2001), helped explain ILP. The Smets and Wouters (2007) model-based ILP is, however, counterfactual relative to the post-1985 evidence of PLP shown in panel (a).

Next, we examine the cross-correlations based on the simulated data from the Iacoviello (2005) model of housing that has two types of householdspatient and impatient - and an endogeneous borrowing constraint tied to the value of housing faced by the impatient agent. This model framework has been widely used in studying the role of monetary and fiscal policies in the presence of durable (housing) goods. As shown in panel (c), the real interest rate-output cross-correlations based on the simulated data do not match either the ILP in the pre-1985 data or the PLP in the post-1985 data. ${ }^{13}$ The largest correlation implied by the model is contemporaneous. The model also implies that the real interest rate is highly countercyclical which contradicts the post-1985 data. The final example is Basu and Bundick (2017) who study the role of countercyclical markups, sticky prices, and monetary policy in producing contractionary comovement among macroeconomic aggregates after an increased uncertainty about the future. We generate simulated data from their model and compute the real interest rate-output cross-correlations. In the present context, although their model generates a positive contemporaneous correlation between output and the real interest rate consistent with that observed in the post-1985 data, the lead-lag pattern turns out to be

For each model we generate 1000 simulations of 1280 observations, dropping the first 1000 observations to control for initial starting condition issues. We compute cross-correlations for each sample and take the median cross-correlation across the 1000 samples.

${ }^{13}$ The Iacoviello (2005) model does not have consumption habits. 
counterfactual. In their model, real interest rates lead output by one quarter and with a positive sign.

Based on the comparison between the cross-correlations in the post-1985 data and the models, we conclude that a broad class of contemporary DSGE models do not match the PLP - the defining property of real interest rates over the business cycle in the post-1985 data. Identifying new mechanisms to explain the positive lagging property of real interest rates is, therefore, an important research direction.

Previously, Boldrin, Christiano and Fisher (2001) provided an explanation for the ILP of real interest rates in a model with intersectoral rigidities and consumption habits. Models with these features, however, cannot explain the PLP in the post-1985 period. Through a set of examples, we made the point that a broad class of contemporary DSGE models featuring a variety of mechanisms also do not produce PLP. This property of real interest rates is a serious challenge to developing a DSGE model-based explanation.

\subsubsection{Labour Productivity Negatively Lags Output}

Panels (a) and (b) in Figure 1.4 show the cross-correlations between output and labour productivity, $L P_{t}$, where the latter variable is measured as output per hour and output per person, respectively. The cross-correlations in the figure represent $\operatorname{Corr}\left(Y_{t}, L P_{t+k}\right): k=\{-5,-4, \ldots, 0, \ldots, 4,5\}$.

While the decline in the procyclicality of labour productivity has been widely discussed in the literature, the post-1985 data show a prominent inverted lagging property of labour productivity over the cycle. Labour productivity shifted from leading the cycle in the pre-1985 period with a positive sign to lagging by at least a year with a negative sign. The absolute magnitude of these cross-correlations are substantially larger than the contemporaneous correlations, indicating the presence of a strong business cycle relationship not captured by comovement alone.

A natural question is: Do models that can either qualitatively or quanti- 
tatively explain the decline in the procyclicality of labour productivity also account for the lead-lag shift in the data that we have documented in panel (a) of Figure 1.4? To answer this question we consider two recent contributions to the literature, Galí and van Rens (2020) and Garin, Pries and Sims (2018). Both models have successfully explained the decline in the procylicality of labour productivity.

The main mechanism discussed in Galí and van Rens (2020) is the decline in turnover reflecting reduced hiring frictions since the mid-1980s as a force behind the vanishing procyclicality of labour productivity. Panel (c) shows the cross-correlations based on the simulated data where we set the separation rate $\delta=0.35$ for the pre-1985 period and $\delta=0.15$ for the post-1985 period, as in Galí and van Rens (2020).

Consistent with the results in Galí and van Rens (2020), the diminished procyclicality of labour productivity is evident in panel (c). This exercise, however, also reveals that the model produces counterfactual crosscorrelations for the two sub-samples. The model implies a contemporaneous correlation that is the largest in absolute value in both periods. We, therefore, conclude that the same mechanism - the decline in turnover - as developed in Galí and van Rens (2020), cannot account either qualitatively or quantitatively for (i) the switch from labour productivity leading output to lagging output and (ii) the switch in sign from positive to negative cross-correlation as shown in panel (a) of Figure 1.4.

The second example is Garin, Pries and Sims (2018) who develop a model in which they show that the importance of sectoral shocks relative to aggregate shocks can account for the decline in the procyclicality of labour productivity in the US economy. We use the simulated data from their model to compute cross-correlations between labour productivity and output. ${ }^{14}$ Panel (d) of Figure 1.4 shows the cross-correlations for the pre- and post-1985 pe-

\footnotetext{
${ }^{14}$ We thank Eric Sims and Julio Garin for providing us with the replication code for their paper.
} 


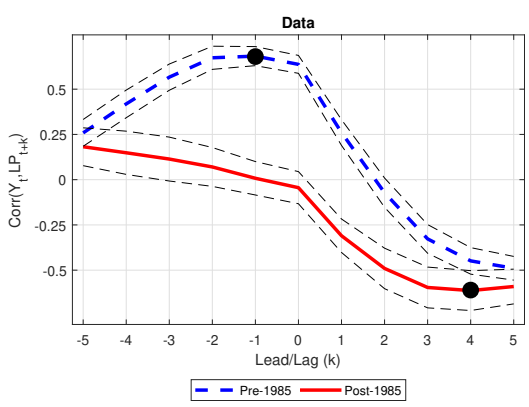

(a)

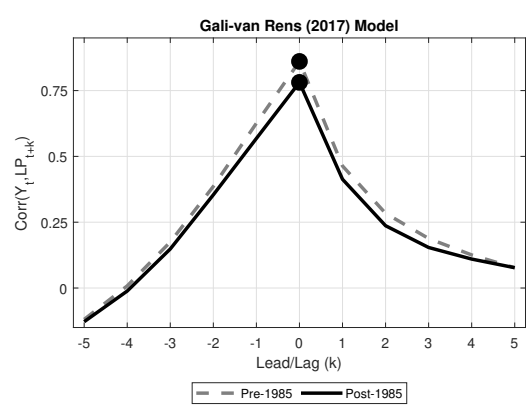

(c)

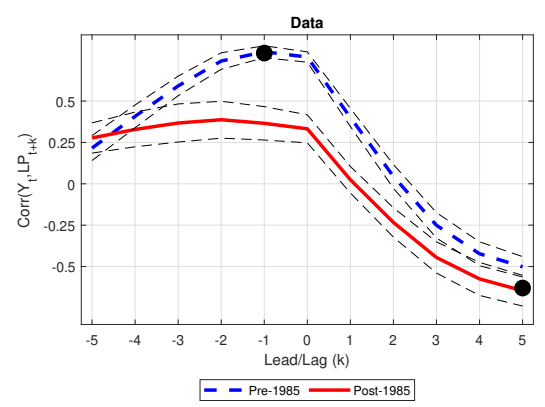

(b)

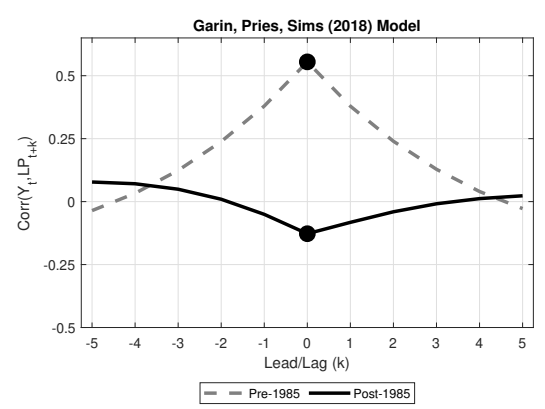

(d)

Figure 1.4: Cross-correlations between output and labour productivity

Note: $k$ denotes the number of leads (negative values) or lags (positive values) between output and labour productivity. The correlations at the black dashed line represent the contemporaneous correlations. Black solid circles denote the largest cross- or contemporaneous correlation that occurs at the $k$ th lead/lag, $\max \mid\left\{\operatorname{Corr}\left(Y_{t}, L P_{t+k}\right), k=\right.$ $-5,-4, \ldots, 0, \ldots, 4,5\} \mid$. Actual data and model data in Garin et al. (2018) and Galí and van Rens (2020) are HP filtered. The black dashed bands represent one standard deviation confidence bands computed using GMM. 
riod. While the model can clearly account for the decline in the procyclicality of labour productivity, it produces a counterfactual cross-correlation pattern between output and labour productivity. The cross-correlations based on the simulated data are very close to zero for the post-1985 calibration in Garin, Pries and Sims (2018).

There is little work in the literature that has addressed the lead-lag properties of labour productivity over the US business cycle. An early contribution by Burnside and Eichenbaum (1993) discussed the ability of the factorhoading model to generate dynamic correlations between labour productivity and output. ${ }^{15}$ The presence of factor hoarding behaviour, however, causes labour productivity to lead output, as noted in Burnside (1998). This means that changes in factor-hoarding are unlikely to explain the negatively lagging labour productivity over the business cycle in the post-1985 period.

In summary, existing models and mechanisms that have been used to explain the declining procyclicality of labour productivity do not account for its changing role in the lead-lag property over the business cycle. In light of the new evidence from the post-1985 period shown in panel (a) of Figure 1.4, explaining the shift in labour productivity from leading positively to lagging negatively is an important direction for future research.

To further understand the forces underlying the shift in the lead-lag properties of labour productivity, consider the following constant-returns-to-scale production function expressed in terms of labour productivity

$$
\ln \left(\frac{Y}{H}\right)=\ln A+\ln \left(f\left(\frac{K}{L}\right)\right)=\ln A+\ln \left(\phi\left(\frac{W}{R}\right)\right)
$$

where $Y / H$ is labour productivity per hour, $A$ is Total Factor Productivity (TFP), $K / L$ is the capital services to labour ratio, and $W / R$ is the real

\footnotetext{
${ }^{15}$ See Figure 3 in Burnside and Eichenbaum (1993) based on US data from 1955I 1992IV. The discussion of cross-correlations is omitted in the published version (Burnside and Eichenbaum (1996)).
} 


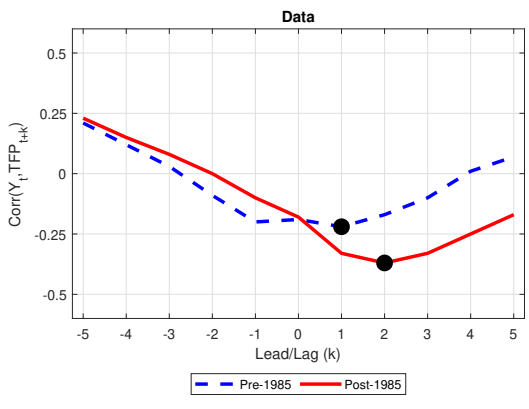

(a)

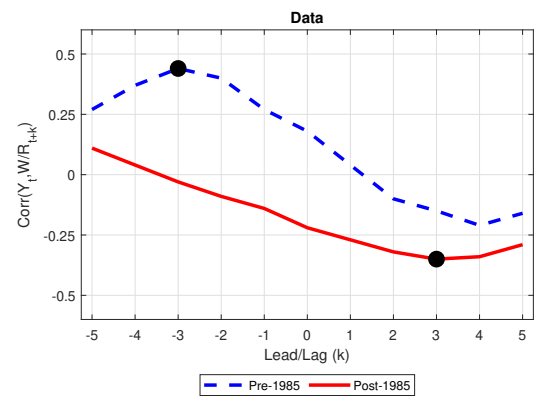

(b)

Figure 1.5: Cross-correlations of output with total factor productivity (Fernald (2014)) and wage-interest ratio

Note: $k$ denotes the number of leads (negative values) or lags (positive values) of either $T F P$ or $W / R$ with respect to output. Black solid circles denote the largest cross- or contemporaneous correlation that occurs at the $k$ th lead/lag, $\max \mid\left\{\operatorname{Corr}\left(Y_{t}, \mathrm{TFP}_{t+k}\right), k=\right.$ $-5, \ldots, 0, \ldots, 5\} \mid$ or $\max \left|\left\{\operatorname{Corr}\left(Y_{t}, \mathrm{~W} / \mathrm{R}_{t+k}\right), k=-5, \ldots, 0, \ldots, 5\right\}\right|$.

wage to real interest rate ratio. The second equality imposes the equilibrium condition in perfectly competitive factor markets. This decomposition allows us to examine if the shifts in labour productivity have occurred either through changes in forces driving $\mathrm{TFP}$ or those related to input markets reflected in factor prices, or both. We use Fernald (2014) data on utilizationadjusted TFP growth, convert it to a log level series, and then apply the HP filter to compute the cross-correlations. As shown in Panel (a) in Figure 1.5 TFP displayed a negative lagging property in the pre-1985 data relative to output over the business cycle, with $\operatorname{Corr}\left(Y_{t}, T F P_{t+1}\right)=-0.22$. In the post-1985 data, this negative lagging property became more enhanced, with $\operatorname{Corr}\left(Y_{t}, T F P_{t+2}\right)=-0.37$. So, although there is no shift in the leadlag property, the stronger negative lagging property is consistent with the pattern observed for labour productivity. In both sub-samples, TFP has a negative contemporaneous correlation. Panel (b) shows that the factor price ratio displayed a strong positive leading property in the pre-1985 data 
with $\operatorname{Corr}\left(Y_{t},(W / R)_{t-3}\right)=0.44$. This property shifted to a strongly lagging factor price ratio with a negative sign, $\operatorname{Corr}\left(Y_{t},(W / R)_{t+3}\right)=-0.35$. The factor price ratio also shifted from slightly procyclical to countercyclical. The shifts in the factor price comovement properties suggest that changes in factor market dynamics since the post-1985 period may have contributed to the negative lagging property of labour productivity, with the TFP dynamics enhancing this pattern.

\subsubsection{Labour Inputs Negatively Lead Labour Produc- tivity}

The dynamic relationship between total hours worked and productivity features prominently in a large body of business cycle research (see, for example, Benhabib, Rogerson and Wright (1991), Christiano and Eichenbaum (1992), Galí (1999) for early contributions). Panels (a) and (b) in Figure 1.6 show two sets of cross-correlations. The first is between total hours worked, $H_{t}$, and output per hour. The second is between total employment, $E_{t}$, and output per worker. In the pre-1985 data, total hours worked lagged output per hour by three quarters and with a positive sign, $\operatorname{Corr}\left(L P_{t}, H_{t+3}\right)=0.62$. In the post-1985 data, however, this relationship has switched with total hours worked leading output per hour by two quarters. Employment also leads output per person by four quarters. Both of these cross-correlations have a negative sign, $\operatorname{Corr}\left(L P_{t}, H_{t-2}\right)=-0.67$ and $\operatorname{Corr}\left(L P_{t}, E_{t-4}\right)=-0.62$, respectively. The contemporaneous correlations between labour input and labour productivity measures have also switched signs from positive to negative. In particular, they have switched from $\operatorname{Corr}\left(L P_{t}, H_{t}\right)=0.21$ in the pre-1985 sample to -0.53 in the post-1985 sample for output per hour. ${ }^{16}$ Similarly, they switched from $\operatorname{Corr}\left(L P_{t}, E_{t}\right)=0.24$ to -0.27 for output per person.

\footnotetext{
${ }^{16}$ This shift in contemporaneous correlation is similar to that reported in Galí and van Rens (2020), Table 1.
} 


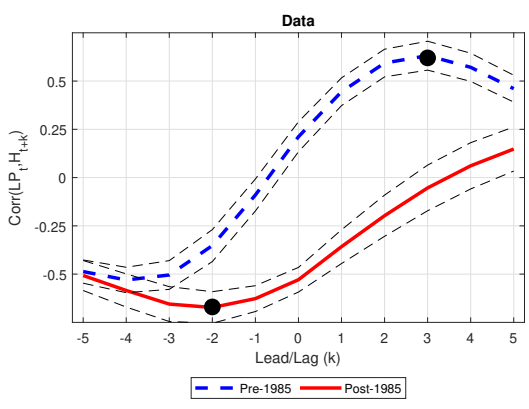

(a)

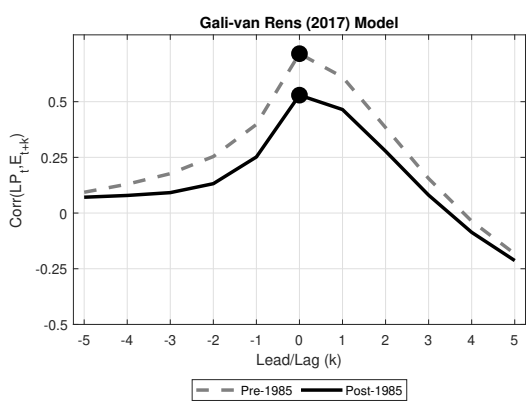

(c)

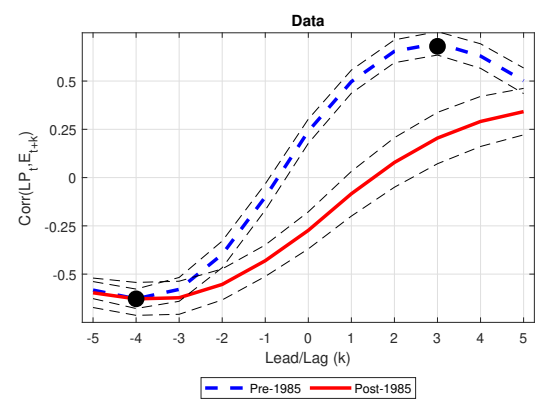

(b)

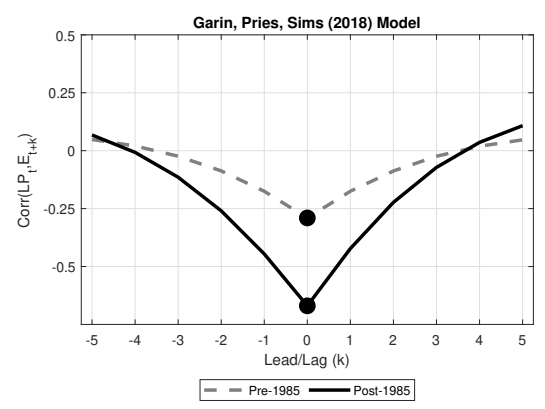

(d)

Figure 1.6: Cross-correlations between labour productivity and labour inputs

Note: $k$ denotes the number of leads (negative values) or lags (positive values) between labour productivity and labour inputs. The correlations at the black dashed line represent the contemporaneous correlations. Black solid circles denote the largest cross- or contemporaneous correlation that occurs at the $k$ th lead/lag, $\max \mid\left\{\operatorname{Corr}\left(L P_{t}\right.\right.$, Labour Input $\left.\left._{t+k}\right), k=-5, \ldots, 0, \ldots, 5\right\} \mid$. Actual data and simulated data from Garin et al. (2018) and Galí and van Rens (2020) are HP filtered. The black dashed bands represent one standard deviation confidence bands computed using GMM. 
The pre-1985 evidence of total hours worked lagging output per worker is consistent with the evidence reported in Figure 1.6 of Burnside and Eichenbaum (1993). They show that the factor hoarding model does a good job of matching the cross-correlations. The switch in the lead-lag property, with total hours worked leading output per worker with a negative sign in the post-1985 data, however, suggests that the factor hoarding behaviour of firms cannot reconcile this evidence. We now examine the cross-correlations between labour productivity and employment through the lens of the Galí and van Rens (2020) and Garin, Pries and Sims (2018) models. Panel (c) shows the cross-correlations based on the simulated data from Galí and van Rens (2020). The model qualitatively matches the decrease in contemporaneous correlations, but does not match the sign switch in the contemporaneous correlation and the lead-lag pattern is counterfactual. Panel (d) shows the cross-correlations based on the simulated data from Garin, Pries and Sims (2018). Unlike, Galí and van Rens (2020), their model does generate a negative contemporaneous correlation, but does not match the sign switch from positive to negative. From the perspective of our paper, it is important to note that the model produces a lead-lag pattern between labour productivity and employment which is counterfactual.

\subsubsection{Unemployment Rate Positively Leads Labour Pro- ductivity}

The relationship between labour productivity and the unemployment rate is a key component in models of search and matching (see, for example, Mortensen and Pissarides (1994), Mertz (1995), Andolfatto (1996), Shimer (2005), Hall (2005), among many other contributions). Recently, Barnichon (2010) noted that the contemporaneous correlation between cyclical unemployment and labour productivity over the post-WWII period switched sign in the mid-1980s: from significantly negative the correlation became significantly positive. 
Panel (a) in Figure 1.7 shows that in the pre-1985 data the largest crosscorrelation between the civilian unemployment rate, $U_{t}$ and output per hour is $\operatorname{Corr}\left(U_{t}, L P_{t-2}\right)=-0.64$, indicating that unemployment lagged output per hour by two quarters with a negative sign. Increases in productivity were associated with declines in unemployment two quarters ahead. This relationship switched in the post-1985 data to $\operatorname{Corr}\left(U_{t}, L P_{t+2}\right)=0.66$. Thus, increases in the unemployment rate are associated with an increase in productivity two quarters ahead.

Barnichon (2010) also notes in passing that the cross-correlogram between unemployment and productivity look 'dramatically different' (p. 1015). His focus, however, is on the shift in the contemporaneous correlation between unemployment and productivity and he, therefore, does not examine if the largest absolute cross-correlation has changed or if the model produces this shift, which is the main focus of our paper. Interestingly, the absolute magnitude of the contemporaneous correlations in both pre-1984 and post-1984 periods that Barnichon (2010) considers are smaller than the cross-correlations. This observation reinforces our point that the focus in many recent papers has been on contemporaneous correlations, and the shifts in the lead-lag patterns (the largest absolute magnitude of cross-correlations) capturing important business cycle comovement relationships have either remained unnoticed or have received very little attention.

We simulate data from Barnichon (2010)'s model for pre-and post-1985 periods and compute the cross-correlations between unemployment and labour productivity. ${ }^{17}$ Panel (b) in Figure 1.7 shows the model-based cross-correlations. We find that the model does not produce any lead-lag pattern for the post1985 period. $^{18}$ For the pre-1985 period, the model produces a lead of labour

\footnotetext{
${ }^{17}$ We thank Regis Barnichon for providing us with the replication codes.

${ }^{18}$ In Barnichon (2010)'s model, employment is a state variable and does not respond on impact to shocks. We compute the contemporaneous correlation as $\operatorname{Corr}\left(U_{t+1}, L P\right)$, and all leads and lags based on this vertical translation, consistent with the approach applied in the paper.
} 


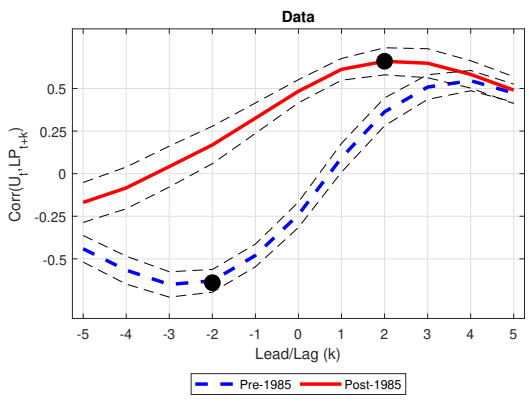

(a)

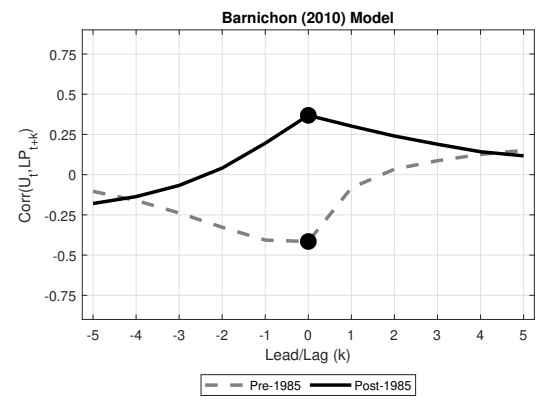

(b)

Figure 1.7: Cross-correlations between the unemployment rate and labour productivity

Note: $k$ denotes the number of leads (negative values) or lags (positive values) between the unemployment rate and labour productivity. Black solid circles denote the largest cross- or contemporaneous correlation that occurs at the $k$ th lead/lag, $\max \mid\left\{\operatorname{Corr}\left(U_{t}, L P_{t+k}\right), k=\right.$ $-5, \ldots 0, \ldots, 5\} \mid$. Both actual and model-simulated data are HP filtered. The black dashed bands represent one standard deviation confidence bands computed using GMM.

productivity over unemployment. Both of these properties are counterfactual relative to the stylized facts for the two sub-samples.

\subsubsection{An informative check}

A well known fact is that residential investment $(I N V R)$ leads the cycle. We find that this fact is robust across pre-1985 and post-1985 data, and therefore, did not experience the type of shifts we have highlighted in the previous sections. In the post-1985 data, $I N V R$ leads output by two quarters over the business cycle, the same as in the pre-1985 data. As shown in Figure 1.8, the largest cross-correlations are $\operatorname{Corr}\left(Y_{t}, I N V R_{t-2}\right)=0.67$ and $\operatorname{Corr}\left(Y_{t}, I N V R_{t-2}\right)=0.68$, respectively. This finding is also robust to using the $\mathrm{BK}, \mathrm{CF}$, and the $h p$ filters. The evidence for the robust leading property of residential investment across the two periods is quite informative as it allays any concern about measurement errors in aggregate data being the 


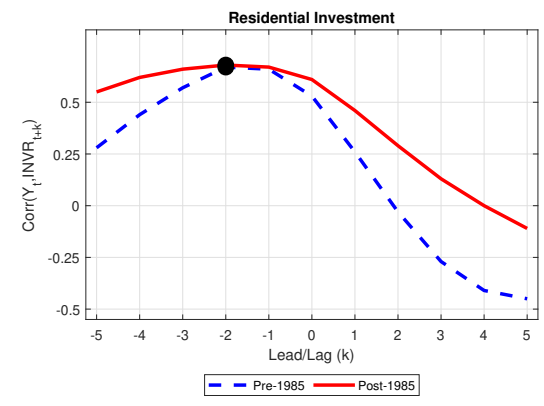

Figure 1.8: Cross-correlations between output and residential investment

Note: $k$ denotes the number of leads (negative values) or lags (positive values) between output and residential investment. Black solid circles denote the largest cross- or contemporaneous correlation that occurs at the $k$ th lead/lag, $\max \mid\left\{\operatorname{Corr}\left(Y_{t}, I N V R_{t+k}\right), k=\right.$ $-5, \ldots 0, \ldots, 5\} \mid$.

source of the shifts in the lead-lag properties.

\subsection{Robustness}

In this section we present a variety of robustness checks to establish that the shifts in lead-lag properties are indeed robust stylized facts across the two sample periods in the US data.

\subsubsection{Alternative filters}

Our choice of using the HP filtered data as the baseline to present the lead-lag properties is advantageous for two reasons: first, the HP filter is arguably the most common method for obtaining the cyclical component from aggregate data, and second, it allows us to contrast the new stylized facts with those in the previous literature. All the lead-lag shifts that we have documented remain robust to Baxter and King (1999) (BK) and Christiano and Fitzgerald 
(2003) (CF) band-pass filters. ${ }^{19}$ These filters have been used in the literature as an alternative to the HP filter. Tables A.3 and A.4 in the Appendix present the results for the $\mathrm{BK}$ and $\mathrm{CF}$ filters, respectively. As is evident, the magnitude and signs of the cross-correlations are similar to the HP filter.

Recently, Hamilton (2018) has proposed an alternative to the HP filter. ${ }^{20}$ This new filtering method requires obtaining residuals from a regression of a variable $h$-periods ahead on its $p$ most recent values as of date $t$. We refer to this regression-based procedure as the $h p$ filter. To implement the $h p$ filter, we use $h=8$ and $p=4$, which are Hamilton (2018)'s suggested parametric specification for detrending quarterly data. ${ }^{21}$ The $h p$ results are summarized in Table A.2 in the Appendix. All the four headline stylized facts are consistent with the $h p$ filter. There is, however, one measure of labour productivity, output per worker, which does not exhibit a shift in its lead over total employment or output. But the shift in the lead-lag properties of labour productivity measured as output per hour remains consistent across $\mathrm{HP}, \mathrm{BK}, \mathrm{CF}$, and $h p$ filters.

\subsubsection{Broader business cycle phase of 8-50 quarters}

Recently Beaudry, Galizia and Portier (2020) have documented that many macroeconomic aggregates appear to exhibit a peak in their spectral densities at periodicities between 32 and 50 quarters. Their work suggests that broadening the definition of the business cycle to include up to 50 quarters to may be the more appropriate view of business cycles. With this background, it is of interest to determine if the lead-lag shifts that we document occur

\footnotetext{
${ }^{19}$ Previously, Burnside (1998), in his comment on Canova (1998), has noted that that business cycle stylized facts obtained from different filters do not necessarily have to agree. Specifically, Burnside (1998) (on page 514) states I will argue that when the facts differ according to the filter, this simply means there are many facts to be explained.

${ }^{20}$ Schüler (2018) presents a detailed assessment of the Hamilton (2018) filter and discusses some of its shortcomings.

${ }^{21}$ Specially, for a series $y_{t}$, we run the regression $y_{t+h}=\beta_{0}+\sum_{j=0}^{p} \beta_{j+1} y_{t-j}+v_{t+h}$ and construct the cyclical component as the residuals $\hat{v}_{t+h}=y_{t+h}-\left(\hat{\beta}_{0}+\sum_{j=0}^{p} \hat{\beta}_{j+1} y_{t-j}\right)$.
} 
when we expand the conventional view of the business cycles (fluctuations occurring between 8 and 32 quarters) to include the lower frequencies. Using the BK and CF filter we confirm that all the lead-lag shifts that we have documented occur across this broader definition of the business cycle (see Tables A.10 and A.11 in the Appendix).

\subsubsection{Demographic adjusted hours}

Are the lead-lag shifts in labour productivity related to demographic changes that have occurred over time? Using demographically adjusted hours from Wolters (2018) we recompute the cross-correlations containing output per hour. ${ }^{22}$ These results are reported in Table A.15 in the Appendix. As it turns out, the results reflect the same pattern as the baseline case. These finding suggests that the labour productivity shifts are not related to demographic changes.

\subsubsection{Standardized variables}

Sharp increases in volatility, as in the stock market data, across sub-samples may introduce a bias in unconditional correlation (Forbes and Rigobon (2002), Stock and Watson (2002)). While this is less of a concern in aggregate US macroeconomic data, we recompute the cross-correlations after standardizing the cyclical components to have variance equal to one in the entire sample, and then variance equal to one in each subsample. These results are reported in Tables A.12 and A.13 in the Appendix. The cross-correlations are nearly identical in both cases, suggesting that the changes in cross-correlations are not driven by changes in volatility after the Great Moderation.

\footnotetext{
${ }^{22}$ We thank Maik Wolters for providing us with the adjusted hours data.
} 


\subsubsection{Filtering on subsamples}

The baseline cross-correlations presented in the paper are computed by first filtering the entire data, proceeded by splitting the data at 1984:4. Since the HP filter used in the paper is a two-sided filter, we investigate if the filter leads to any unintended spillovers between the cyclical data in each sample. Table A.14 highlights that the changes in lead-lag properties are robust to whether one filters on the entire sample or the pre- and post-1985 data independently.

\subsubsection{Alternative samples}

The baseline samples used in the paper are 1948:I-1984:IV and 1985I:2016IV. As highlighted earlier, the changes in post-1985 data are robust to the exclusion of the Great Recession (ending the sample in 2007:IV). These results are reported in Table A.8 in the Appendix. In addition, we report results for an alternative onset of the Great Moderation (1983:I). All changes in the lead-lag properties discussed are robust to this alternative sample. These results are presented in Table A.9 in the Appendix.

\subsubsection{Parameterization versus model structure}

The contemporary business cycle models considered in the paper were unable to match the cross-correlations in the post-1985 data. However, it remains unclear if this is related to the structure of the model or parameterization. As an inquiry into this point we take the Smets and Wouters (2007) model estimated on post-1985 data and generate 10,000 random draws of parameters from the posterior distributions. Figure 1.9 plots the upper and lower bounds (97.5\% and 2.5\%) of the distribution of cross-correlations generated by the model alongside the empirical cross-correlation in the post-1985 data. The PLP we identify lays outside the distribution of cross-correlations generated by the model, suggesting that parameterization alone cannot resolve 


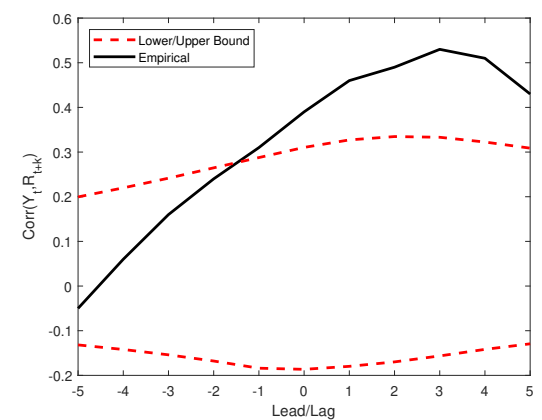

Figure 1.9: Cross-correlations from Smets and Wouters (2007) under alternative parameterizations from the post-1985 posterior

Note: The upper and lower bounds are the theoretical moments from the model. The bounds are for the $97.5 \%$ and $2.5 \%$ cross-correlations in the distribution generated from 10,000 random draws of parameters from the posterior estimated on 1985Q1-2007Q4 data.

this property.

\subsection{Conclusion}

In this paper, we document shifts in the lead-lag properties of the US business cycle since the onset of the Great Moderation period of the mid-1980s. We characterize four new stylized facts in terms of cross-correlations based on cyclical data. First, real interest rates positively lag output. Second, labour productivity negatively lags output. Third, labour inputs negatively lead labour productivity, and fourth, the unemployment rate positively leads labour productivity. The large absolute magnitude of these cross-correlations relative to contemporaneous correlations suggest important empirically relevant business cycle forces at work that are not reflected in contemporaneous correlations alone. We show that many contemporary DSGE models produce counterfactual lead-lag patterns, with incorrect signs. An open questionwhich is beyond the scope of this paper - is what implications missing these moments have for DSGE models. However, we believe these findings are im- 
portant for two main reasons. First, it is not well understood if DSGE models with incorrect cross-correlations suffer in their ability to forecast or perform policy evaluations. Second, cross-correlations of macroeconomic aggregates often serve as rule-of-thumbs in anticipating future changes in the business cycle. ${ }^{23}$ Then these rule-of-thumbs can represent misleading future macroeconomic conditions to policymakers and practitioners. Our empirical findings suggest that explaining why shifts in US business cycle lead-lag comovement have occurred since the mid-1980s is a promising area for future research for improving DSGE models, for studying the consequences for macroeconomic forecasts, and for developing leading indicators for policy analysis.

\footnotetext{
${ }^{23}$ See, for example, a recent Vox publication emphasizing the inverted leading property of real interest rates: https://voxeu.org/content/predicting-real-interest-rate.
} 


\section{Bibliography}

Andolfatto, D.: 1996, Business cycles and labour-market search, American Economic Review 86(1), 112-132.

Barnichon, R.: 2010, Productivity and unemployment over the business cycle, Journal of Monetary Economics (57), 1013-1025.

Basu, S. and Bundick, B.: 2017, Uncertainty shocks in a model of effective demand, Econometrica 85(3), 937-958.

Baxter, M. and King, R. G.: 1999, Measuring business cycles: Approximate band-pass filters for economic time series, The Review of Economics and Statistics 81(4), 575-593.

Beaudry, P., Galizia, D. and Portier, F.: 2020, Putting the cycle back into business cycle analysis, American Economic Review 110(1), 1-47.

Beaudry, P. and Guay, A.: 1996, What do interest rates reveal about the functioning of real business cycle models?, Journal of Economic Dynamics and Control 20, 1661-1682.

Benhabib, J., Rogerson, R. and Wright, R.: 1991, Homework in macroeconomics: household production and aggregate fluctuations, Journal of Political Economy 99(6), 666-689.

Blanchard, O. J. and Watson, M. W.: 1986, Are business cycles all alike?, University of Chicago Press, pp. 123-180.

Boldrin, M., Christiano, L. J. and Fisher, J. D. M.: 2001, Habit persistence, asset returns, and the business cycle, American Economic Review 91(1), 149-166.

Brault, J. and Khan, H.: 2020, The shifts in lead-lag properties of the U.S. business cycle, Economic Inquiry 58(1), 319-334. 
Burnside, C.: 1998, Detrending and business cycle facts: A comment, Journal of Monetary Economics 41, 513-532.

Burnside, C. and Eichenbaum, M. S.: 1993, Factor hoarding and the propagation of business cycle shocks, Working Paper 4675, NBER.

Burnside, C. and Eichenbaum, M. S.: 1996, Factor hoarding and the propagation of business-cycle shocks, American Economic Review 86(5), 11541174 .

Canova, F.: 1998, Detrending and business cycle facts, Journal of Monetary Economics 41(3), 475-512.

Chari, V. V., Christiano, L. J. and Eichenbaum, M.: 1995, Inside money, outside money, and short-term interest rates, Journal of Money, Credit and Banking 27(4), 1354-1386.

Christiano, L. J. and Eichenbaum, M. S.: 1992, Current real-business-cycle theories and aggregate labor-market fluctuations, American Economic Review 82(3), 430-450.

Christiano, L. J. and Fitzgerald, T. J.: 2003, The band pass filter, International Economic Review 44(2), 435-465.

Cooley, T. F. and Hansen, G. D.: 1995, Money and the Business Cycle, Princeton University Press, chapter Chapter 7, pp. 175-216.

Daly, M. C., Fernald, J. G., Óscar Jordà and Nechio, F.: 2017, Shocks and adjustments, Working Paper 2013-32, Federal Reserve Bank of San Francisco.

Dotsey, M., Lantz, C. and Scholl, B.: 2003, The behavior of the real rate of interest, Journal of Money, Credit and Banking 35(1), 91-110. 
Fernald, J. G.: 2014, A quarterly, utilization-adjusted series on total factor productivity, Working Paper 2012-19, Federal Reserve Bank of San Francisco.

Fernald, J. G. and Wang, J. C.: 2016, Why has the cyclicality of productivity changed? what does it mean?, Annual Review of Economics 8, 465-96.

Fiorito, R. and Kollintzas, T.: 1994, Stylized facts of business cycles in the $\mathrm{g} 7$ from a real business cycle perspective, European Economic Review 38(2), 235-269.

Forbes, K. and Rigobon, R.: 2002, No contagion, only interdependence: Measuring stock market comovements, Journal of Finance 57(5), 2223-2261.

Galí, J.: 1999, Technology, employment, and the business cycle: Do technology shocks explain aggregate fluctuations?, American Economic Review 89(1), 249-271.

Galí, J. and Gambetti, L.: 2009, On the sources of the great moderation, American Economic Journal: Macroeconomics 1(1), 26-57.

Galí, J. and van Rens, T.: 2020, The Vanishing Procyclicality of Labour Productivity, The Economic Journal 131(633), 302-326.

Garin, J., Pries, M. J. and Sims, E. R.: 2018, The relative importance of aggregate and sectoral shocks and the changing nature of economic fluctuations, American Economic Journal: Macroeconomics 10(1), 119-148.

Hall, R.: 2005, Employment fluctuations with equilibrium wage stickiness, American Economic Review 95(1), 50-65.

Hall, R.: 2007, How much do we understand about the modern recession?, Brookings Papers on Economic Activity pp. 13-30.

Hamilton, J. D.: 2018, Why you should never use the hodrick-prescott filter, The Review of Economics and Statistics 100(5), 831-843. 
Hodrick, R. J. and Prescott, E. C.: 1980, Postwar U.S. business cycles: An empirical investigation, Technical report, Carnegie Mellon University.

Hodrick, R. J. and Prescott, E. C.: 1997, Postwar U.S. business cycles: An empirical investigation, Journal of Money, Credit and Banking 29(1), 116.

Iacoviello, M.: 2005, House prices, borrowing constraints, and monetary policy in the business cycle, American Economic Review 95(3), 739-764.

King, R. G. and Watson, M. W.: 1996, Money, Prices, Interest Rates and the Business Cycle, The Review of Economics and Statistics 78(1), 35-53.

Kiyotaki, N. and Moore, J.: 1997, Credit cycles, Journal of Political Economy 105(2), 211-248.

Kydland, F. E. and Prescott, E. C.: 1990, Business cycles: Real facts and a monetary myth, Federal Reserve Bank of Minneapolis Quarterly Review pp. $3-18$.

Mertens, E.: 2010, Structural shocks and the comovements between output and interest rates, Journal of Economic Dynamics and Control 34, 11711186 .

Mertz, M.: 1995, Search in the labor market and the real business cycle, Journal of Monetary Economics 36(2), 269-300.

Mortensen, D. and Pissarides, C.: 1994, Job creation and job destruction in the theory of unemployment, Review of Economic Studies 61, 397-415.

Pintus, P. A., Wen, Y. and Xing, X.: 2017, The inverted leading indicator property and redistribution effect of the interest rate, Working paper, Yale University. 
Pintus, P. A., Wen, Y. and Xing, X.: 2018, International credit markets and global business cycles, Working Paper WP 2018-Nr 14, Aix-Marseille School of Economics.

Schüler, Y. S.: 2018, On the cyclical properties of Hamilton's regression filter, Working paper, Deutsche Bundesbank.

Shimer, R.: 2005, The cyclical behaviour of equilibrium unemployment and vacancies, American Economic Review 95(1), 25-49.

Smets, F. and Wouters, R.: 2007, Shocks and frictions in US business cycles: A Bayesian DSGE approach, American Economic Review 97(3), 586-606.

Stiroh, K. J.: 2009, Volatility accounting: A production perspective on increased economic stability, Journal of the European Economic Association $7(4), 671-696$.

Stock, J. H. and Watson, M. W.: 1999, Business cycle fluctuations in US macroeconomic time series, in J. B. Taylor and M. Woodford (eds), Handbook of Macroeconomics, Vol. 1 of Handbook of Macroeconomics, Elsevier, chapter 1, pp. 3-64.

Stock, J. H. and Watson, M. W.: 2002, Macroeconomic forecast using diffusion indexes, Journal of Business $\&$ Economic Statistics 20(2).

Wolters, M. H.: 2018, How the baby boomers' retirement wave distorts model-based output gap estimates, Journal of Applied Econometrics 33(5), 680-689.

Wu, J. C. and Xia, F. D.: 2016, Measuring the macroeconomic impact of monetary policy at the zero lower bound, Journal of Money, Credit and Banking 48(2-3), 253-291. 


\section{Chapter 2}

\section{Monetary policy uncertainty and the cyclicality of interest rates}

\section{$2.1 \quad$ Introduction}

One of the central aims of business cycle analysis is to understand the comovement between macroeconomic aggregates. An important feature of comovement is leading indicators, which are variables that tend to precede movements in output over the business cycle. These indicators are an important source of information for policymakers, practitioners, and market participants since they yield information about future economic conditions without having to formulate a structural theory for why these relationships exists.

Among these indicators, a large literature has emphasized that short term nominal and real interest rates are leading indicators of the US business cycle. ${ }^{1}$ Lower current nominal and real interest rates are strongly correlated with higher future output, a property that King and Watson (1996) refer

\footnotetext{
${ }^{1}$ I use short term to refer to the three month treasury bill rate.
} 
to as the "inverted leading indicator" property of nominal and real interest rates.

But recently Brault and Khan (2020) have documented significant shifts in the cyclicality of US short term nominal and real interest rates since the onset of the Great Moderation. First, the inverted leading indicator property highlighted by King and Watson (1996) has completely disappeared. Instead both short term nominal and real interest rates positively lag movements in output. Second, the contemporaneous correlations between output and interest rates (both nominal and real) experienced a dramatic rise in their procyclicality. These changes are depicted in Figure 2.1, which plots the cross-correlogram between output, nominal and real interest rates. ${ }^{2}$

In this paper I provide a structural interpretation of these changes using a New-Keynesian model with imperfect information. In the model agents and the central bank are subject to symmetric imperfect information about the current state of the economy and must solve a signal extraction problem in the presence of noisy signals about macroeconomic aggregates. The model's ability to explain the changes in the cyclicality of nominal and real interest rates rests on the fact that uncertainty about the current state of the economy has become less severe since the onset of the Great Moderation.

Uncertainty about the current state of the economy can arise from several sources. One prominent source emphasized in a series of articles by Athanasios Orphanides (e.g., Orphanides (2001, 2003a,b)) is that monetary policymakers must make decisions based on real-time data, even though these data are often substantially revised in the future as more comprehensive information becomes available and methodologies improve. Real-time policy recommendations can then differ quite dramatically from what would have been recommended if policymakers had access to ex-post revised data.

A second source of uncertainty is that there is often a publication lag

\footnotetext{
${ }^{2}$ In this paper I use a strict statistical definition of leading and lagging indicators. A variable is considered is leading indicator if the largest absolute correlation in the crosscorrelogram, $\rho\left(y_{t}, x_{t+k}\right)$, belongs to the variable at any time for $k=[-5,-1]$.
} 

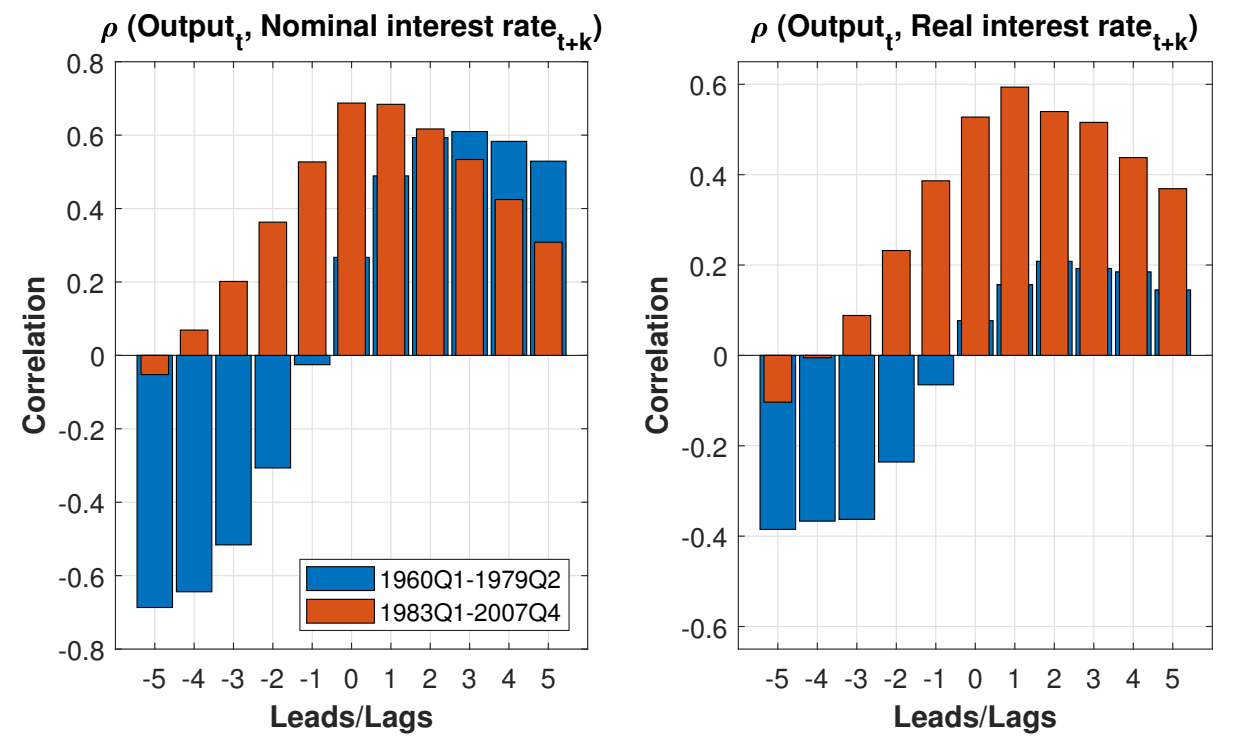

Figure 2.1: Cross-correlogram between output, nominal and real interest rates

Notes: The real interest rate is an ex-post measure defined as the federal funds rate at time $t$ less realized inflation (annualized) between $t$ and $t+1$. Output is real GDP per capita detrended. Both output and interest rates are detrended using the Hodrick-Prescott filter with a smoothing parameter, $\lambda=1600$. 
between the period when monetary authorities set their policy rate and the data which are available. Policymakers then need to rely on a combination of staff projections using historical data and advanced estimates from agencies such as the Bureau of Economic Analysis (BEA). For example, when FOMC members meet this year on November 4-5, only advanced estimates of third quarter GDP will be released by the BEA.

Both of the above examples suggest that in reality central banks are faced with the challenge of setting their policy rate while being uncertain about the true state of macroeconomic aggregates such as output, the output gap, and inflation. These information challenges are emphasized by former Federal Reserve's Chair Ben Bernanke,

The measurement issues I just raised point to another important concern of policymakers, namely, the necessity of making decisions in "real time," under conditions of great uncertainty including uncertainty about the underlying state of the economy - and without the benefit of hindsight. ${ }^{3}$

But have these information challenges remained relatively constant throughout postwar US business cycles? The evidence put forth in this paper suggests that they have not and information-related issues have declined since the onset of the Great Moderation.

I begin by investigating two potential sources of information improvements. The first is evidence on real-time data from the Federal Reserve Bank of Philadelphia. This evidence suggests that real-time data has become more accurate, providing monetary authorities with better information about the current state of the economy. I construct real-time measurement errors in output growth and GDP deflator-based inflation by comparing initial releases

\footnotetext{
3 "Outstanding Issues in the Analysis of Inflation", a speech made by Ben Bernanke at the Federal Reserve Bank of Boston's 53rd Annual Economic Conference (2008). A transcript of the speech is available at https://www.federalreserve.gov/newsevents/speech/bernanke20080609a.htm.
} 
to most recent values. I find that the standard deviation of output growth and inflation real-time measurement errors has fallen by $45 \%$ and $16 \%$ since the onset of the Great Moderation.

The second source of information improvement I investigate comes from the Federal Reserve's Greenbook. The Greenbook is produced before each FOMC meeting and contains staff projections about current and future states of the economy. The rationale for studying these projections is that even with the same real-time data, Federal Reserve employees may have improved techniques and understanding about the macroeconomy, allowing them to produce more accurate forecasts. I construct forecast errors in output growth and inflation by comparing Greenbook forecasts to the most recent values for these variables. I find that forecast errors have become significantly smaller since the onset of the Great Moderation, with output growth forecast errors falling by $45 \%$ and inflation errors by $14 \%$.

The empirical evidence points to improvements in both real-time data and Federal Reserve forecasts. While I remain agnostic about the source of the decline in real-time measurement and forecast errors, the important point for this paper is that both sources support the interpretation that information challenges about the current state of the US economy have declined since the onset of the Great Moderation.

To understand how a reduction in information frictions matters for interest rate cyclicality, I construct a small scale New-Keynesian model where agents and the central bank have symmetric imperfect information about current state of the economy. ${ }^{4}$ Agents and the central bank receive noisy

\footnotetext{
${ }^{4}$ The assumption of symmetric information between agents and the central bank may appear strong given recent work by Nakamura and Steinsson (2018). The authors document a Fed information effect where private agent forecasts about future output growth increase in response to unexpected increases in interest rates, the opposite of what would be predicted by a symmetric information model (i.e., the Fed has superior information about the economy). But recently, Bauer and Swanson (2020) challenge this interpretation by showing that both the Fed and private agents are responding to news and there is little role of a Fed information effect. The latter work is supportive of a symmetric information assumption. This assumption can be relaxed, but it is made to keep the model
} 
signals about output and inflation, and must solve a signal extraction problem to formulate optimal estimates about the current state of the economy. These optimal estimates are formulated through a Kalman filter updating equation as in Svensson and Woodford (2003). After obtaining estimates about the current state of the economy, the central bank conducts monetary policy according to a Taylor rule which responds to deviations of expected inflation and the output gap. The model features six sources of exogenous variation, including: neutral technology shocks, cost-push shocks, preference (demand) shocks, monetary policy shocks, and shocks to the signals about output and inflation (which I refer to as noise shocks). Larger noise shocks generate more uncertainty about the current economic state.

I estimate the structural parameters of the model for two different subsamples using Bayesian maximum likelihood methods. The first subsample (1960Q1:1979Q2) corresponds to the Great Inflation period where interest rate dynamics were characterized by an inverted leading indicator property, and the second subsample corresponds to the Great Moderation period (1983Q1:2007Q4) where interest rate dynamics displayed a positive lagging property. Estimates of the structural parameters indicate a substantial fall in noise shocks. From the Great Inflation to the Great Moderation, output and inflation noise shocks fell by approximately $68 \%$ and $51 \%$, respectively.

I emphasize three novel channels in which uncertainty matters for the cyclicality of nominal and real interest rates. Two channels which were prominent during the Great Inflation period produce inverted leading comovements between output, nominal, and real interest rates. The third channel, which was muted during the Great Inflation period and more prominent during the Great Moderation, produces positive lagging comovements between output, nominal, and real interest rates.

In the first channel I emphasize that because the central bank relies on optimal estimates about the current state of the economy to set its policy tractable. 
rate, a reduction in uncertainty leads policy rate responses which are closer to the policy responses implied by the Taylor rule under perfect information. That is, a reduction in uncertainty reduces undesirable movements in the policy rate. Interactions between these undesirable movements and real rigidities generate inverted leading comovements in the nominal and real interest rate, similar to monetary policy shocks in a standard macroeconomic model.

In the second channel I emphasize the role that a relative reduction in inflation noise shocks has played. A positive inflation noise shock leads the central bank to believe both output and inflation have risen and consequently the central bank incorrectly tightens monetary policy by raising the nominal interest rate and due to sticky prices, the real interest rate. Since actual inflation and output were initially unchanged, the rise in the real interest rate causes households to reduce consumption and output through intertemporal substitution. In the presence of real rigidities, this produces a negative leading comovement between output, nominal, and real interest rates.

In the third channel I show that a reduction in uncertainty fundamentally alters the propagation of preference shocks. A fall in uncertainty allows the central bank to more easily distinguish preference shocks from statistical noise, which leads to more aggressive policy rate responses. More aggressive policy rate responses produce stronger positive lagging comovements between output, nominal, and real interest rates.

To emphasize the strength of the proposed channels I conduct a simple counterfactual experiment where I change only the amount of uncertainty and examine the implications for the cyclicality of nominal and real interest rates. I find that by changing the amount of uncertainty, the change in the cross-correlograms closely resembles the changes in the unconditional data presented in Figure 2.1. In particular, both nominal and real interest rates experience a dramatic rise in their procyclicality and the real interest rate switches from an inverted leading indicator to a positive lagging indica- 
tor. The magnitude of the cross-correlations is comparable with those in the unconditional data.

In terms of practical relevance, my paper clarifies that short term nominal and real interest rates should not be considered leading indicators of future economic conditions when policy is conducted in close accordance with a Taylor rule based on ex-post revised data. ${ }^{5}$ Additionally, the paper provides a structural rationale for why nominal and real interest rates displayed an inverted leading indicator property during the Great Inflation period. This was primarily because policy implementation was challenging due to significant misunderstandings about the current state of the economy. The necessity of setting the policy rate in real time suggests that information frictions will never completely disappear, and by extension, even in periods of good monetary policy short term nominal and real interest rates can be expected to positively lag output over the business cycle.

Shocks versus structure: One alternative explanation that readers may find compelling is that this change is driven primarily by a shift in the relative importance of technology, aggregate demand, and monetary policy shocks. For reasons which I discuss below this does not seem to be the entire story.

First, a large literature has documented a rise in the relative importance of neutral technology shocks since the onset of the Great Moderation (e.g., Galí and Gambetti (2009), Barnichon (2010)); A result that is consistent with my structural estimates. Mertens (2010) argues that changes in the cyclicality of the real interest rate between the Great Inflation and the Great Moderation can mostly be attributed to this fact.

But this interpretation is problematic when one also considers the changes in the cyclicality of the nominal interest rate. Neutral technology shocks generate a negative comovement between output and the nominal interest rate

\footnotetext{
${ }^{5}$ For a recent example emphasizing real interest rates as an inverted leading indicator, see the following video from Vox's Centre for Economic Policy Research (CEPR): https://voxeu.org/content/predicting-real-interest-rate.
} 
(both empirically and in a New-Keynesian model). Then a rise in the relative importance of technology shocks would suggest an increasingly negative comovement between output and the nominal interest rate. However this is exactly opposite to the observed rise in procyclicality in the data. The mechanism in the present paper can account for the observed rise in procyclicality of both the nominal and real interest rate.

Second, Brault and Khan (2020) take the Smets and Wouters (2007) (SW) model and estimate the model on pre-1984 and post-1984 data. This model features a wide array of structural shocks, real and nominal frictions intended to provide an accurate representation of the data. But the model is unable to generate the change in comovement between output, nominal and real interest rates exhibited by the data even though the relative importance of exogenous shocks changes substantially. Since model features in SW are embedded in many contemporary models, this suggests that standard models will be unable to capture this change.

Related literature: This paper is broadly related to two strands of literature. One strand seeks to explain why nominal (or real) interest rates lead the business cycle. King and Watson (1996) document the inverted leading indicator property of nominal and real interest rates in the unconditional data. ${ }^{6}$ Additionally they investigate the ability of a real business cycle model, a sticky price model, and a liquidity effect model to account for these facts. They show that while each model can capture one aspect, none can account for all of the facts they document. Beaudry and Guay (1996) show that a modified RBC model with habit formation and capital adjustment costs significantly improves the model's ability to explain the comovement between output and real interest rates. However this improvement depends largely on

\footnotetext{
${ }^{6}$ Other works documenting this property for either real or nominal interest rates include Zarnowitz (1992), Bernanke and Blinder (1992), Fiorito and Kollintzas (1994), Chari et al. (1995), Beaudry and Guay (1996), Stock and Watson (1999), Boldrin et al. (2001), Dotsey et al. (2003), and Mertens (2010).
} 
comparing with the comovement induced by identified technology shocks and not the unconditional data. Boldrin, Christiano and Fisher (2001) present a two-sector RBC model with habit formation and limited factor mobility and show that real interest rates are inversely correlated with future output. Lastly, Pintus, Wen and Xing (2017) show that a model featuring collateral constraints in the style of Kiyotaki-Moore with redistribution shocks can account for the inverted leading indicator property of real interest rates.

Relative to this strand of literature this paper is the first, to my knowledge, to provide a comprehensive explanation of why nominal and real interest rates featured an inverted leading indicator property during the Great Inflation and a positive lagging property during the Great Moderation.

A second related strand of literature explores imperfect information as a propagation mechanism and source of endogenous persistence in DSGE models. Lippi and Neri (2007) estimate a small scale DSGE model with imperfect information and discretionary monetary policy for the euro area. They find that under information frictions the weight on output gap stabilization is small and that observations on unit labour costs contain important information on potential output. Collard, Dellas and Smets (2009) estimate a small scale New-Keynesian DSGE model with a variety of imperfect information structures and find that information frictions provide a plausible mechanism for inertia in variables such as inflation and increase the model's fit relative to a full information structure. Collard and Dellas (2010) consider imperfect information about monetary shocks and show that the model can exhibit inflation inertia without ad hoc model features such as price indexation. Neri and Ropele (2011) estimate a small scale NK model using real-time data in the euro area and compare to a model with perfect information. They find that the estimated policy rule is more inertial and less aggressive towards inflation. Additionally, they assess the output gap inflation tradeoff facing the ECB. Givens and Salemi (2015) estimate an NK model with optimal discretionary policy using real-time and ex-post US data for the 1965-2010 period. 
They find that the Federal Reserve increased its concern for stabilizing the output gap after 1979 and that the tension between optimal and observed policy is smaller during this period.

Relative to this literature, I focus on a particular set of moments nominal and real interest rate cyclicality - and whether changes in the degree of uncertainty can explain the changes in cyclicality since the onset of the Great Moderation.

The rest of the paper is organized as follows. Section 2.2 explores two plausible sources of information improvements and shows that both point to improvements in understanding about real-time macroeconomic conditions. Section 2.3 describes the DSGE model, including how the model is solved and estimated under the assumption of symmetric imperfect information. Section 2.4 describes the three channels in which a reduction in uncertainty can help to explain the change in the cyclicality of the nominal and real interest rates. Section 2.5 contains concluding remarks.

\subsection{Empirical investigation into noise}

In the following section I explore two potential sources in which monetary policy authorities may have better information about the current state of the economy: Better real-time information and improved forecasting/signal extraction methods from the Fed.

\subsubsection{Real-time measurement error}

One source of uncertainty in the implementation of monetary policy is that the information available (i.e., real-time data) is often substantially revised in the future as more comprehensive information becomes available. Then a naive policymaker who sets the policy rate based on this information may do so incorrectly (according to a Taylor rule) due to the presence of measurement error in real-time data. 
But given the advances in technology and data processing over the past several decades it is reasonable to believe that such advances could lead to more accurate real-time data, and by extension a reduction in uncertainty on behalf of policymakers. However, as Arouba (2008) notes, it is also quite possible that the rise in technology has made real-time data collection more challenging since there has been a large increase in the variety of goods.

To investigate if real-time data measurement has become more accurate since the onset of the Great Moderation, I construct a series of real-time measurement errors for output growth and inflation using data from the Federal Reserve Bank of Philadelphia's Real-Time Data Set for Macroeconomists (more information on the data is available in Appendix B.4). Measurement errors are constructed by comparing first releases of output growth and inflation to their most recent values. ${ }^{7}$ Specifically, measurement errors are defined as,

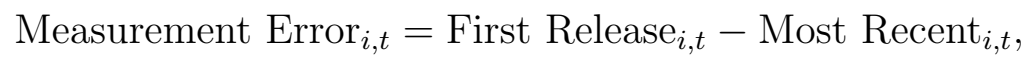

for $i \in\{$ Output growth, Inflation $\}$. Equation (2.1) says that positive errors correspond to periods where initial estimates of output growth and inflation overstate the true values. In this case positive errors could lead the central bank to increase their policy rate more than would be required by their Taylor rule.

Figure 2.2 plots real-time measurement errors for quarter-over-quarter output growth and inflation from 1965Q3:2007Q4 (in annualized percentage points). ${ }^{8}$

It is worth remarking on two facts about Figure 2.2. First, the size of measurement errors in output growth and inflation are quantitatively large.

\footnotetext{
${ }^{7}$ Since I am only examining data up to 2007Q4, treating the most recent observations as the true value seems reasonable given that most of the revisions have already taken place.

${ }^{8}$ The measurement error series starts in 1965Q3 due to data limitations.
} 

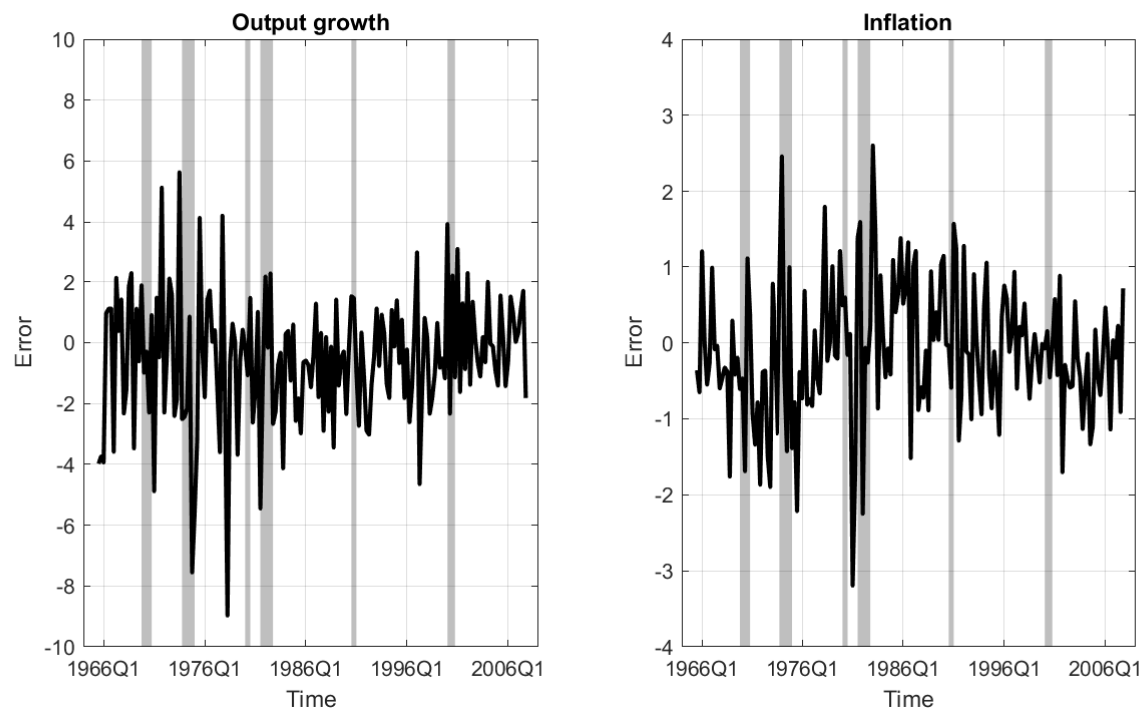

Figure 2.2: Real-time measurement error in output growth and inflation

Notes: Output growth and inflation errors are reported in quarter over quarter rates in annualized percentage points. The inflation measure corresponds to prices in the GDP deflator. Gray bands indicate recessions as defined by the NBER Business Cycle Dating Committee.

The figure implies that at points in the sample, initial reports of output growth differed from the true value by as much as $8 \%$ in annualized terms (approximately $2 \%$ in quarterly growth rates). Inflation errors are smaller, but still quantitatively large with errors being as large as $0.75 \%$ in quarterly terms. To put these errors in perspective, average output growth and inflation in the ex-post revised data over this period was $3.27 \%$ and $4.01 \%$ in annualized terms. This implies that there were periods where initial releases of output growth and inflation were substantially different than their final values.

Second, it is apparent from the figure that there is a substantial difference in the magnitude of measurement errors when comparing the Great Inflation period to the Great Moderation. Large errors are visually noticeable in both 
output growth and inflation during the Great Inflation period, but have since declined quite dramatically. How large the declines? Table 2.1 reports the standard deviation of measurement errors for output growth and inflation in the pre-1979 and post-1983 periods.

\begin{tabular}{l|cc} 
Moment $\downarrow /$ Time $\rightarrow$ & 1965Q3:1979Q2 & 1983Q1:2007Q4 \\
\hline$\sigma\left(\Delta y^{M E}\right)$ & 2.89 & 1.58 \\
$\sigma\left(\pi^{M E}\right)$ & 0.93 & 0.78
\end{tabular}

Notes: Output growth and inflation are quarter-over-quarter growth rates in annualized terms.

Table 2.1: Standard deviation of output growth and inflation real-time measurement errors

It is evident from the table that measurement errors in output growth are largest, and have also exhibited the largest decline. The measurement errors for output growth have declined by about $45 \%$, while measurement errors for inflation have declined by about $16 \%$. This suggests that real-time data has become more accurate and points to one potential source of reduction in uncertainty for policymakers.

\subsubsection{Fed Greenbook forecasts}

A second distinct source of reduction in uncertainty may come from the Federal Reserve itself through a variety of channels. First, Assumption 1 in the structural model assumes that agents and the central bank are aware of the structural equations, parameters values, and shock processes governing the economy. This is clearly a strong assumption, and the more likely case is that both agents and the central bank have learned more about structure and dynamics over time.

A second channel in which the Fed could have reduced its uncertainty is through its information set itself. In the structural model which will presented in this paper it is assumed that only output and inflation are ob- 
servable with some error. In reality there is a wide array of information available, some of which may provide more accurate information on variables such as output and inflation. An example showing information set expansion as a useful tool in reducing uncertainty is presented in Nimark (2008), who adds a bond market with different maturity bonds into a small scale New-Keynesian model. Since bond yields are observed at a much higher frequency, if the bond market is not too noisy, then bond returns can provide important real-time information to the central bank about macroeconomic variables and structural shocks.

Lastly, it is quite possible that the Fed has a better understanding about what drives measurement errors in the first place. For example, Arouba (2008) shows that real-time measurement errors can be forecast using other real-time variables. Amir-Ahmadi, Matthes and Wang (2017) use a Bayesian VAR with sign restrictions to examine the impact of monetary policy shocks on real-time and ex-post measures of real activity. They find that impulse responses to a monetary shock can be significantly different when one compares IRFs based on real-time versus ex-post data, something that policymakers should be aware of. Both of the above suggest that the Fed may have a better understanding of where measurement errors comes from and how to extract information from noisy signals.

To consider the above possibilities I examine forecasts about the current state of the economy from the Federal Reserve Greenbook. ${ }^{9}$ The Greenbook contains internal forecasts from Federal Reserve staff about past, current, and future macroeconomic variables. I focus on forecasts about the current state of output growth and inflation using the last forecast in a given quarter about that specific quarter (e.g., the forecast of output growth in September for the third quarter of that year) and compare those forecasts to most recent values. ${ }^{10}$

\footnotetext{
${ }^{9}$ Due to data limitations, I only examine forecasts from 1967Q1 onwards.

${ }^{10} \mathrm{I}$ also examined forecasts from the beginning and middle of each quarter. There is no significant difference between the timing of the forecast within a quarter and the
} 
Similar to the construction of real-time measurement errors, I define forecast errors by the following equation,

Forecast Error $_{i, t}=$ Greenbook forecast $_{i, t}-$ Most Recent $_{i, t}$,

for $i \in\{$ Output growth, Inflation\}. Equation (2.2) states that when the Fed projections are overly optimistic about output growth and inflation, errors will be positive and potentially lead to unnecessary tightening of monetary policy. These forecast errors are pictured in Figure 2.3.
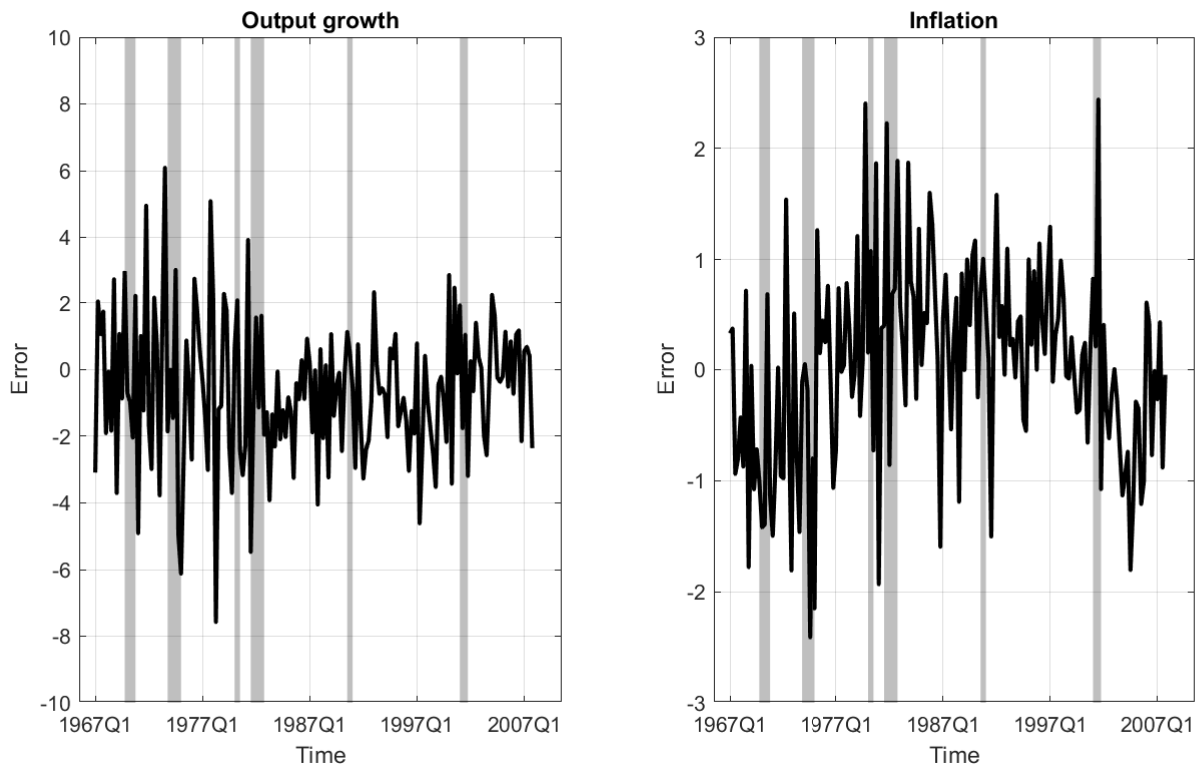

Figure 2.3: Greenbook forecast errors in output growth and inflation

Notes: Output growth and inflation errors are reported in quarter over quarter rates in annualized percentage points. The inflation measure corresponds to prices in the GDP deflator. Gray bands indicate recessions as defined by the NBER Business Cycle Dating Committee.

conclusions I draw about the quality of forecasts before and after the Great Moderation. 
Similar to the measurement errors in the previous section, forecasts errors from the Federal Reserve's Greenbook are quantitatively large and appear to decline since the onset of the Great Moderation, substantially so in the case of output growth. I report the standard deviation of these forecast errors for output growth and inflation in Table 2.2.

\begin{tabular}{l|cc} 
Moment $\downarrow /$ Time $\rightarrow$ & 1967Q1:1979Q2 & 1983Q1:2007Q4 \\
\hline & & \\
$\sigma\left(\Delta y^{F E}\right)$ & 2.85 & 1.57 \\
$\sigma\left(\pi^{F E}\right)$ & 0.90 & 0.77
\end{tabular}

Notes: Output growth and inflation are quarter-over-quarter growth rates in annualized terms.

Table 2.2: Standard deviation of Greenbook forecast errors in output growth and inflation

Interestingly, the level and decline in Fed forecasts errors almost identically matches the level and decline from the real-time data. Output growth forecast errors have declined by $45 \%$ and inflation forecast errors by $14 \%$ since the onset of the Great Moderation.

The above suggests that both real-time data and Fed forecasts have become more accurate since the onset of the Great Moderation period, and by extension, monetary policymakers should face lower levels of uncertainty about the current state of the economy. In the following section I estimate a structural model where agents and the central bank face imperfect information due to noise shocks. I estimate the magnitude of noise in output and inflation in the model, but the magnitudes of measurement errors and forecast errors in this section serve as useful comparisons. 


\subsection{Model, Solution, and Estimation}

\subsubsection{Model}

The model in this section is a small scale New-Keynesian model comprised of a continuum of intermediate goods firms who operate in a monopolistically competitive environment. Intermediate goods firms produce output with labour as the only input and are subject to sticky prices via the Calvo mechanism. Final goods firms package intermediate goods into a final aggregate good which are sold in a perfectly competitive environment. Households optimize over consumption, labour supply, and one period riskless bonds. The model is closed by a monetary policy authority who sets nominal interest rates in response to deviations of inflation and the output gap with interest rate smoothing.

Since many features of this model are relatively standard (e.g., Galí (2015, Ch. 3)), I simply report the log-linearized equations of the model and leave the derivation to Appendix B.2. I use $\tilde{x}$ to denote a variable $x$ that has been log-linearized around its steady state. The model structure is given by,

$$
\begin{aligned}
\tilde{y}_{t}=\frac{h}{1+h} \tilde{y}_{t-1}+ & \frac{1}{1+h} \tilde{y}_{t+1 \mid t}-\frac{1-h}{1+h}\left(\tilde{i}_{t}-\tilde{\pi}_{t+1 \mid t}\right)+\frac{1-h}{1+h} \tilde{v}_{t}^{y}\left(1-\rho_{y}\right) \\
& \tilde{\pi}_{t}=\kappa_{1}\left(\tilde{y}_{t}-\tilde{y}_{t}^{F}\right)+\kappa_{2}\left(\tilde{y}_{t-1}-\tilde{y}_{t-1}^{F}\right)+\beta E_{t} \tilde{\pi}_{t+1}+\tilde{v}_{t}^{\pi} \\
& \tilde{i}_{t}=\rho_{i} \tilde{i}_{t-1}+\left(1-\rho_{i}\right)\left\{\alpha_{\pi} \tilde{\pi}_{t \mid t}+\alpha_{y}\left(\tilde{y}_{t \mid t}-\tilde{y}_{t \mid t}^{F}\right)\right\}+\tilde{v}_{t}^{m}
\end{aligned}
$$

where $\tilde{y}$ is output, $\tilde{i}$ is the nominal interest rate, and $\tilde{\pi}$ is the inflation rate. $\tilde{v}^{y}, \tilde{v}^{\pi}$, and $\tilde{v}^{m}$ are structural shocks to demand, inflation, and the monetary policy rule. Equation (2.3) is the dynamic IS equation, (2.4) is the New Keynesian Phillips curve, and (2.5) is a Taylor-type rule which allows for interest rate smoothing. The nominal interest rate and inflation are reported in percentage point deviation from steady state (i.e., $x_{t}-\bar{x}$ ). All remaining variables are reported in percentage deviation from steady state (i.e., $\frac{x_{t}-\bar{x}}{\bar{x}}$ ). 
The reduced form parameters are given by: $\kappa_{1}=\frac{(1-\beta \theta)(1-\theta)}{\theta} \frac{1+\eta(1-\varphi)(1-h)}{1-h}$ and $\kappa_{2}=\frac{(1-\beta \theta)(1-\theta)}{\theta} \frac{h}{1-h}$. $\beta$ is the household discount factor, $\theta$ is the Calvo probability of a firm being able to reset its price in a given period, $h$ is the external habit formation parameter, $\eta$ is the inverse Frisch elasticity of labour supply, and $\varphi$ is the fraction of fixed costs in total production. The natural rate of output, the level of output that would prevail in the absence of sticky prices, is given by,

$$
\tilde{y}_{t}^{F}=\frac{(1-h)(1+\eta)}{1+\eta(1-\varphi)(1-h)} \tilde{a}_{t}+\frac{h}{1+\eta(1-\varphi)(1-h)} \tilde{y}_{t-1}^{F},
$$

where $\tilde{y}_{t}^{F}$ denotes output in the flexible price environment and $a_{t}$ is a neutral technology shock. This shock, along with the structural shocks in (2.3), (2.4), and (2.5), are governed by the following processes,

$$
\begin{aligned}
\log a_{t}=\rho_{a} \log a_{t-1}+\left(1-\rho_{a}\right) \log (\bar{a})+\epsilon_{t}^{a} & \epsilon_{t}^{a} \sim N\left(0, \sigma_{a}^{2}\right), \\
\log v_{t}^{y}=\rho_{y} \log v_{t-1}^{y}+\epsilon_{t}^{y} & \epsilon_{t}^{y} \sim N\left(0, \sigma_{y}^{2}\right), \\
\log v_{t}^{\pi}=\rho_{\pi} \log v_{t-1}^{\pi}+\epsilon_{t}^{\pi} & \epsilon_{t}^{\pi} \sim N\left(0, \sigma_{\pi}^{2}\right), \\
\log v_{t}^{m}=\epsilon_{t}^{m} & \epsilon_{t}^{m} \sim N\left(0, \sigma_{m}^{2}\right) .
\end{aligned}
$$

There are two points worth mentioning about the model setup above. First, expectations about future output and inflation are consistent with rational expectations in the sense that forecast errors are unpredictable. However the expectations will differ from a standard full information rational expectations model since agents imperfectly observe the true state of the economy and use these imperfect observations in their formation of expectations about future output and inflation. In an attempt to differentiate this from standard notation, the expectations are denoted $x_{t+1 \mid t}$ for $x \in\{\tilde{y}, \tilde{\pi}\}$.

Second, since estimates of the current state are an input variable into the 
central bank's feedback rule, these estimates will be affected by the imperfect information. I have denoted limited information of these variables by $x_{t \mid t}$ for $x \in\left\{\tilde{y}, \tilde{\pi}, \tilde{y}^{F}\right\}$. In the following subsection I discuss how these estimates of the state are formed and what information is assumed to be known.

\subsubsection{Solution}

In the following subsection I describe the solution the model in the presence of imperfect information. This solution method closely follows Svensson and Woodford (2003). The log-linearized model can be represented in compact matrix form by,

$$
\left[\begin{array}{c}
\mathbf{X}_{1, t+1} \\
E_{t} \mathbf{X}_{2, t+1}
\end{array}\right]=\mathbf{A}_{1}\left[\begin{array}{l}
\mathbf{X}_{1, t} \\
\mathbf{X}_{2, t}
\end{array}\right]+\mathbf{A}_{2}\left[\begin{array}{l}
\mathbf{X}_{1, t \mid t} \\
\mathbf{X}_{2, t \mid t}
\end{array}\right]+\mathbf{C} \boldsymbol{\epsilon}_{t}
$$

where $\mathbf{X}_{1}$ is comprised of predetermined and exogenous variables, $\mathbf{X}_{2}$ contains the forward looking variables (output and inflation), and $\epsilon$ is a vector of structural shocks. The matrices $\mathbf{A}_{1}, \mathbf{A}_{2}$, and $\mathbf{C}$ contain non-linear functions of the structural parameters.

The primary difference between a standard full information New-Keynesian model and the model presented here is that agents and the central bank cannot perfectly observe all variables in the model. Instead they only observe a subset of these variables with noise and lag, and must solve a signal extraction problem to infer their true values. Agent's and the central bank's observation equation is given by,

$$
\mathbf{Z}_{t}=\left[\begin{array}{c}
\tilde{\pi}_{t-1} \\
\tilde{y}_{t-1}
\end{array}\right]+\left[\begin{array}{l}
\tilde{v}_{t}^{\eta_{\pi}} \\
\tilde{v}_{t}^{\eta_{y}}
\end{array}\right]
$$

where $\tilde{v}_{t}^{\eta_{\pi}}$ and $\tilde{v}_{t}^{\eta_{y}}$ are noise shocks preventing the central bank from perfectly 
observing lags of output and inflation. ${ }^{11}$ Equation (2.12) implies that agents and the central bank do not observe structural shocks or the natural rate of output. However since there is symmetric information, agents are aware of the central bank's interest rate, and by extension any monetary policy shocks. The noise shocks are allowed to be potentially serially correlated and their process is given by,

$$
\begin{array}{rlrl}
\ln v_{t}^{\eta_{\pi}} & =\rho_{\eta_{\pi}} \ln v_{t-1}^{\eta_{\pi}}+\epsilon_{t}^{\eta_{\pi}} & & \epsilon_{t}^{\eta_{\pi}} \sim N\left(0, \sigma_{\eta_{\pi}}^{2}\right), \\
\ln v_{t}^{\eta_{y}}=\rho_{\eta_{y}} \ln v_{t-1}^{\eta_{y}}+\epsilon_{t}^{\eta_{y}} & \epsilon_{t}^{\eta_{y}} \sim N\left(0, \sigma_{\eta_{y}}^{2}\right) .
\end{array}
$$

It is assumed that there is no correlation between the noise shocks and underlying structural shocks. This structure gives rise to Assumption 1.

Assumption (A1). The information set of agents and the central bank at any time $t$ is composed of $I_{t} \equiv\left\{\mathbf{A}_{1}, \mathbf{A}_{2}, \mathbf{C}, \mathbf{D}_{1}, \boldsymbol{\Sigma}_{\epsilon \epsilon}, \boldsymbol{\Sigma}_{v v}, \mathbf{Z}_{t-s} \mid s \geq 0\right\}$.

Assumption 1 states that agents and the central bank know the structural equations of the model and the corresponding values of the structural parameters. Additionally, it is assumed that they know the distributions of the exogenous shocks (both structural shocks and noise shocks). Lastly, it is assumed that they have access to the full history of observables, $\mathbf{Z}_{t-s}$.

Under this setup it is well known that the solution to the rational expectations equilibrium is independent of the computation of the state (i.e., the signal extraction problem). This is commonly referred to as the separation principle (e.g., Pearlman (1992), Svensson and Woodford (2003)). Then one can solve for the linear mapping between the predetermined/exogenous vari-

\footnotetext{
${ }^{11} \mathrm{~A}$ compromise is made in terms of inflation observation timing. The model is based on a quarterly frequency, but inflation data are reported at a monthly frequency and thus a one quarter lag is too long.
} 
ables and the forward looking variables using standard techniques. ${ }^{12}$ This mapping is given by,

$$
\mathbf{X}_{2, t \mid t}=\mathbf{G}^{\star} \mathbf{X}_{1, t \mid t}
$$

Given the linear mapping in (2.15), it is straightforward to cast the model in state space form and use the one-sided Kalman filter to compute the expected values of the state variables. The dynamics of the model are then represented by the following set of equations,

$$
\begin{array}{r}
\mathbf{X}_{t+1}=\mathbf{H X}_{t}+\mathbf{J} \mathbf{X}_{t \mid t}+\mathbf{B} \epsilon_{t+1} \\
\mathbf{X}_{t \mid t}=\mathbf{X}_{t \mid t-1}+\mathbf{K}\left(\mathbf{Z}_{t}-\mathbf{Z}_{t \mid t-1}\right), \\
\mathbf{Z}_{t}=\mathbf{L} \mathbf{X}_{t}+\mathbf{M} \mathbf{X}_{t \mid t}+\mathbf{v}_{t}
\end{array}
$$

where,

$$
\begin{array}{r}
\mathbf{H}=\mathbf{A}_{11}^{1}-\mathbf{A}_{12}^{1}\left(\mathbf{A}_{22}^{1}\right)^{-1} \mathbf{A}_{21}^{1}, \\
\mathbf{J}=\mathbf{A}_{12}^{1}\left[\left(\mathbf{A}_{22}^{1}\right)^{-1} \mathbf{A}_{21}^{1}+\mathbf{G}^{\star}\right]+\mathbf{A}_{11}^{2}+\mathbf{A}_{12}^{2} \mathbf{G}^{\star}, \\
\mathbf{L}=\mathbf{D}_{1}^{1}-\mathbf{D}_{2}^{1}\left(\mathbf{A}_{22}^{1}\right)^{-1} \mathbf{A}_{21}^{1}, \\
\mathbf{M}=\mathbf{D}_{2}^{1}\left[\left(\mathbf{A}_{22}^{1}\right)^{-1} \mathbf{A}_{21}^{1}+\mathbf{G}^{\star}\right], \\
\mathbf{K}=\mathbf{P L}^{\prime}\left(\mathbf{L} \mathbf{P} \mathbf{L}^{\prime}+\mathbf{\Sigma}_{v}^{2}\right)^{-1},
\end{array}
$$

where the subscripts on the matrix $\mathbf{A}$ refer to the number of rows or columns associated with the predetermined or forward looking variables (e.g., $\mathbf{A}_{11}$ is

\footnotetext{
${ }^{12}$ In this paper I use a simple iterative fixed point algorithm. Alternatively, one could also solve for the matrix $\mathbf{G}^{\star}$ using the Blanchard-Kahn method.
} 
the first $n_{1}$ rows and columns of $\mathbf{A}$, where $n_{1}=11$, the number of predetermined and exogenous variables) and $\mathbf{P}$ is a covariance matrix of prediction errors. In Appendix B.3 I report the matrices $\mathbf{A}_{0}, \mathbf{A}_{1}, \mathbf{A}_{2}$, and $\mathbf{C}$ which are used in the solution, as well as additional details on the solution of the model.

There are a few points worth emphasizing about the above model dynamics relative to a standard full information rational expectations DSGE model. First, Equation (2.16) highlights that the signal extraction problem endogenously feeds back into the dynamics of the model through estimates of the current state of the economy. Second, these estimates will also impact the expectations channels in the dynamic IS and NKPC equations through Equation (2.15). As the literature on imperfect information has documented (e.g., Collard et al. (2009)), these properties generate rich dynamics between the signal extraction problem and the impact of exogenous shocks.

One convenient feature of this model setup is that it nests the perfect information case when $\mathbf{X}_{t \mid t}=\mathbf{X}_{t}$. In this case the standard state space representation can be obtained by adding matrices $\mathbf{H}$ and $\mathbf{J}$ together, and adding $\mathbf{L}$ and $\mathbf{M}$ together.

\subsubsection{Estimation}

The model in Section 2.3.1 is estimated using US quarterly data on out-

put, inflation, and the nominal interest rate. I estimate the model for two different periods. The first is a subsample corresponding to the period 1960Q1:1979Q2. The rationale for estimating the model on this subsample is that nominal and real interest rates displayed an inverted leading indicator property during this period. The second subsample corresponds to the period 1983Q1:2007Q4. A similar rationale exists for this sample, nominal and real interest rates displayed a positive lagging property during this period.

Output is measured as real per capita GDP, inflation as the log difference in the GDP deflator, and the nominal interest rate is the average quarterly 
federal funds rate. Since I do not model any non-stationary factors in the structural model, I detrend real GDP using a one-sided Hodrick-Prescott filter. Inflation and the federal funds rate are converted to quarterly units. I provide more information on the construction of the data in Appendix B.4.

The vector of observables corresponds to the following in the model,

$$
\left[\begin{array}{c}
100 \times \pi_{t} \\
100 \times Y_{t}^{1 h p} \\
100 \times i_{t}
\end{array}\right]=\left[\begin{array}{c}
\bar{\pi} \\
0 \\
\bar{i}
\end{array}\right]+\left[\begin{array}{c}
\pi_{t} \\
y_{t} \\
i_{t}
\end{array}\right],
$$

where $\bar{\pi}=100(\pi-1)$ and $\bar{i}=100\left(\frac{1}{\beta}-1\right)$.

I use the Kalman filter to evaluate the log-likelihood of the model and use the first 4 observations to initialize the Kalman filter. After obtaining a posterior mode using a simulated annealing algorithm, I estimate the posterior density functions of the structural parameters using the random walk Metropolis-Hastings algorithm with 5,000,000 draws. I drop the first $10 \%$ of draws to eliminate any issues associated with initial conditions.

Prior to estimation I fixed the inverse Frisch elasticity of labour supply parameter, $\eta$, to 1 . My rationale for fixing this parameter was motivated by previous estimation attempts in which I found the parameter to be poorly identified. Posterior estimates had large standard deviations and no clear peak. The lack of identification likely stems from no inclusion of a wage observable, which is a standard observable used in medium scale DSGE models (e.g., Smets and Wouters (2007)).

The remaining structural parameters are estimated. The vector of estimated structural parameters is given by $\Theta=\left\{\beta, h, \pi, \varphi, \theta, \alpha_{\pi}, \alpha_{y}, \rho_{a}, \rho_{y}, \rho_{v}, \rho_{i}\right.$, $\left.\rho_{\eta_{\pi}}, \rho_{\eta_{y}}, \sigma_{a}, \sigma_{v}, \sigma_{y}, \sigma_{m}, \sigma_{\eta_{\pi}}, \sigma_{\eta_{y}}\right\}$. Prior distributions can be found in Table 2.3.

I assign prior distributions which are commonly used in the literature. For the household discount factor I use a beta distribution with a mean of 0.99 and standard deviation of 0.01 . This prior can be justified based on the 


\begin{tabular}{lccccccc}
\multicolumn{9}{c}{ Prior } & \multicolumn{5}{c}{ Posterior } \\
\hline & & & \multicolumn{1}{c}{ 1960Q1:1979Q2 } & 1983Q1:2007Q4 \\
& Distribution & Mean & SD & Mean & SD & Mean & SD \\
\hline$\beta$ & Beta & 0.99 & 0.01 & 0.9859 & 0.0014 & 0.9879 & 0.0014 \\
$h$ & Beta & 0.20 & 0.10 & 0.1858 & 0.0908 & 0.2615 & 0.0754 \\
$\pi$ & Normal & 0.90 & 0.25 & 1.0023 & 0.1809 & 0.6799 & 0.1480 \\
$\varphi$ & Beta & 0.25 & 0.125 & 0.3108 & 0.1454 & 0.3411 & 0.1498 \\
$\theta$ & Beta & 0.66 & 0.05 & 0.7940 & 0.0257 & 0.8303 & 0.0225 \\
$\alpha_{\pi}$ & Normal & 1.50 & 0.25 & 1.4976 & 0.2066 & 1.8484 & 0.1920 \\
$\alpha_{y}$ & Normal & 0.125 & 0.05 & 0.1388 & 0.0459 & 0.1400 & 0.0423 \\
$\rho_{a}$ & Beta & 0.60 & 0.20 & 0.6123 & 0.1890 & 0.6011 & 0.2118 \\
$\rho_{\pi}$ & Beta & 0.60 & 0.20 & 0.8054 & 0.0571 & 0.8666 & 0.0495 \\
$\rho_{y}$ & Beta & 0.60 & 0.20 & 0.6020 & 0.0855 & 0.8215 & 0.0354 \\
$\rho_{i}$ & Beta & 0.60 & 0.20 & 0.5301 & 0.0905 & 0.6661 & 0.0572 \\
$\rho_{\eta_{\pi}}$ & Beta & 0.60 & 0.20 & 0.6962 & 0.1798 & 0.7421 & 0.1621 \\
$\rho_{\eta_{y}}$ & Beta & 0.60 & 0.20 & 0.4102 & 0.1724 & 0.4128 & 0.1726 \\
$\sigma_{a}$ & IG & 0.50 & 4.00 & 0.1544 & 0.1593 & 0.3923 & 0.3810 \\
$\sigma_{\pi}$ & IG & 0.50 & 4.00 & 0.1127 & 0.0229 & 0.0261 & 0.0053 \\
$\sigma_{y}$ & IG & 0.50 & 4.00 & 6.7836 & 2.4763 & 3.9642 & 1.1019 \\
$\sigma_{m}$ & IG & 0.50 & 4.00 & 0.0302 & 0.0100 & 0.0103 & 0.0022 \\
$\sigma_{\eta_{\pi}}$ & IG & 0.50 & 4.00 & 1.6691 & 0.9060 & 0.8125 & 0.4405 \\
$\sigma_{\eta_{y}}$ & IG & 0.50 & 4.00 & 0.8163 & 0.5329 & 0.1699 & 0.1101 \\
\hline & & & & & & &
\end{tabular}

Notes: Posterior means and standard deviations are computed using the random walk Metropolis-Hastings algorithm with 5 million draws. IG in the prior distribution column represents an inverse gamma distribution. The acceptance ratio for the RWMH algorithm in the pre-1979 and post-1983 estimations was 0.2017 and 0.1554 .

Table 2.3: Prior and posterior distributions of structural parameters and shock processes

average real interest rate throughout the postwar period. For fixed costs, I use a beta distribution with a mean of 0.25 and standard deviation of 0.125. For the Calvo parameter I use a beta distribution with a mean of 0.66 and a standard deviation of 0.05 which is consistent with the microeconomic evidence on price adjustments. For the Taylor rule response parameters, I use a normal distributions with a mean of 1.5 and standard deviation of 0.25 for the inflation response parameter and a mean of 0.125 and standard deviation of 0.05 for the output gap response parameter. Since I have relatively little 
information on size and persistence of the noise shock parameters, and how this propagation mechanism will impact other exogenous disturbances, I use relatively neutral priors for persistence parameters with a mean of 0.6 and a standard deviation of 0.2 . For the shock processes I assign inverse gamma distributions with a mean of 0.5 and standard deviation of 4 .

Table 2.3 reports the estimated posterior means and standard deviations of the structural parameters for the two samples. Most of the parameter estimates fall within the range of those found in other studies. However it is worth emphasizing a few parameter estimates which are relevant for this study.

First, estimates of the amount of noise in output and inflation are sizable, and consistent with the interpretation that uncertainty about the state of the economy has become less severe since the onset of the Great Moderation. Both output and inflation noise shocks have declined significantly. The estimated standard deviation of inflation noise shocks declines by roughly $51 \%$ and output noise shocks by roughly $79 \%$. As I discuss in the next section, the decline in noise shocks matters not only for the distribution of structural shocks, but also for the propagation of other shocks in the model.

Second, evidence from papers such as Clarida, Galí and Gertler (2000) and Lubik and Schorfheide (2004) suggests that the Federal Reserve likely did not satisfy a Taylor principle in the Great Inflation period which opened the possibility of a role for self-fulfilling expectations. In this paper I find an estimate for $\alpha_{\pi}$ in the Great Inflation period which is significantly above one (1.49) and rules out any possibility of indeterminacy.

The rationale for this result is that the necessary condition for determinacy under imperfect information is much weaker than the perfect information case. Determinacy in a perfect information setup requires the monetary policy authority to adjust the nominal interest rate greater than one for one to movements in inflation (that is, $\alpha_{\pi}>1$ with respect to $\pi_{t}$ ) in a zero steady state inflation environment. But under an imperfect information setup, de- 
terminacy only requires that the monetary policy authority adjust the nominal interest rate greater than one for one to movements in its expectation of current inflation. Since inflation is noisy, the central bank's expectation of current inflation is much less responsive than actual inflation since it cannot perfectly distinguish inflation from noise. Then movements in the nominal interest rate appear much more sensitive inflation since it is based on expected inflation and this leads to a much larger Taylor rule coefficient (that is, $\alpha_{\pi}>1$ with respect to $\pi_{t \mid t}$ ).

\subsection{Results and discussion}

In the following section I focus on three channels in which changes in the amount of uncertainty about the state of the economy impacts the cyclicality of nominal and real interest rates. The first result is derived analytically while the second and third are shown through a series of impulse response functions.

Additionally, I discuss about the role (or lack thereof) of technology shocks in this setup. Typically in estimated small scale New-Keynesian models, technology shocks play a significant role in output fluctuations. For example, Ireland (2004) finds that technology shocks account for roughly one quarter of output fluctuations in a post-WWII sample and about $40 \%$ in a post-1980 sample. However in this setup technology shocks are second-order in terms of driving movements in output, inflation, and the nominal interest rate. I discuss why this is the case in a model with imperfect information.

But prior to discussing the channels in which uncertainty impacts the cyclicality of nominal and real interest rates, a natural litmus test is to see whether the change in uncertainty about the current state can explain a substantial share of the observed changes in the cyclicality of nominal and real interest rates.

To address this question I run the following counterfactual scenario. First, 
I simulate the model for a large number of periods $(t=20,000)$ using the estimated structural parameters and shock processes from the pre-1979 sample estimation with the magnitude of uncertainty $\left(\sigma_{\eta_{\pi}}\right.$ and $\left.\sigma_{\eta_{y}}\right)$ equal to the pre-1979 levels. I compute the correlograms between output, nominal and real interest rates. Then in a counterfactual experiment I again simulate the model using the same structural parameters and shock processes, but changing only the degree of uncertainty to the estimated values in the post-1983 sample. That is, only changing $\sigma_{\eta_{\pi}}$ and $\sigma_{\eta_{y}}$. Again I compute the correlograms between output, nominal and real interest rates. The results of this experiment are depicted in Figure 2.4.
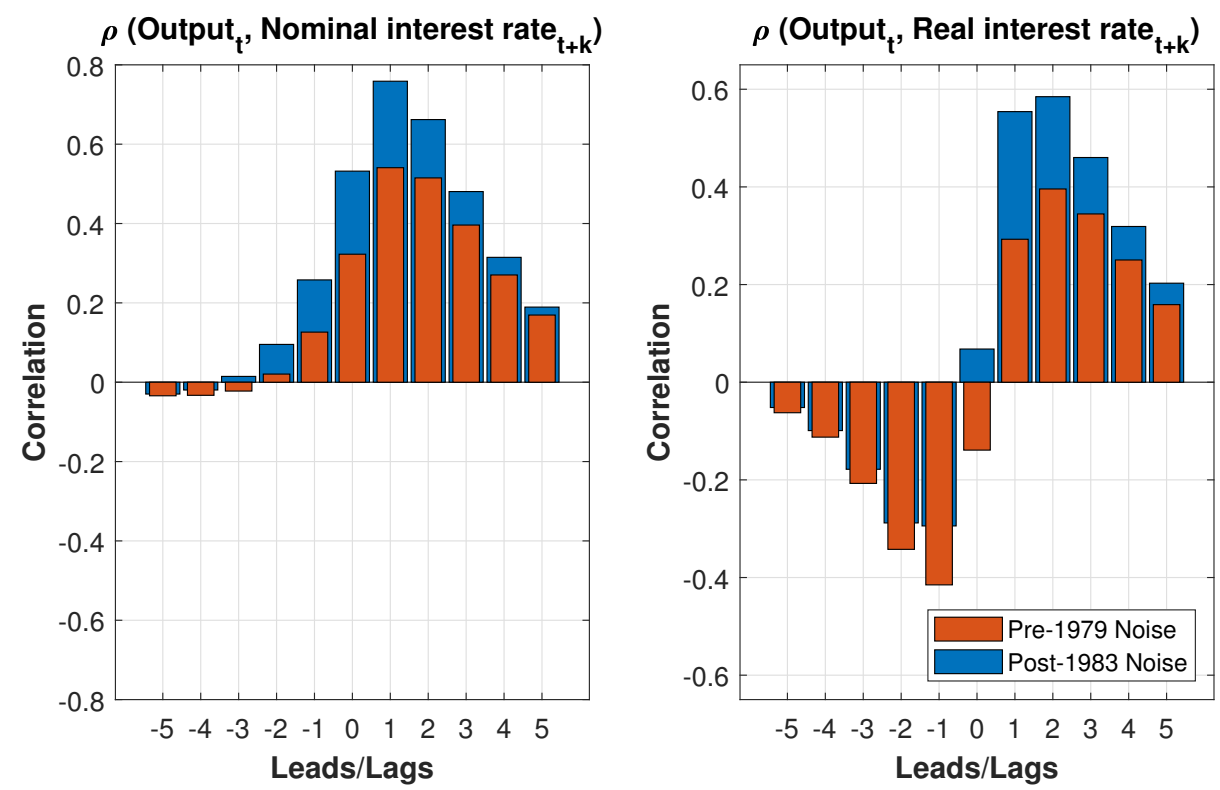

Figure 2.4: Uncertainty and the cyclicality of interest rates counterfactual

Notes: The counterfactual uses structural parameter estimates from the pre-1979 estimation. I then change only $\sigma_{\eta_{\pi}}$ and $\sigma_{\eta_{y}}$ to match the estimates in post-1983 period.

Figure 2.4 highlights that the degree of uncertainty plays a significant role in the cyclicality of both the nominal and real interest rate. When the 
degree of uncertainty equals the amount in the pre-1979 sample, real interest rates are an inverted leading indicator of output with the largest correlation being $\rho\left(y_{t}, r_{t-1}\right)=-0.41$. When the degree of uncertainty is reduced, real interest rates become a positive lagging indicator with the largest correlation becoming $\rho\left(y_{t}, r_{t+2}\right)=0.58$. The model also matches a mildly countercyclical

real interest rate in the pre-1979 period and a modestly procyclical real rate in the counterfactual.

The nominal interest rate also displays changes consistent with the observed changes in its unconditional cyclicality in the data. While the model misses the inverted leading comovement in the pre-1979 period (likely to the almost zero contribution of technology shocks), a change in uncertainty produces a stronger positive lagging indicator in the correlogram and a rise in the procyclicality of the nominal interest rate - both of which are features of the change in unconditional cyclicality.

In the following sections I take a closer inspection of exactly how changes in uncertainty alter the comovements of nominal and real interest rates.

\subsubsection{Uncertainty and the cyclicality of the nominal and real interest rate}

\section{Undesirable policy rate movements}

The first channel in which uncertainty impacts the cyclicality of nominal and real interest rates is through the monetary policy feedback rule. Since the rule relies directly on estimates about the current state of the economy, when the level of uncertainty is high, inferring the true state of the economy becomes more difficult. To see the implications of this, note that the interest rate rule can be written as a function of the expected predetermined and forward looking variables in the following way, 


$$
i_{t}=\mathbf{F}_{1} \mathbf{X}_{1, t \mid t}+\mathbf{F}_{2} \mathbf{X}_{2, t \mid t},
$$

where I have, for the moment, abstracted from monetary policy shocks since they do not alter this illustration. The matrices $\mathbf{F}_{1}$ and $\mathbf{F}_{2}$ are comprised of the monetary policy structural parameters $\rho_{i}, \alpha_{\pi}$ and $\alpha_{y}$. Using (2.15) and (2.17), the feedback rule can be rewritten in the following manner,

$$
i_{t}=\left(\mathbf{F}_{1}+\mathbf{F}_{2} \mathbf{G}^{\star}\right) \mathbf{X}_{1, t \mid t-1}+\left(\mathbf{F}_{1}+\mathbf{F}_{2} \mathbf{G}^{\star}\right) \mathbf{K}\left(\mathbf{Z}_{t}-\mathbf{Z}_{t \mid t-1}\right) .
$$

The first part of (2.26) states that the monetary policy authority sets the nominal interest rate as a function of the expected value of predetermined and exogenous variables conditional on information in $t-1$. But the more relevant part of the equation with respect to this paper is the second term. This implies that the policy rate is impacted by the difference between observables (output and inflation) at any time $t$ and their expected values conditional on information in the previous period, $t-1$.

As emphasized by Neri and Ropele (2011), in essence, this generates undesirable movements in the policy rate and by extension fluctuations in the economy. When uncertainty is higher these conditional expectations will increasingly be at odds with actual output and inflation and fluctuations due to undesirable movements in the policy rate will be more prominent.

What are the properties of these undesirable movements and what do they imply for the cyclicality of nominal and real interest rates in the model? They propagate similar to how exogenous movements in the policy rate would in a perfect information model. An exogenous rise in the policy rate in the presence of sticky prices leads to a rise in the real interest rate, though less than one for one. Households, through the intertemporal substitution channel, reduce consumption and by definition a fall in output occurs. Additionally, 
the interaction of the shock and real rigidities in the form of habit formation produce movements in nominal and real interest rates that are inverted and leading (the largest correlation is with nominal and real rates at $t-1$, albeit this is hard to see in Figure 2.5).

Since errors in the feedback rule due to imperfect information do not directly correspond to an exogenous shock, I simulate this type of error using a standard monetary policy shock. Figure 2.5 plots the IRFs of inflation, output, the nominal and ex-post real interest rate to an exogenous increase in the policy rate by a magnitude of $0.25 \%$.

Since the Great Inflation period is characterized by a higher degree of uncertainty (based on higher estimated values of $\sigma_{\eta_{\pi}}$ and $\sigma_{\eta_{y}}$ ), these types of errors are more prominent. All else equal, an increase in these types of errors has two implications for the cyclicality of nominal and real interest rates: First, since these undesirable policy rate movements generate negative comovement between output, nominal and real interest rates, nominal and real interest rates should appear less procyclical/ more countercyclical over the business cycle; Second, due to the interaction of the undesirable policy rate movements and habit formation, nominal and real interest rates should appear to more often negatively lead output movements. ${ }^{13}$

Both of the above features are consistent with the unconditional data in the pre-1979 period. During this period, nominal and real interest rates were more countercyclical and featured inverted leading properties.

\section{Inflation noise shocks}

The second channel in which uncertainty impacts the cyclicality of nominal and real interest rates is through shocks to the signals about inflation (i.e.,

\footnotetext{
${ }^{13}$ The peak response of output is on impact which is at odds with empirical estimates of a monetary policy shock IRF. This is primarily because the model lacks frictions due to its small scale nature (e.g., internal habit formation or investment adjustment costs in a larger models). Adding these features to the model would increase the magnitude of the lead for the inverted leading indicator property in the pre-1979 period.
} 

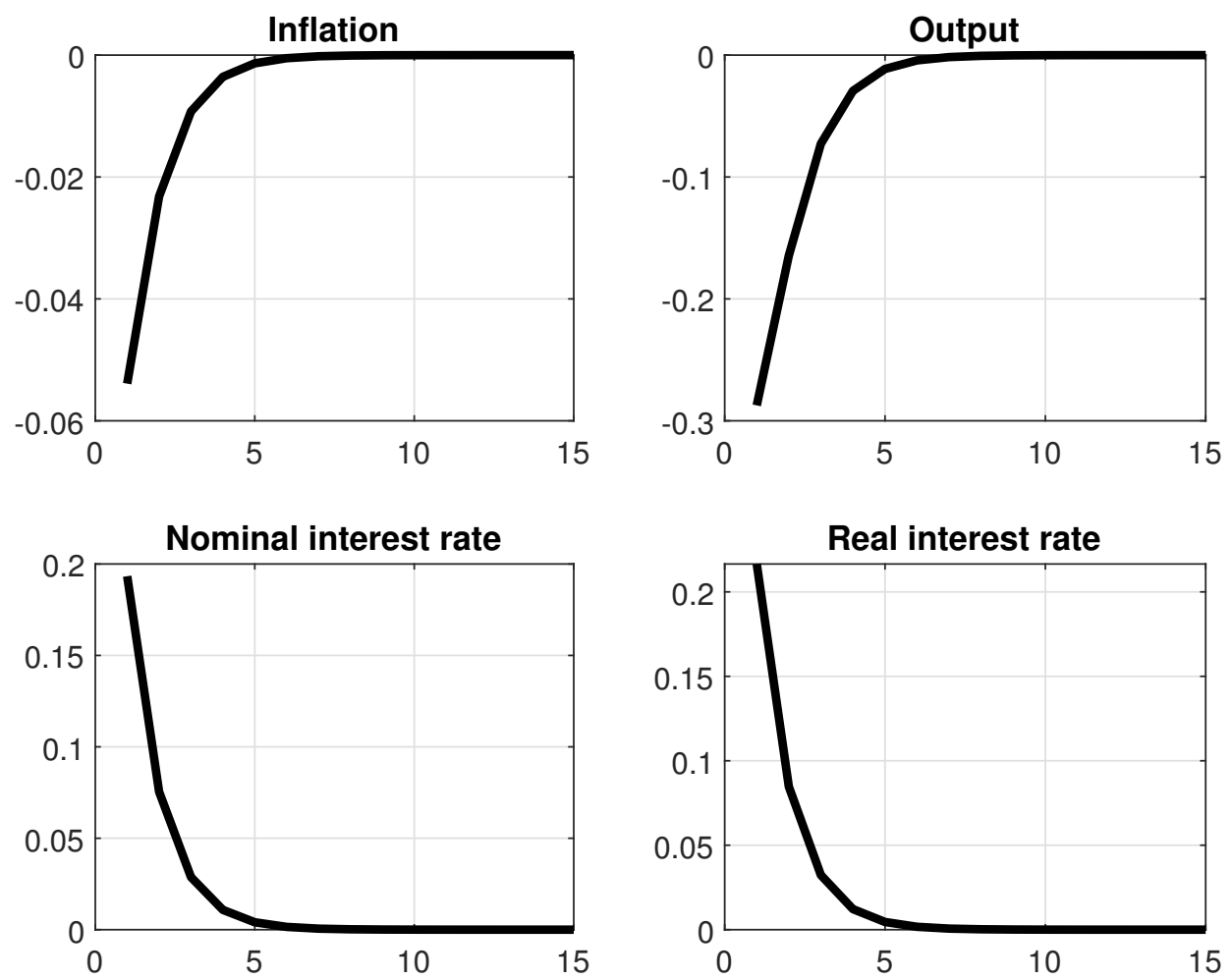

Figure 2.5: Monetary policy shock

Notes: The IRF in this figure uses the estimated structural parameters from the pre-1979 estimation. The real interest rate reported here is the ex-post real interest rate, consistent with the focus in the empirical section of the paper.

an inflation noise shock). ${ }^{14}$ Even though agents and the central bank are cautious in response to signals they receive about output and inflation, noise

\footnotetext{
${ }^{14}$ The section omits a discussion of output noise shocks for two reasons: First, inflation noise shocks are much more prominent in terms of driving output and nominal interest rate fluctuations compared to output noise shocks; Second, output noise shocks generate positive comovement between output, nominal, and real interest rates, suggesting that they cannot explain inverted leading properties of nominal and real interest rates in the pre-1979 period.
} 
shocks still generate movements in their beliefs about the current state of the economy. The extent of this movement is determined by the level of uncertainty.

Consider a positive noise shock to inflation, that is, agents and the central bank receive a signal that output is higher than it actually is. Naturally, agents and the central bank will interpret at least part of the signal as reflecting that inflation is actually higher. Additionally, since the structure of the economy is known (Assumption 1), a perceived rise in inflation also leads to a perceived rise in the output gap. The rise in expected inflation and the output gap leads the central bank to raise the policy rate in an effort to lean against the perceived rise in inflation and the output gap. But since actual inflation and output were unchanged, this rise in the nominal interest rate produces a rise in the real rate and a contraction in output. Figure 2.6 plots the IRF for inflation, output, nominal and ex-post real interest rate to an inflation noise shock.

With respect to the cyclicality of nominal and real interest rates, inflation noise shocks produce countercyclical movements and because of habit formation, these countercyclical movements lead movements in output. This implies that the larger the magnitude of inflation noise shocks, the more nominal and real interest rates should exhibit cyclicality consistent with inverted leading indicators. Inflation noise shocks were especially prominent during the Great Inflation period, with the estimated standard deviation being more than twice as large as the estimated standard deviation during the Great Moderation period. This is consistent with the unconditional data presented in the introduction.

It is worth emphasizing a key difference between the IRF generated by an inflation noise shock and those generated by errors in the policy rate discussed in 2.4.1. This difference comes from the response of inflation itself. While there is a contraction in output induced by the monetary policy response, inflation actually rises, in contrast to the positive comovement be- 

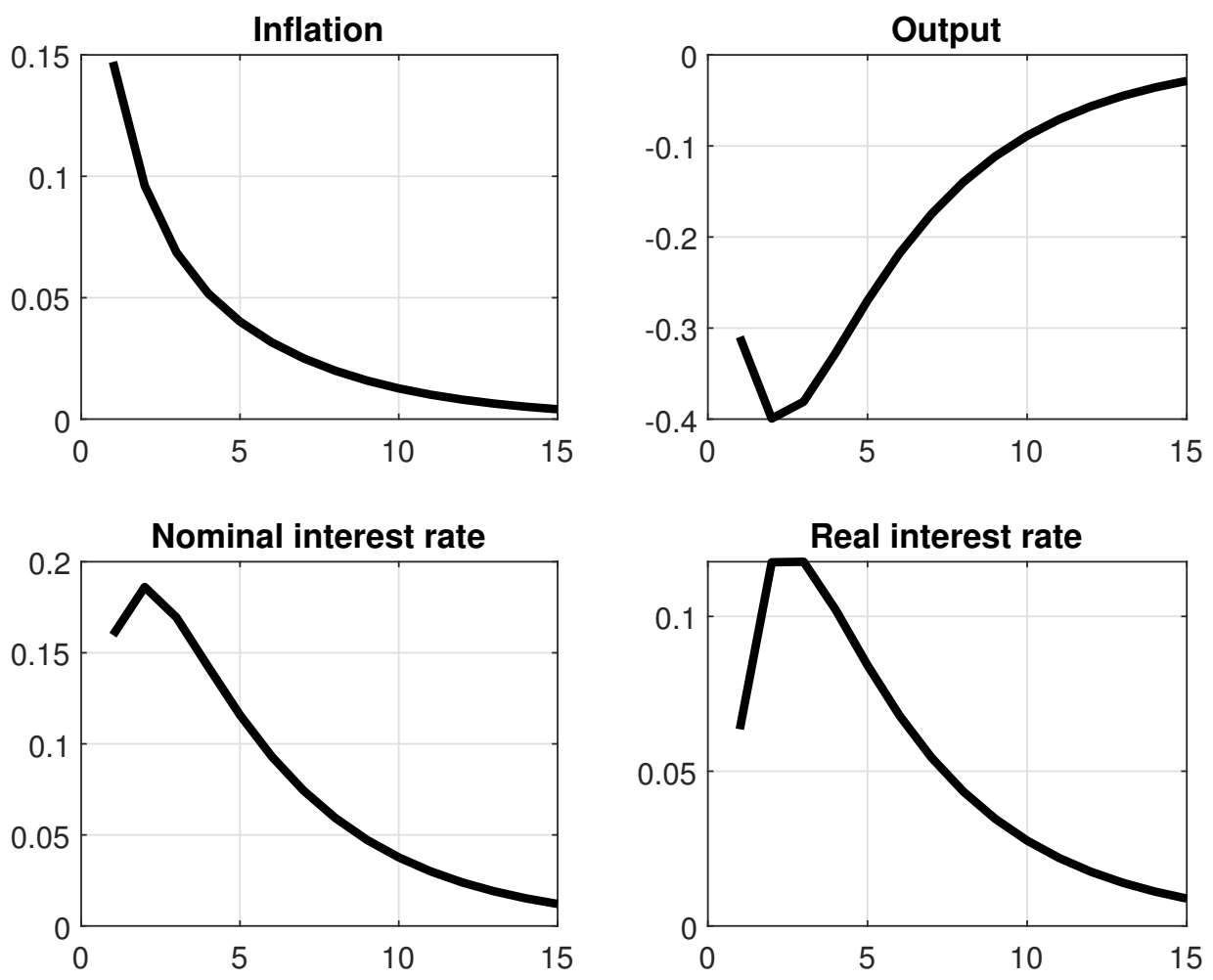

Figure 2.6: Inflation noise shock

Notes: The IRF in this figure uses the estimated structural parameters from the pre-1979 estimation. The real interest rate reported here is the ex-post real interest rate, consistent with the focus in the empirical section of the paper. The impulse response function is computed using a one standard deviation inflation noise shock.

tween output and inflation in the policy rate errors channel. The rationale for this difference is due to the impact of noise on expectations about future inflation, which rise enough to more than offset the downward pressure on inflation through the NKPC.

Another important feature to highlight with respect to reduced uncertainty is that conditional on the same magnitude of inflation noise shock, 
a reduction in uncertainty will lead to a larger impact on inflation, output, nominal and real interest rates. The rationale for this result is that as uncertainty falls, agents and the central bank perceive movements in inflation as increasingly reflecting fundamentals and not noise, leading to larger changes in expected values of inflation, output, and the output gap.

\section{Demand shocks}

The third channel in which uncertainty impacts the cyclicality of nominal and real interest rates is through the propagation of preference shocks (i.e, demand shocks).

In a full information setup a positive preference shock yields an increase in demand for current consumption (and by definition current output). Since the flexible price level of output remains unchanged, an output increase generates a positive output gap and a rise in inflation. In response to a rise in inflation and a positive output gap, the Taylor rule implies a rise in the nominal interest rate and, because of sticky prices, a less than one for one rise in the real interest rate. In terms of comovement, a preference shock generates strong positive comovement between output, nominal and real interest rates.

Under the imperfect information setup, the level of uncertainty fundamentally alters the propagation of preference shocks. Specifically, conditional on a positive preference shock nominal and real interest rates rise less than they would under a full information scenario. The rationale for this change is that when uncertainty about the current state of the economy is higher, agents and the central bank have more difficulty distinguishing the preference shock

from statistical noise. As a result, expectations about the current state of the economy react much more cautiously, leading the central bank to raise the policy rate less than they would if they could perfectly observe the economy. This cautious response decreases the procyclicality of both the nominal and real interest rates and due to the presence of noise, these rates lag output (i.e., increased uncertainty pushes down positive lagging comovements 
of both rates).
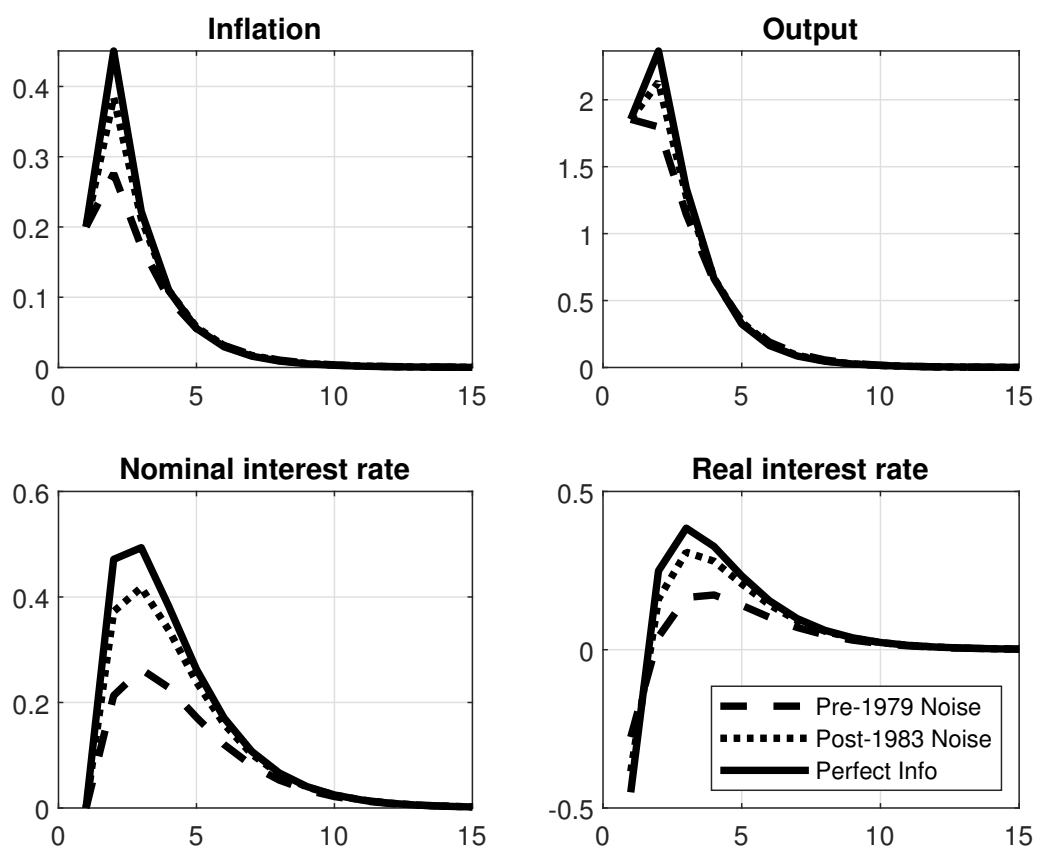

Figure 2.7: Uncertainty and demand shocks

Notes: Impulse response functions are generated using the structural parameters from the 1965Q3:1979Q2 sample. The real interest rate measure is the ex-post real interest rate, consistent with the focus in the empirical section of the paper. The IRF is in response to a one standard deviation preference shock.

To illustrate this channel, Figure 2.7 reports IRFs of inflation, output, nominal and ex-post real interest rates in response to a one standard deviation positive preference shock for three levels of uncertainty. The first level corresponds to the level of uncertainty in the pre-1979 sample, the second to the level of uncertainty in the post-1983 sample and the last to the full information case, where the central bank can perfectly observe output and inflation. ${ }^{15}$

\footnotetext{
${ }^{15}$ It is important to note that perfect information in the figure implies that agents and
} 
The figure highlights that the response of nominal and real interest rates is disproportionately pushed downwards as the level of uncertainty rises. Consequently, the magnitude of the positive comovement between output, nominal and real interest rates is reduced. For example, in the case of perfect information the nominal interest rate peak response occurs three quarters after the impact of the shock with a rise in the nominal rate of 0.4935 . Compared to the case of post-1983 noise, where the peak response occurs three periods after the shock with a rise in the nominal rate equal to 0.4178 . Finally, in the case of pre-1979 noise the peak response again occurs three periods after the shock with a response equal to 0.2630 .

To illustrate why the peak response of the nominal interest rate is much lower when uncertainty rises, Figure 2.8 plots the perceived state (i.e., expectations) of current output and inflation and the associated policy rate response.

The left and middle subfigures depict the central banks expectations about the current state, that is $\pi_{t \mid t}$ and $y_{t \mid t}$. The figure highlights that even a moderate amount of uncertainty reduces the perceived boom in output and inflation substantially. Comparing the case of perfect information to the amount of uncertainty in the Great Inflation period, expectations of the peak inflation and output response fall by $53 \%$ and $57 \%$, respectively.

To quantify the impact of varying levels of uncertainty on the contemporaneous comovement between output, nominal, and ex-post real interest rates, Table 2.4 reports the contemporaneous correlation between these variables conditioned on the preference shock in the figure. That is, $\rho\left(y_{t}, i_{t} \mid \epsilon_{t}^{y}\right)$ and $\rho\left(y_{t}, r_{t} \mid \epsilon_{t}^{y}\right)$.

The conditional correlations align with the intuition in the provided in the IRFs. When uncertainty is higher, the procyclicality of nominal and real interest rates is suppressed. It is important to highlight that if uncertainty is

the central bank only observe the lags of output and inflation perfectly, not all of the state variables. This explains why the policy rate does not respond until the period after the shock. 

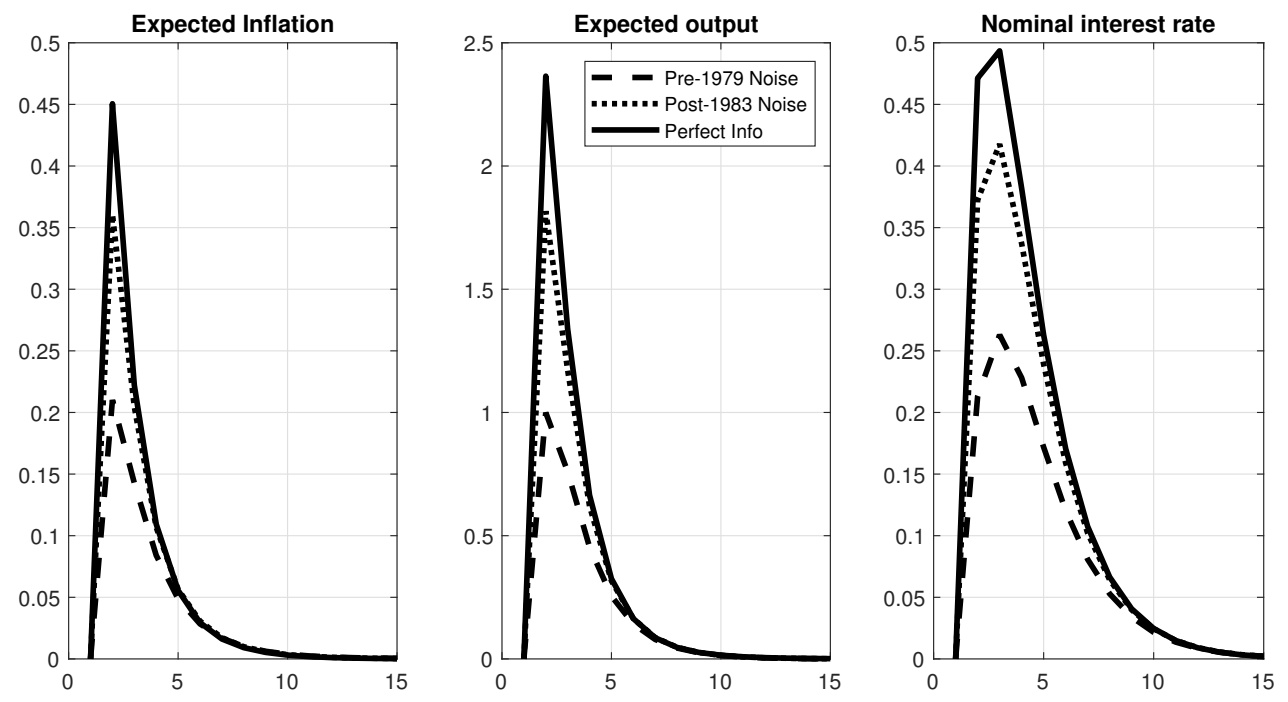

Figure 2.8: Uncertainty and expectations of the state of the economy

Notes: Impulse response functions are generated using the structural parameters from the 1965Q3:1979Q2 sample. The real interest rate measure is the ex-post real interest rate, consistent with the focus in the empirical section of the paper. The IRF is in response to a one standard deviation preference shock.

\begin{tabular}{l|ccc} 
Moment & Pre-1979 Noise & Post-1983 Noise & Perfect Information \\
\hline Corr $\left(y_{t}, i_{t}\right)$ & 0.58 & 0.65 & 0.69 \\
$\operatorname{Corr}\left(y_{t}, r_{t}\right)$ & -0.18 & 0.04 & 0.12
\end{tabular}

Notes: $y_{t}$ is output, $i_{t}$ is the nominal interest rate, and $r_{t}$ is the ex-post real interest rate.

Table 2.4: Contemporaneous comovements conditional on a preference shock

sufficiently high than it is possible for the conditional comovement between output and the ex-post real interest rate to be negative since this comovement is dominated by movements in actual inflation, as opposed to movements in the policy rate.

The above discussion leads to the following proposition. 
Proposition 1. Let $\sigma_{\eta_{\pi}} \rightarrow \infty$ and $\sigma_{\eta_{y}} \rightarrow \infty$. Conditional on a demand shock output and nominal interest rates are uncorrelated. That is, $\operatorname{Corr}\left(Y_{t}, i_{t}\right) \rightarrow 0$ and $\operatorname{Corr}\left(Y_{t}, r_{t}\right)$ is entirely determined by the comovement between output and the negative of one period ahead inflation.

Proof is in Appendix B.1.

Proposition 1 establishes that the level of uncertainty alters the contemporaneous comovement output, nominal, and real interest rates in response to preference shocks. Additionally, since all of the peak responses in nominal and real rates occur after the peak response in output, uncertainty also depresses positive lagging correlations of nominal and real interest rates. Since the Great Inflation period is characterized by a higher degree of uncertainty, this channel implies that nominal and real interest rates should appear less procyclical/ more countercyclical and less procyclical for positive lags of these variables. Both of which are features consistent with the correlogram in Figure 2.1.

\subsubsection{Technology shocks}

The channels in which uncertainty impacted the cyclicality of nominal and real interest rates was void of any discussion about technology shocks, I discuss the reasons for this here.

Typically technology shocks play a non-negligible role in generating fluctuations in estimated small scale New-Keynesian models. But in the current setup, estimation results suggest technology shocks play almost no role. The rationale for this result is due to a breakdown in the usual propagation mechanism of technology shocks when imperfect information is introduced.

In a full information model, a positive shock to technology reduces firm's marginal costs and raises the natural rate of output. The consequences of this is a fall in inflation due to negative output gap. In an attempt to 

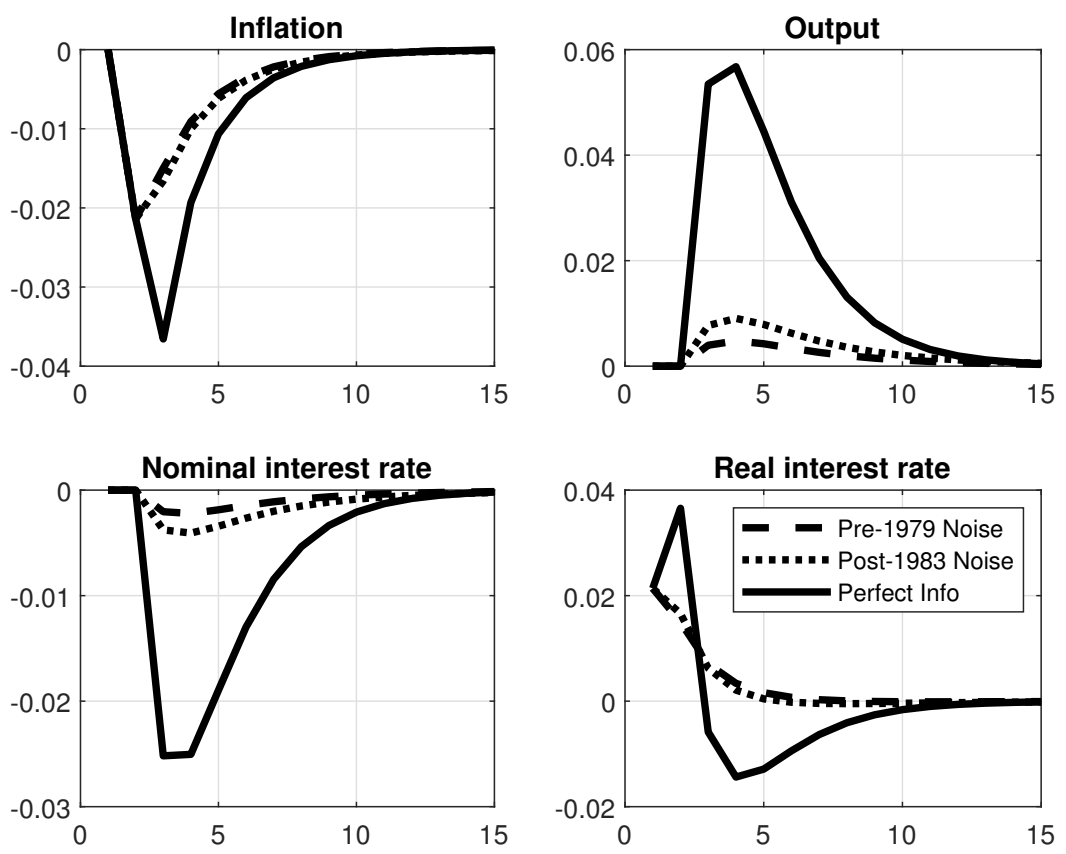

Figure 2.9: Uncertainty and technology shocks

Notes: IRF is in response to a two standard deviation positive technology shock. I use the estimated structural parameters from the 1965Q3:1979Q2 sample.

stabilize inflation the central bank lowers nominal interest rates greater than one for one to inflation, ultimately causing a decline in the real interest rate. Through the intertemporal substitution channel, households increase current consumption and output.

Under imperfect information this channel is disrupted by the fact that inflation is only imperfectly observed. Then a positive technology shock which leads to a decline in inflation only generates a small decline in the nominal interest rate as the central bank cannot distinguish the technology shock from noise. Since the nominal interest rate (and real rate) exhibit a smaller decline, the intertemporal substitution channel is largely muted and the associated output response is small. To illustrate this, Figure 2.9 
displays the response of inflation, output, nominal and real interest rates to a two standard deviation technology shock under different levels of uncertainty.

The quantitatively small effects of technology shocks I find lines up well with others estimating this class of models (see, e.g., (Collard, Dellas and Smets 2009, Figure 5) or (Givens and Salemi 2015, Table 5)).

\subsection{Conclusion}

In this paper I have proposed a structural interpretation to explain changes in the cyclicality of short term nominal and real interest rates since the onset of the Great Moderation period. This structural explanation hinges on uncertainty about the current state of the economy becoming less severe since the onset of the Great Moderation.

When uncertainty declines, the cyclicality of nominal and real interest rates is impacted by three primary channels. First, a decline in uncertainty leads to a better understanding about the current state of the economy and allows monetary policy authorities to set their policy rate in much closer accordance with rule outcomes based on ex-post revised data. When realtime policy rates differ from what ex-post outcomes would suggest, the difference results in macroeconomic fluctuations similar to monetary policy shocks. These fluctuations feature inverted leading properties for nominal and real interest rates.

Second, shocks to signals about inflation (what I refer to in the paper as noise shocks), lead to policy responses which attempt to lean against perceived inflation booms. But since the origin of the boom is purely noise, policy actions generate macroeconomic fluctuations characterized where nominal and real interest rates are characterized by inverted leading properties. These fluctuations are distinct from the first channel since inflation noise generates strong impacts on expectations about future inflation. This leads to positive comovements between nominal interest rates and inflation (contrary to the 
negative comovement between these variables in the first channel).

Third, uncertainty leads the central bank to react increasingly cautious to demand shocks since monetary policy authorities cannot distinguish the demand shock from statistical noise. This depresses the procyclicality of current and future nominal and real interest rates (i.e., the lagging crosscorrelations). This effect can be sufficiently strong that real interest rates are negatively correlated with output in response to a demand shock.

Taken together, these channels imply that the Great Inflation, which was characterized by a larger degree of uncertainty, should exhibit comovements in nominal and real interest rates most consistent with channels one and two. That is, rates should appear more countercylcical and leading. The shift in the Great Moderation should place more emphasis on channel three, that is, rates should positively lag output. This is precisely what the unconditional data show, suggesting that the above mechanism is a promising explanation for the change in the cyclicality of nominal and real interest rates.

Empirical evidence on real-time macroeconomic data releases and Federal Reserve forecasts are both consistent with the notion that monetary policy authorities have a better understanding of current macroeconomic conditions than in the past. Real-time data errors and Federal Reserve forecast errors of output growth and inflation have fallen substantially since the onset of the Great Moderation, supporting the proposed explanation herein.

The implications of the paper are to reaffirm that nominal and real interest rates are not leading indicators of the business cycle and should not be treated as such. The Great Inflation period in the US featured a leading indicator property because implementation of monetary policy was challenging due to difficultly understanding current macro aggregates. Well functioning monetary policy (that is, in close accordance with a rule used here under perfect information) will lead to nominal and real interest rates lagging the business cycle. 


\section{Bibliography}

Amir-Ahmadi, P., Matthes, C. and Wang, M.-C.: 2017, Measurement errors and monetary policy: Then and now, Journal of Economic Dynamics and Control 79, $66-78$.

Arouba, S. B.: 2008, Data revisions are not well behaved, Journal of Money, Credit and Banking 40(2-3), 319-340.

Barnichon, R.: 2010, Productivity and unemployment over the business cycle, Journal of Monetary Economics (57), 1013-1025.

Bauer, M. D. and Swanson, E. T.: 2020, The fed's response to economic news explains the "fed information effect", Working Paper Series 2020-06, Federal Reserve Bank of San Francisco.

Beaudry, P. and Guay, A.: 1996, What do interest rates reveal about the functioning of real business cycle models?, Journal of Economic Dynamics and Control 20, 1661-1682.

Bernanke, B. S. and Blinder, A. S.: 1992, The federal funds rate and the channels of monetary transmission, American Economic Review 82(4), 901-921.

Boldrin, M., Christiano, L. J. and Fisher, J. D. M.: 2001, Habit persistence, asset returns, and the business cycle, American Economic Review 91(1), 149-166.

Brault, J. and Khan, H.: 2020, The shifts in lead-lag properties of the U.S. business cycle, Economic Inquiry 58(1), 319-334.

Chari, V. V., Christiano, L. J. and Eichenbaum, M.: 1995, Inside money, outside money, and short-term interest rates, Journal of Money, Credit and Banking 27(4), 1354-1386. 
Clarida, R., Galí, J. and Gertler, M.: 2000, Monetary Policy Rules and Macroeconomic Stability: Evidence and Some Theory, The Quarterly Journal of Economics 115(1), 147-180.

Collard, F. and Dellas, H.: 2010, Monetary misperceptions, output, and inflation dynamics, Journal of Money, Credit and Banking 42(2-3), 483502 .

Collard, F., Dellas, H. and Smets, F.: 2009, Imperfect information and the business cycle, Journal of Monetary Economics 56, S38 - S56.

Dotsey, M., Lantz, C. and Scholl, B.: 2003, The behavior of the real rate of interest, Journal of Money, Credit and Banking 35(1), 91-110.

Fiorito, R. and Kollintzas, T.: 1994, Stylized facts of business cycles in the $\mathrm{g} 7$ from a real business cycle perspective, European Economic Review 38(2), 235-269.

Galí, J.: 2015, Monetary Policy, Inflation, and the Business Cycle: An Introduction to the New Keynesian Framework and Its Applications, Princeton University Press.

Galí, J. and Gambetti, L.: 2009, On the sources of the great moderation, American Economic Journal: Macroeconomics 1(1), 26-57.

Givens, G. E. and Salemi, M. K.: 2015, Inferring monetary policy objectives with a partially observed state, Journal of Economic Dynamics and Control 52, $190-208$.

Ireland, P. N.: 2004, Technology Shocks in the New Keynesian Model, The Review of Economics and Statistics 86(4), 923-936.

King, R. G. and Watson, M. W.: 1996, Money, Prices, Interest Rates and the Business Cycle, The Review of Economics and Statistics 78(1), 35-53. 
Lippi, F. and Neri, S.: 2007, Information variables for monetary policy in an estimated structural model of the euro area, Journal of Monetary Economics 54(4), 1256-1270.

Lubik, T. A. and Schorfheide, F.: 2004, Testing for indeterminacy: An application to u.s. monetary policy, American Economic Review 94(1), 190-217.

Mertens, E.: 2010, Structural shocks and the comovements between output and interest rates, Journal of Economic Dynamics and Control 34, 11711186.

Nakamura, E. and Steinsson, J.: 2018, High-Frequency Identification of Monetary Non-Neutrality: The Information Effect, The Quarterly Journal of Economics 133(3), 1283-1330.

Neri, S. and Ropele, T.: 2011, Imperfect information, real-time data and monetary policy in the euro area, The Economic Journal 122, 651-674.

Nimark, K.: 2008, Monetary policy with signal extraction from the bond market, Journal of Monetary Economics 55, 1389-1400.

Orphanides, A.: 2001, Monetary policy rules based on real-time data, American Economic Review 91(4), 964-985.

Orphanides, A.: 2003a, Monetary policy evaluation with noisy information, Journal of Monetary Economics 50(3), 605-631.

Orphanides, A.: 2003b, The quest for prosperity without inflation, Journal of Monetary Economics 50(3), 633-663.

Pearlman, J. G.: 1992, Reputational and nonreputational policies under partial information, Journal of Economic Dynamics and Control 16(2), 339357. 
Pintus, P. A., Wen, Y. and Xing, X.: 2017, The inverted leading indicator property and redistribution effect of the interest rate, Working paper, Yale University.

Smets, F. and Wouters, R.: 2007, Shocks and frictions in US business cycles: A Bayesian DSGE approach, American Economic Review 97(3), 586-606.

Stock, J. H. and Watson, M. W.: 1999, Business cycle fluctuations in US macroeconomic time series, in J. B. Taylor and M. Woodford (eds), Handbook of Macroeconomics, Vol. 1 of Handbook of Macroeconomics, Elsevier, chapter 1, pp. 3-64.

Svensson, L. E. and Woodford, M.: 2003, Indicator variables for optimal policy, Journal of Monetary Economics 50(3), 691 - 720.

Zarnowitz, V.: 1992, Composite indexes of leading, coincident, and lagging indicators, in V. Zarnowitz (ed.), Business Cycles: Theory, History, Indicators, and Forecasting, The University of Chicago Press, chapter 11, pp. 316-356. 


\section{Chapter 3}

\section{Has the US Business Cycle Become More Asymmetric?}

\subsection{Introduction}

The observation that the US business cycle is characterized by asymmetric fluctuations dates at least as far back as Mitchell (1927, pg. 333), who noted that "business contractions appear to be briefer and more violent than business expansions". Recent empirical evidence has documented, both in the US and internationally, that the business cycle has become increasingly asymmetric (e.g., Popov (2014); Jordà et al. (2016); Jensen et al. (2020); Garin et al. (2018)). However, the asymmetry of focus has typically been on the negative skewness in the growth rate of real GDP.

The contribution of this paper is twofold. First, we examine the evidence for changes in the asymmetry of the US business cycle since the mid-1980s through the lens of two different forms of asymmetry, deepness and steepness (Sichel 1993). Deep cycles describe cyclical behavior where troughs are further from trend than peaks are above. Steep cycles are characterized by cyclical behavior where the speed of contraction is larger in absolute value than the speed of expansion. The sample split we consider has been widely stud- 
ied in the literature in the context of declining macroeconomic volatility and changes in the cyclicality of macroeconomic variables (e.g., McConnell and Perez-Quiros (2000); Brault and Khan (2020)). This paper defines the business cycle using the Hamilton (2018) filter and quarter over quarter growth rates. While a large amount of research has examined US macroeconomic time series for these two types of asymmetry, the changes in asymmetry has not been examined from this perspective. ${ }^{1}$ A key distinction this paper makes is that in addition to examining US real GDP as the measure of the business cycle, we also investigate asymmetry in the two largest components of GDP, consumption (aggregate, durable and non-durable/services) and investment (aggregate private, residential, and non-residential). This distinction turns out to be important in explaining asymmetry in GDP as consumption and investment components feature different magnitudes and types of asymmetry, suggesting relevant and empirically important macroeconomic channels not captured by examining GDP alone.

Secondly, we highlight that models with occasionally binding collateral constraints produce a particular form of asymmetry, deepness. While other mechanisms are capable of producing asymmetry over the business cycle, the focus on the collateral channel in this paper arises due to recent attempts to motivate this channel through skewness in the growth rate of real GDP (for example, Jensen et al. (2020)). To highlight that deepness is the primary asymmetry generated by occasionally binding collateral constraint models, we first present a simple partial equilibrium model where housing serves as collateral for borrowing in the presence of exogenous house price shocks. To confirm these findings translate into general equilibrium, we present evidence from a recent DSGE model via Guerrieri and Iacoviello (2017).

Results indicate that US GDP, consumption, and investment have been characterized by increasingly deep cycles since the onset of the Great Moder-

\footnotetext{
${ }^{1}$ See, for example, Sichel (1993), Verbrugge (1997), Razzak (2001), Hansen and Prescott (2005), Atolia et al. (2018), Ferraro (2018).
} 
ation. A robust feature of this pattern is that all series considered show deepness coefficients consistent with increasingly asymmetric fluctuations even if the Great Recession is excluded from the post-Great Moderation sample. The evidence for increasing steepness is not uniform across all variables. Consistent with the previous literature, we find that growth rate of real GDP has become much more negatively skewed (e.g., Jensen et al. (2020); Garin et al. (2018)). However, a key insight provided in this paper is that the increasing steepness of GDP is driven largely by investment. Steepness in consumption has remained relatively unchanged since the onset of the Great Moderation. In contrast, both residential and non-residential investment have experienced large increases in the steepness of their cycles, even if the Great Recession is excluded.

This paper proceeds as follows: In Section 3.2 we describe deepness and steepness in further detail and how to test for changes in these types of asymmetry. In Section 3.3 we report the empirical evidence for changes in deepness and steepness in output, consumption components, and investment components. In Section 3.4 we describe a partial equilibrium model with an occasionally binding constraint alongside results from a modern DSGE model. Section 3.5 concludes.

\subsection{Deepness and Steepness}

Deepness refers to cyclical behavior where busts are further from trend than booms are above. ${ }^{2,3}$ Steepness describes cyclical behavior where the speed of contractions is larger in absolute magnitude than the speed of expansions.

\footnotetext{
${ }^{2}$ Alternatively, deepness could be interpreted as the average deviation above trend being smaller than the average deviation below trend as in Hansen and Prescott (2005).

${ }^{3}$ In this sense I am using boom and busts as described by McKay and Reis (2006). Expansions and contractions characterize the behavior of a macroeconomic time series from trough to peak and peak to trough. Booms and busts refer periods where the time series is above or below trend. A boom then includes the latter part of the expansion and beginning of the contraction.
} 
Under these definitions, deepness implies that the probability density function (PDF) of the cyclical component will exhibit negative skewness while steepness implies that the PDF of the growth rate will exhibit negative skewness. These distinct forms of asymmetry can occur separately or together. Figure 3.1 plots hypothetical deep and steep cycles,
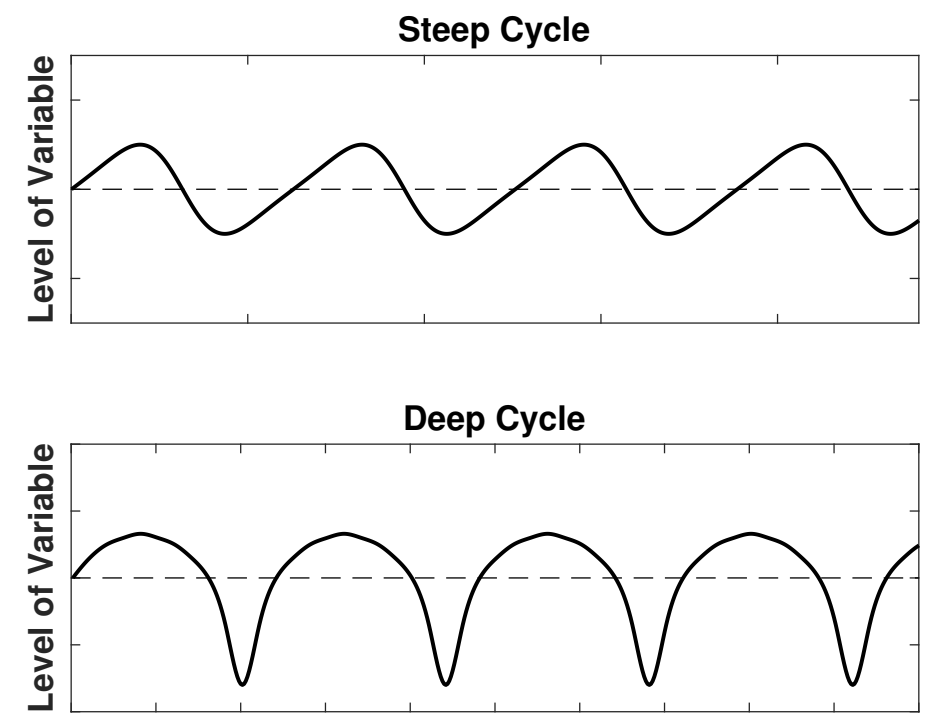

Figure 3.1: Steep and Deep Business Cycles (Sichel 1993)

While the focus thus far has been on negative skewness in the distribution of the cyclical component and of the growth rates, deepness and steepness also have several other predictions for the behavior of macroeconomic series over the business cycle. Deepness implies that the average of the cyclical component above trend is less than the average of the cyclical component below trend. In addition, the duration of booms relative to busts is increasing in the degree of deepness. Steepness implies that the average growth rate during expansions is smaller in absolute magnitude than growth rates during contractions. In addition, the duration of expansions relative to contractions 
is increasing in the degree of steepness. These informal measures of asymmetry are used to support evidence of changes in deepness and steepness.

\subsubsection{Detrending}

As discussed by Sichel (1993, pg. 228), testing for asymmetry requires the following to be satisfied: First, each series must be rendered stationary, since by definition most macroeconomic time series are upward trending. Second, the detrending method must extract the exact component to be used in the test. For deepness this is the cyclical component in deviation from trend, and steepness, the first-difference (i.e., the growth rate since all variables are log transformed). Finally, the detrending method must not induce any additional asymmetry into the series.

To obtain the cyclical component in deviation from trend, I use the filter suggested by Hamilton (2018). The filter amounts to obtaining obtaining forecast residuals from a univariate regression $h$ periods ahead using the $p$ most recent realizations as explanatory variables. I use Hamilton's suggested parametric specification for detrending quarterly data which sets $h=8$ and $p=4$,

$$
\hat{v}_{t+h}=y_{t+h}-\hat{\beta}_{0}+\hat{\beta}_{1} y_{t}+\hat{\beta}_{2} y_{t-1}+\hat{\beta}_{3} y_{t-2}+\hat{\beta}_{4} y_{t-3}
$$

Since the variables are log transformed, the cyclical components from the filter have the interpretation of being the percentage deviation from trend. Testing for steepness requires testing on the rate of change in each series. I employ the first-difference filter and since the variables are log transformed this amounts to hypothesis testing on the growth rates of variables. 


\subsubsection{Coefficient of Skewness Test}

To test for deepness and steepness this paper uses a coefficient of skewness test applied to cyclical components and growth rates as in Sichel (1993). Since the particular form of asymmetry this paper is interested in is deep recessions and steep downturns, the null hypothesis is that the reference series contains no deepness or steepness, and the alternative is that there is evidence of deepness or steepness. This leads to the following one-tailed hypothesis test,

$$
\begin{aligned}
& H_{0}: \text { Deepness/Steepness } \geq 0, \\
& H_{A}: \text { Deepness/Steepness }<0,
\end{aligned}
$$

and using the cyclical components obtained from the Hamilton filter, the deepness test statistic is computed using the familiar coefficient of skewness formula,

$$
\hat{\tau}=\frac{\mathrm{E}\left[\left(c-\mu_{c}\right)^{3}\right]}{\mathrm{E}\left[\left(c-\mu_{c}\right)^{2}\right]^{3 / 2}}=\frac{\mu_{3}}{\sigma^{3}},
$$

where $c$ and $\mu_{c}$ represent the cyclical component and mean of the cyclical component for each reference series, respectively. ${ }^{4}$ The coefficient of skewness will be negative if the average deviation in busts is further from trend than the average deviation is above in booms. Analogously, the test for steepness is computed using the coefficient of skewness, except the cyclical components, $c$, obtained through the Hamilton filter are replaced with growth rates obtained after taking first-difference of the log of the reference series. The test for steepness will be negative if the growth rates during contractions are larger

\footnotetext{
${ }^{4}$ Since the Hamilton (2018) filter contains a constant, $\mu_{c}$ is approximately zero for all the series.
} 
in absolute magnitude than growth rates experienced during expansions.

The coefficient of skewness test follows an asymptotic normal distribution only when data are assumed to be independent and identically distributed. However, both components in growth rates and cyclical components obtained through the Hamilton filter contain an unknown form of serial correlation. ${ }^{5}$ To compute standard errors this paper uses a correction suggested by Bai and $\mathrm{Ng}$ (2005, see Corollary 1, pg. 50). ${ }^{6}$

Finally, after computing sample skewness for the subsamples, we test whether sample skewness coefficients are statistically different since the onset of the Great Moderation (defined as post-1984). Since sample skewness coefficients for deepness and steepness are negative, a more asymmetric sample skewness in the post-1984 period would suggest the appropriate hypotheses,

$$
\begin{aligned}
& H_{0}: \hat{\tau_{1}}-\hat{\tau_{2}} \leq 0 \\
& H_{A}: \hat{\tau_{1}}-\hat{\tau_{2}}>0
\end{aligned}
$$

which I test using a test of the following form,

$$
Z=\frac{\left(\hat{\tau_{1}}-\hat{\tau_{2}}\right)-\left(\mu_{1}-\mu_{2}\right)}{\sqrt{\sigma_{\tau_{1}}^{2}+\sigma_{\tau_{2}}^{2}}}
$$

To compute P-values for the test we use a circular block bootstrap with 9,999 replications. The block bootstrap routine resamples blocks of observations from the two samples (pre- and post Great Moderation) to approximate empirical distributions which we use to test the hypothesis. Block length is

\footnotetext{
${ }^{5}$ Ljung-Box test statistics for cyclical components and growth rates are reported in Table C.2. The tests allow for serial correlation up to order 10. The null hypothesis that the data are i.i.d. is rejected for all variables in levels and growth rates at the $1 \%$ level.

${ }^{6}$ For a further description of the Bai and $\mathrm{Ng}$ (2005) approach to calculating standard errors for sample skewness in the presence of serial correlation, see the appendix.
} 
chosen according to the rule-of-thumb $B=T^{1 / 3} \cdot{ }^{7}$ These results are discussed in Section 3.3.

\subsection{Results}

The hypotheses discussed above are applied to US GDP, consumption, and investment. ${ }^{8}$ I present results that distinguish between components of consumption (aggregate, durable, and non-durable/services) and components of investment (gross private, non-residential, and residential). The data span 1947:I-2018:II, but since the Hamilton filter discards 11 observations from the beginning of the sample, all tests are performed on data from 1949:42018:2. I consider three subsamples in the data: 1949:4-1983:4 (pre-1984), 1984:1-2007:4 (Great Moderation), 1984:1-2018:2 (post-1984). The purpose of the Great Moderation sample is to assess the extent to which asymmetry results are driven by the Great Recession. However, statistical tests on the difference in sample skewness are only performed on the pre-1984 and post-1984 samples.

Before presenting sample skewness coefficients, I present some informal measures of business cycle asymmetry relating to average booms, busts, expansions, and contractions that were discussed in relation to deepness and steepness in Section 3.2. ${ }^{9}$ Table 3.1 reports the average boom, bust, expansion growth rate, and contraction growth rate. Expansion and contraction growth rates reported are demeaned to highlight the fundamental asymme-

\footnotetext{
${ }^{7}$ Results are generally insensitive to the choice of block size. Alternative rules of thumb included $T^{1 / 2}$ and $T^{1 / 4}$. The conclusions reached in the baseline case remain unchanged.

${ }^{8}$ Data are obtained from the Federal Reserve Bank of St. Louis Economic Database (FRED). All nominal variables are converted to real measures using their corresponding price deflators. FRED codes are provided in Table C.1 in the Appendix.

${ }^{9}$ The emphasis on average booms, busts, expansions, and contractions as opposed to durations of these phases is due to the splitting of the sample. For example, the decision to include a boom spanning the split in the two samples into the pre-1984 or post-1984 sample is not obvious. In addition this choice is quantitatively important for the results. Instead I focus on averages of the phases which does not require this decision.
} 
try. The Hamilton (2018) filtered data are by definition approximately mean zero because the filter includes a constant in the regression.

\begin{tabular}{cccccc} 
Variable & Sample & Boom & Bust & Expansion & Contraction \\
\hline \hline \multirow{2}{*}{ GDP } & & & & & \\
& $1949.3-1983.4$ & 2.795 & -3.579 & 0.315 & -1.647 \\
& $1984.1-2018.2$ & 2.027 & -2.196 & 0.083 & -1.351 \\
Consumption & $1949.3-1983.4$ & 2.223 & -2.269 & 0.447 & -0.802 \\
& $1984.1-2018.2$ & 1.802 & -2.382 & 0.086 & -0.903 \\
Durable Consumption & $1949.3-1983.4$ & 7.514 & -10.305 & 1.984 & -3.563 \\
& $1984.1-2018.2$ & 5.461 & -9.069 & 0.390 & -4.099 \\
Non-durable/Services & $1949.3-1983.4$ & 1.568 & -1.670 & 0 & - \\
& $1984.1-2018.2$ & 1.303 & -1.795 & 0.042 & -0.925 \\
Gross Private Investment & $1949.3-1983.4$ & 9.566 & -11.701 & 2.793 & -4.565 \\
& $1984.1-2018.2$ & 9.928 & -10.697 & 1.213 & -2.869 \\
Non-residential Inv. & $1949.3-1983.4$ & 7.610 & -7.769 & 1.111 & -2.791 \\
& $1984.1-2018.2$ & 7.197 & -8.672 & 0.678 & -2.662 \\
Residential Inv. & $1949.3-1983.4$ & 13.688 & -18.639 & 3.788 & -4.720 \\
& $1984.1-2018.2$ & 13.501 & -18.145 & 1.566 & -3.346 \\
\hline
\end{tabular}

Table 3.1: Average Booms, Busts, Expansions and Contractions

Note: Booms are defined as periods above trend defined from the Hamilton filter and busts are defined as periods below trend. To identify expansions and contractions I use the BBQ algorithm defined by Harding and Pagan (2002) which expands on the business cycle turning point algorithm of Bry and Boschan (1971). Average expansion and contraction growth rates are demeaned. The BBQ algorithm does not identify a contraction in consumption of non-durables and services from 1949:4-1983:4.

Several common patterns emerge across the variables presented. First, aside from gross private investment, all variables experience a fall in the average boom in the post-1984 data. In contrast the average bust across variables is much more mixed. Turning to expansions and contractions, a similar pattern emerges; all variables experience a fall in the average growth rate during expansions in the post-1984 data. ${ }^{10}$ While contraction growth rates have fallen across most variables, these changes are relatively small in

\footnotetext{
${ }^{10}$ This statement does not hold for non-durable consumption. However this result should be interpreted with caution. As the footnote in Table 3.1 mentions, the BBQ algorithm does not identify a contraction in non-durable consumption during the pre-1984 data and as such the demeaned expansion growth rate is zero by definition.
} 
comparison to expansions. This evidence is consistent with the literature which suggests that changing business cycle fluctuations are driven largely by changes in the expansion phase of the business cycle (see, e.g., Fatàs and Mihov (2013)). This evidence is suggestive of changing business cycle asymmetry consistent with both deepness and steepness. Booms and expansions have become less apparent while busts and contractions have remained relatively unchanged. Turning to more formal statistical measures of asymmetry, Table 3.2 presents sample skewness coefficients across the subsamples.

Sample skewness coefficients for deepness provide two key insights. First, there is strong statistical evidence that fluctuations in GDP, consumption, and investment are characterized by negative skewness in the distribution of the cyclical component in the post-1984 data. This result contrasts the pre-1984 data where there is little evidence for deepness, consistent with the existing literature (e.g., Sichel (1993)). This result suggests that fluctuations in these variables feature deep troughs and relatively modest booms since the mid-1980s. The second insight is that the sample skewness coefficients for all variables have become increasingly asymmetric across the subsamples. A robust feature of this pattern is that deepness is increasing even if the Great Recession is excluded from the post-1984 sample. Not surprisingly, the largest increase in deepness arises in the residential investment sector, but all other variables also show a large increase in deepness asymmetry.

The evidence for changing steepness is less uniform, but this lack of uniformity provides a key insight into business cycle steepness that would not be uncovered by examining GDP alone. GDP has been characterized by increasingly steep fluctuations; in the pre-1984 data GDP has a steepness coefficent of -0.16 and this is not statistically different from 0 . In the post-1984 data, GDP exhibits a steepness coefficient of -1.11 and this is statistically significant at the $10 \%$ level. The insight highlighted here is that this increased steepness of the business cycle is not evident in consumption data, where steepness has fallen at the aggregate level. This suggests that the driving 


Sample Deepness P-value Steepness P-value

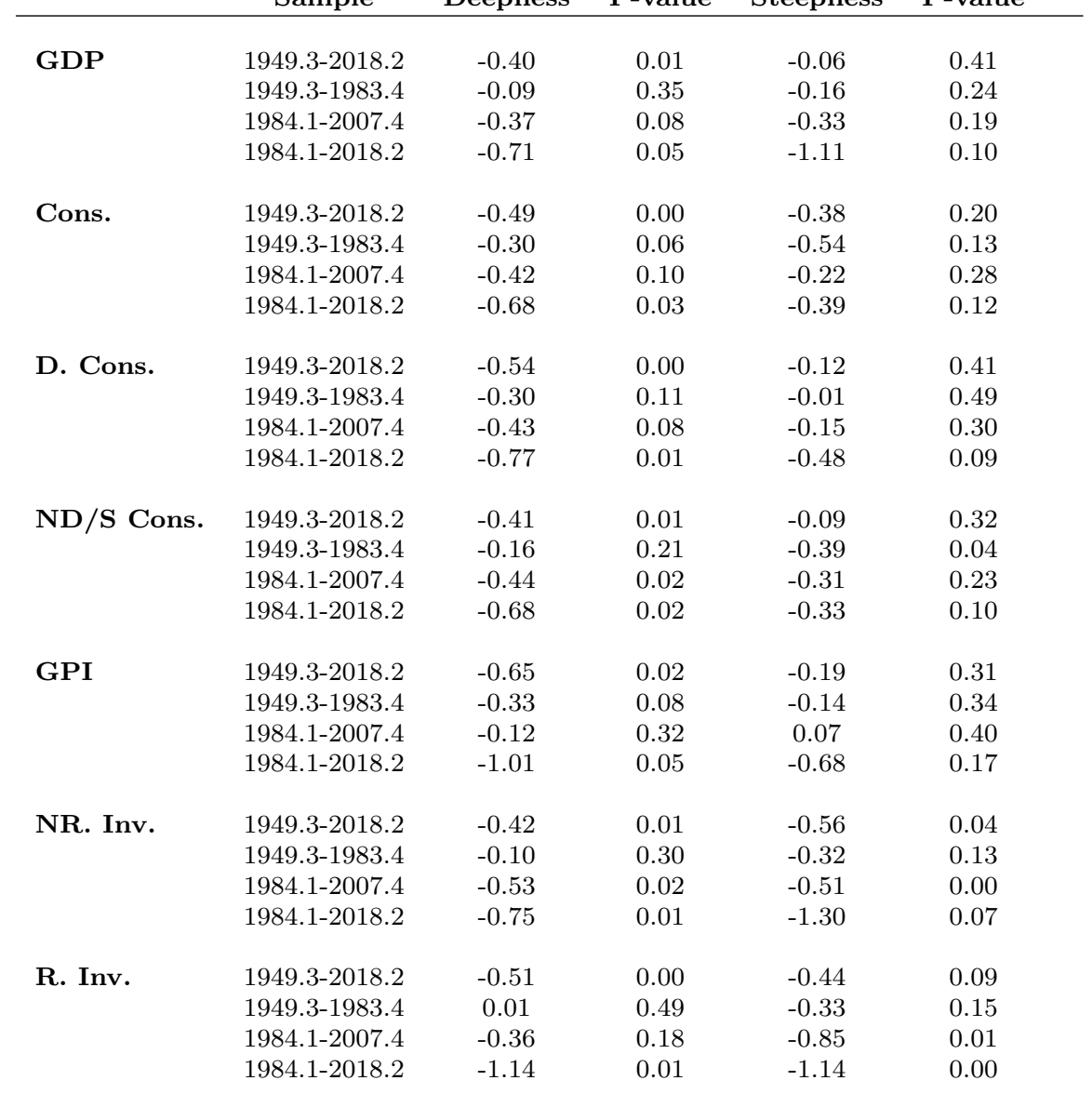

\section{Table 3.2: Coefficient of skewness test}

Note: D. represents durable, ND\&S non-durable and services, GPI gross private investment, NR. non-residential, and R. residential. P-values reported for a one-sided hypothesis test of $H_{0}$ : Deepness/Steepness $\geq 0$ and $H_{A}$ : Deepness/Steepness $<0$. P-values are computed using the Bai and $\mathrm{Ng}$ (2005) correction which is described further in the appendix. 
force behind the increased steepness of the business cycle comes from investment. Both non-residential investment and residential investment show large increases in steepness since the onset of the Great Moderation. These steepness coefficients are statistically significant at the $1 \%$ level.

While the pattern of sample skewness coefficients is suggestive of increasingly deep and steep cycles in GDP, consumption, and investment, I formally test for differences in the pre- and post-1984 periods. Table 3.3 reports hypothesis tests for differences in deepness and steepness from pre-1984 to post-1984.

\begin{tabular}{lcccccc} 
& Deepness & P-value & Decision & Steepness & P-value & Decision \\
\hline \hline GDP & 1.419 & 0.040 & Reject & 2.422 & 0.002 & Reject \\
Cons. & 0.769 & 0.121 & Do Not Reject & -0.452 & 0.605 & Do Not Reject \\
D. Cons. & 1.077 & 0.096 & Reject & 1.664 & 0.159 & Do Not Reject \\
ND/S Cons. & 1.025 & 0.059 & Reject & -0.114 & 0.539 & Do Not Reject \\
GPI & 1.736 & 0.019 & Reject & 2.018 & 0.086 & Reject \\
NR. Inv. & 1.244 & 0.026 & Reject & 3.129 & 0.013 & Reject \\
R. Inv. & 2.391 & 0.008 & Reject & 2.344 & 0.007 & Reject
\end{tabular}

Table 3.3: Changing Business Cycle Asymmetry

Note: D. represents durable, ND\&S non-durable and services, GPI gross private investment, NR. nonresidential, and $\mathrm{R}$. residential. The hypothesis test is $H_{0}: \hat{\tau_{1}}-\hat{\tau_{2}}<0$ and $H_{A}: \hat{\tau_{1}}-\hat{\tau_{2}} \geq 0$. The test is comparing deepness and steepness from 1949:4-1983:4 to 1984:1-2018:2. P-values are bootstrapped using a moving-block bootstrap with 9999 replications. The null hypothesis was rejected for P-values $<0.1$.

The evidence for changing business cycle deepness is clear. GDP, consumption (excluding aggregate), and investment have been characterized by increasingly deep fluctuations since the onset of the Great Moderation. The evidence for steepness highlights that GDP experienced a significant change in steepness over the business cycle, and this increased steepness is largely driven by the change in steepness in investment. There is little evidence that steepness in consumption has changed dramatically over the business cycle 
since the onset of the Great Moderation.

\subsubsection{Sensitivity}

In this section I show that the results on the changes in deepness and steepness over the business cycle in GDP, consumption, and investment are robust to various filters, definitions of growth rates, and alternative dates for the onset of the Great Moderation. Specifically, I test for changes in deepness and steepness in the following ways:

1. Alternative filters. The baseline trend cycle decomposition for deepness in the paper uses the Hamilton (2018) filter. Table C.3 presents hypothesis tests for difference in deepness from pre- and post-1984 using the Beveridge and Nelson (1981) decomposition (henceforth BN) and Hodrick and Prescott $(1980,1997)$ (henceforth HP) filter. The evidence using the BN filter is nearly identical with the baseline case, while the HP filter suggests much less evidence for changes in deepness. But as Psaradakis and Sola (2003) highlight, the HP filter struggles to detect cyclical asymmetry relative to the $\mathrm{BN}$ decomposition so it is not surprising to get largely different results between the filters.

2. Alternative growth rate measures. Coefficients of skewness for steepness were computed using quarter over quarter growth rates. But such growth rates tend to overemphasize high frequency fluctuations and are often not what researchers typically think of as the business cycle. Table C.4 reports hypothesis test results for changing steepness pre- and post-1984 using year-over-year growth rates and a moving average of growth rates. The conclusions are nearly identical to those reached under quarter over quarter growth rates, however there is more evidence that changes in steepness are present in the consumption data as well. 
3. Changing volatility. The onset of the Great Moderation coincided with declining macroeconomic volatility, among other changes. To ensure that the changes in deepness and steepness are not driven by changes to the standard deviations, Table C.5 reports the third central moment (the numerator in deepness and steepness coefficients) for each variable across the subsamples. The pattern highlights that deepness results are driven by changes in asymmetry, not macroeconomic volatility. For steepness, GDP does not experience a large change in its third central moment which suggests that it is driven more by the change in the volatility.

4. Alternative onset of the Great Moderation. The baseline results in the paper use 1984:I as the beginning of the Great Moderation. Table C.6 reports hypothesis tests for changing business cycle asymmetry using the onset of the Great Moderation to be 1985:I. The results are nearly identical to the baseline results.

The change in deepness and steepness of US business cycle fluctuations since the onset of the Great Moderation point to empirically important changes in the behavior of the macroeconomy. Understanding the fundamental causes of these changes is an important research question. One promising direction is the rise in rapid accumulation of credit by US households as documented by Jordà et al. (2016).

\subsection{Models With Occasionally Binding Con- straints}

In this section I present a simple partial equilibrium model with occasionally binding collateral constraints where the only source of uncertainty is a stochastic process for the price of housing. The purpose of the model is not to provide a complete characterization of output or consumption behavior over 
the business cycle, but instead to show that models with occasionally binding collateral constraints generate a specific form of asymmetry, deepness. However, even in this simple model the asymmetry generated is consistent with the empirical evidence on deepness in consumption. ${ }^{11}$

Finally, I present evidence from a larger scale general equilibrium model via Guerrieri and Iacoviello (2017) where impatient households are occasionally bound by a collateral constraint tied to housing. This model generates asymmetry consistent with the deepness of consumption presented in 3.3, but does not match the asymmetry of investment or output.

\subsubsection{A Partial Equilibrium Model With Housing As Collateral}

In this simple model a representative agent maximizes the following utility function,

$$
\max E_{0} \sum_{t=0}^{\infty} \beta^{t}\left\{\log \left(C_{t}\right)+\epsilon_{H} \log \left(H_{t}\right)\right\}
$$

where $C$ is consumption of non-durable goods and services and $H$ is consumption of housing. $\beta$ is the discount factor and $\epsilon_{H}$ is the weight of housing consumption in the utility function, respectively. The agent maximizes utility subject to the following budget constraint,

$$
Y_{t}+H_{t-1} Q_{t}+B_{t}=C_{t}+R B_{t-1}+H_{t} Q_{t} . \quad \text { (Budget constraint) }
$$

In the model I treat $Y$ as fixed and known, $B_{t}$ denotes current period bor-

\footnotetext{
${ }^{11}$ Morley and Piger (2012) present empirical evidence that support the use of nonlinear time series models. Occasionally binding constraints introduce non-linearity into DSGE models.
} 
rowing, and $R$ is the exogenous gross real interest rate. $Q$ is the price of housing and is guided by the following exogenous $\operatorname{AR}(1)$ process,

$$
\begin{array}{r}
\log \left(Q_{t}\right)=\rho_{q} \log \left(Q_{t-1}\right)+u_{q, t}, \\
u_{q, t} \sim N\left(0, \sigma_{q}^{2}\right) .
\end{array}
$$

Lastly, the representative agent is subject to a collateral constraint bounding borrowing from exceeding a fraction $s$ of the present value of next periods housing wealth,

$$
B_{t} \leq s \frac{E_{t}\left\{Q_{t+1}\right\} H_{t}}{R} .
$$

(Collateral constraint)

This borrowing constraint yields a complementary slackness condition which states that $\mu_{t}$, the borrowing constraint multiplier, is strictly greater than zero when the constraint is binding and zero when the agent is unconstrained,

$$
\mu_{t}\left(s \frac{E_{t}\left\{Q_{t+1}\right\} H_{t}}{R}-B_{t}\right)=0 .
$$

To pin down the steady state of the model it is assumed that the representative agent is sufficiently impatient such that the agent prefers consumption today relative to consumption in the future. This implies that $R \beta<1$ and $\mu$, the constraint on borrowing, is strictly greater than 0 in the steady state. To gain some insight into the type of asymmetry generated by the model I calibrate and simulate the model using the following parameter values: $R=1.02$, 
$\beta=0.96, \rho_{q}=0.95, s=0.9$ and $\epsilon_{H}=0.0827 .{ }^{12}$ Figure 3.2 presents impulse responses to a $10 \%$ positive and negative house price shock.
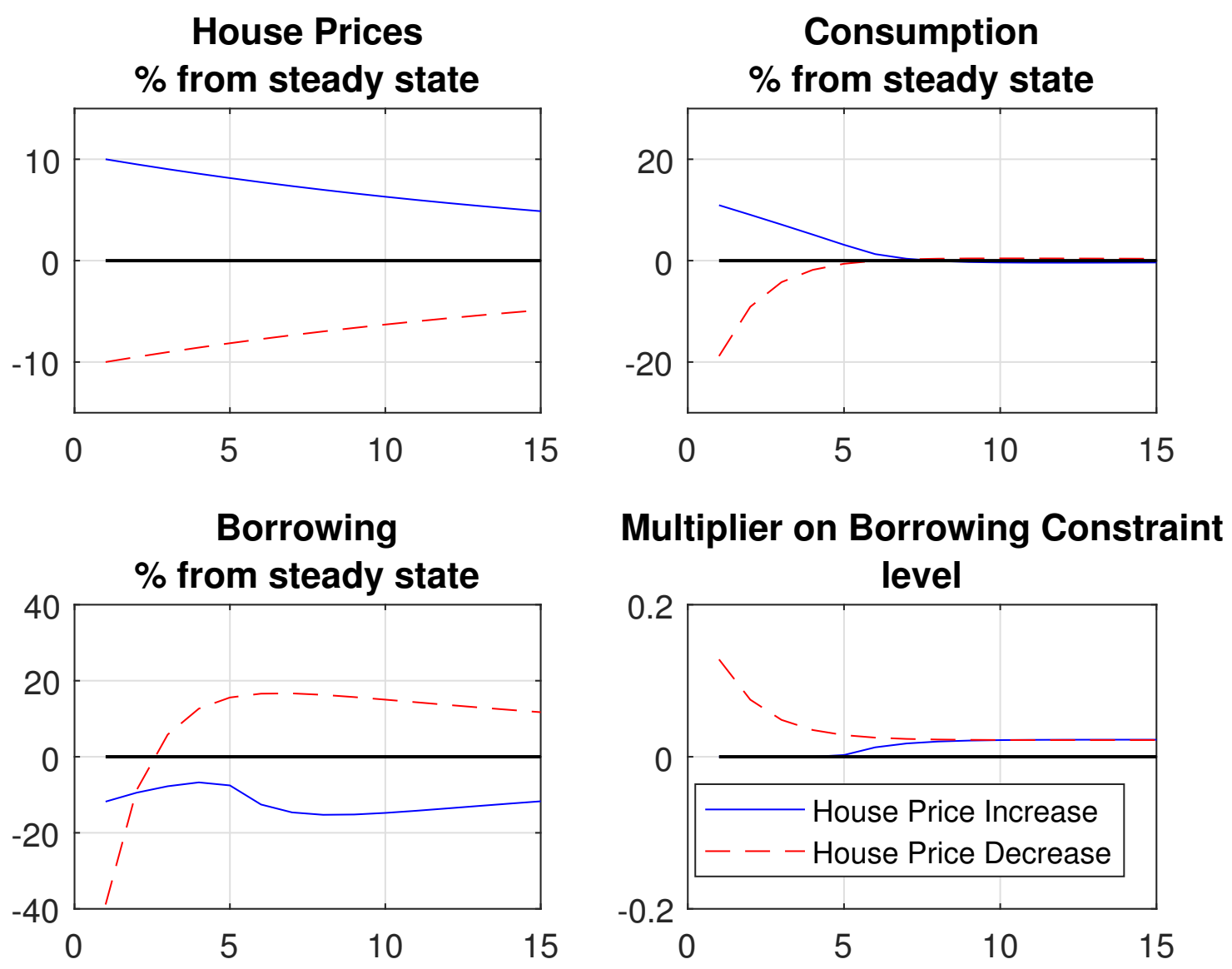

Figure 3.2: IRF to a $10 \%$ housing price shock

Note: Impulse responses are computed using a $10 \%$ shock to house prices.

The response of consumption to equally sized housing price shocks illus-

\footnotetext{
${ }^{12}$ To solve the model I use the dynareOBC toolkit provided by Holden (2016). Solving the model using the Occbin framework from Guerrieri and Iacoviello (2015) yields nearly identical results.
} 
trates the fundamental asymmetry in the model. Since the agent's borrowing constraint is binding in the steady state, a negative house price shock causes consumption to fall greater than one for one. This response is driven by two channels: the first is that a fall in housing leads to a wealth effect, the second, is a debt de-leveraging effect. Since the borrowing constraint is binding, any downward movements in house prices require that the agent pay down some of their existing debt. These two effects in combination lead to the greater than one for one response of consumption to downward house price movements.

In contrast, a positive shock to house prices leads to a roughly one for one response in consumption. This asymmetric response is driven by the fact that the borrowing multiplier reaches the lower bound, staying there for 5 periods (as depicted in the bottom right quadrant of the IRF). The borrowing constraint being 0 implies that $B_{t}<s \frac{E_{t}\left\{Q_{t+1}\right\} H_{t}}{R}$, the agent's borrowing constraint is not binding. This non-binding versus binding response leads to the asymmetric response of consumption, but the key insight is that this asymmetry is a level asymmetry consistent with deepness as described by Sichel (1993). Consumption falls more in response to the same shock than it rises in response to the positive shock.

To reinforce this point, I simulate the model setting $\sigma_{q}=0.0175$ to match the standard deviation of the growth rate of house prices in the data (Guerrieri and Iacoviello 2017). Table 3.4 reports deepness and steepness coefficients.

\begin{tabular}{l|cc} 
& Case I: $\sigma_{q}=0.0175$ \\
\hline & Deepness & Steepness \\
House Prices & -0.03 & 0.018 \\
Consumption & -0.241 & 0.021
\end{tabular}

Table 3.4: Deepness and steepness from the model

\footnotetext{
Note: The model is simulated for 11,000 periods and the first 1,000 periods are dropped to avoid any issues with initial conditions. Before computing deepness the simulated data is passed through the Hamilton (2018) filter, but this no impact on the result. Under this calibration the borrowing constraint is binding roughly $15 \%$ of the time.
} 
The simulation offers results consistent with the intuition provided for the impulse response functions. The main type of asymmetry generated by the collateral channel in this model is deepness, a level asymmetry. Symmetric house price movements lead to asymmetric movements in consumption.

\subsubsection{General Equilibrium}

The partial equilibrium model provides insights into the fundamental type of asymmetry generated from occasionally binding collateral constraints, but whether this intuition would hold when expanded to a larger general equilibrium model with a variety of shocks and frictions is not obvious. To reinforce that this intuition does hold, I simulate evidence from Guerrieri and Iacoviello (2017) (henceforth GI). The GI model is an estimated two agent new Keynesian (TANK) model where impatient households are subject to an occasionally binding collateral constraint and there is a zero lower bound (ZLB) on nominal interest rates set by the central bank. The model contains a variety of frictions including habit formation in consumption and housing, investment adjustment costs, and sticky prices and wages. The model contains 6 different shocks which include housing demand shocks, investment specific technology shocks, price and wage markup shocks, monetary policy shocks, and an intertemporal preference shock. To isolate the impact of occasionally binding collateral constraints on asymmetry, Table 3.5 reports deepness and steepness in the model for a case where the ZLB is imposed and a case where it is not imposed. 
Case I: Two OBCs: Collateral constraint \& ZLB

\begin{tabular}{l|cc}
\hline & Deepness & Steepness \\
Output & -0.112 & -0.014 \\
Aggregate Consumption & -0.156 & -0.059 \\
Patient Consumption & -0.017 & -0.024 \\
Impatient Consumption & -0.523 & -0.114 \\
Investment & -0.066 & -0.005 \\
& \multicolumn{2}{|l}{} \\
\hline & Case II: One OBC: Collateral constraint \\
\hline & Deepness & Steepness \\
Output & -0.106 & -0.015 \\
Aggregate Consumption & -0.155 & -0.059 \\
Patient Consumption & -0.017 & -0.024 \\
Impatient Consumption & -0.520 & -0.112 \\
Investment & -0.005 & -0.005
\end{tabular}

Table 3.5: Deepness and Steepness from Guerrieri and Iacoviello (2017)

Note: The model is simulated for 11,000 periods and the first 1,000 periods are dropped to avoid any issues with initial conditions. Before computing deepness the simulated data is passed through the Hamilton (2018) filter, but this has no impact on the results. The calibration used in the simulation of the model is the baseline calibration presented in Guerrieri and Iacoviello (2017).

Deepness and steepness from GI indicate that the conclusions reached from the partial equilibrium model do indeed hold in the general equilibrium framework. The model generates deepness in impatient consumption, but only moderately deep consumption cycles at the aggregate level. In addition, the deepness in investment and output are counterfactual to the data. Likewise, the model does not inherently generate steepness which is also counterfactual to the data.

\subsection{Conclusion}

The empirical evidence presented in this paper documents significant deepness in output, consumption, and investment. Deepness has increased in all of these variables since the onset of the Great Moderation. Turning to steepness, output has exhibited significant increases in the steepness of its 
cycle, however the evidence herein suggests that this is driven by changes in the fluctuations of investment over the business cycle. These results are robust to a variety of trend cycle decompositions, growth rate measures, and definitions of the onset of the Great Moderation.

In the second half of this paper I highlighted the main asymmetry generated from models featuring occasionally binding collateral constraints is deepness. The paper presented a simple partial equilibrium model where housing serves as collateral in the presence of disturbances to house prices. This simple model generated asymmetric consumption responses to house price shocks. To verify this asymmetry is present in larger scale DSGE models, I presented simulation evidence from Guerrieri and Iacoviello (2017). This model also generated deepness in consumption, however the model did not match the asymmetries in output or investment which were documented in the empirical section.

Documenting asymmetry and its changing nature is important to business cycle research which relies heavily on stylized facts about fluctuations. By definition linearized models with symmetric disturbances cannot capture asymmetry. The collateral channel offers one mechanism for generating deepness, however these mechanisms fail to match the steepness present in the output and investment data. A model that can explain both types of asymmetry and account for the changing nature of these asymmetries is an open and important research avenue. 


\section{Bibliography}

Atolia, M., Gibson, J. and Marquis, M.: 2018, Asymmetry and the amplitude of business cycle fluctuations: A quantitative investigation of the role of financial frictions, Macroeconomic Dynamics 22(2), 279-306.

Bai, J. and Ng, S.: 2005, Tests for skewness, kurtosis, and normality for time series data, Journal of Business \& Economic Statistics 23, 49-60.

Beveridge, S. and Nelson, C. R.: 1981, A new approach to decomposition of economic time series into permanent and transitory components with particular attention to measurement of the 'business cycle', Journal of Monetary Economics 7, 151-174.

Brault, J. and Khan, H.: 2020, The shifts in lead-lag properties of the U.S. business cycle, Economic Inquiry 58(1), 319-334.

Bry, G. and Boschan, C.: 1971, Cyclical Analysis of Time Series: Selected Procedures and Computer Programs, National Bureau of Economic Research, Inc.

Fatàs, A. and Mihov, I.: 2013, Recoveries, CEPR Discussion Papers 9551, C.E.P.R. Discussion Papers.

Ferraro, D.: 2018, The asymmetric cyclical behavior of the u.s. labor market, Review of Economic Dynamics 30, 145 - 162.

Garin, J., Pries, M. J. and Sims, E. R.: 2018, The relative importance of aggregate and sectoral shocks and the changing nature of economic fluctuations, American Economic Journal: Macroeconomics 10(1), 119-148.

Guerrieri, L. and Iacoviello, M.: 2015, Occbin: A toolkit for solving dynamic models with occasionally binding constraints easily, Journal of Monetary Economics 70(C), 22-38. 
Guerrieri, L. and Iacoviello, M.: 2017, Collateral constraints and macroeconomic asymmetries, Journal of Monetary Economics 90(C), 28-49.

Hamilton, J. D.: 2018, Why you should never use the hodrick-prescott filter, The Review of Economics and Statistics 100(5), 831-843.

Hansen, G. and Prescott, E.: 2005, Capacity constraints, asymmetries, and the business cycle, Review of Economic Dynamics 8(4), 850 - 865.

Harding, D. and Pagan, A.: 2002, Dissecting the cycle: a methodological investigation, Journal of Monetary Economics 49(2), 365-381.

Hodrick, R. J. and Prescott, E. C.: 1980, Postwar U.S. business cycles: An empirical investigation, Technical report, Carnegie Mellon University.

Hodrick, R. J. and Prescott, E. C.: 1997, Postwar U.S. business cycles: An empirical investigation, Journal of Money, Credit and Banking 29(1), 116.

Holden, T.: 2016, Computation of solutions to dynamic models with occasionally binding constraints, EconStor Preprints 130143, ZBW - Leibniz Information Centre for Economics.

Jensen, H., Petrella, I., Ravn, S. H. and Santoro, E.: 2020, Leverage and deepening business-cycle skewness, American Economic Journal: Macroeconomics 12(1), 245-81.

Jordà, Ò., Schularick, M. and Taylor, A. M.: 2016, Macrofinancial history and the new business cycle facts, NBER Macroeconomics Annual 2016, Volume 31, NBER Chapters, National Bureau of Economic Research, Inc, pp. 213-263.

McConnell, M. M. and Perez-Quiros, G.: 2000, Output fluctuations in the united states: What has changed since the early 1980's?, American Economic Review 90(5), 1464-1476. 
McKay, A. and Reis, R.: 2006, The Brevity and Violence of Contractions and Expansions, NBER Working Papers 12400, National Bureau of Economic Research, Inc.

Mitchell, W. C.: 1927, Business cycles: The problem and its setting, Technical report, National Bureau of Economic Research, Inc.

Morley, J. and Piger, J.: 2012, The asymmetric business cycle, The Review of Economics and Statistics 94(1), 208-221.

Popov, A.: 2014, Credit constraints, equity market liberalization, and growth rate asymmetry, Journal of Development Economics 107(1), 202-214.

Psaradakis, Z. and Sola, M.: 2003, On detrending and cyclical asymmetry, Journal of Applied Econometrics 18(3), 271-289.

Razzak, W.: 2001, Business cycle asymmetries: International evidence, Review of Economic Dynamics 4(1), 230-243.

Sichel, D.: 1993, Business cycle asymmetry: A deeper look, Economic Inquiry 31(2), 224-236.

Verbrugge, R.: 1997, Investigating cyclical asymmetries, Studies in Nonlinear Dynamics \& Econometrics 2(1), Article 2. 


\section{Chapter 4}

\section{The real interest rate channel is structural in contemporary New-Keynesian models: A Note}

\subsection{Introduction}

How does monetary policy affect inflation and output? According to contemporary New Keynesian (NK) models that are widely used in academia and central banks, it is via the the real interest rate channel. ${ }^{1}$ An increase in the short-term nominal interest rate increases the real interest rate in the presence of sticky prices. Households and firms then reduce consumption and investment, respectively. As demand and output contract, inflation declines. In a recent provocative paper, Rupert and Šustek (2019) challenge this widely held view. They write:

The main message of this paper is that the transmission mecha-

\footnotetext{
${ }^{1}$ This chapter of my thesis is forthcoming in the Journal of Money, Credit and Banking. The preprint is not currently available.
} 
nism of monetary policy in New-Keynesian models does not operate through the real interest rate channel. Any consistency with the real interest rate channel is purely observational, not structural, due to a specific parameterization. Rupert and Šustek (2019), p. 54.

Based on their analysis using an NK model with capital, they conclude that from a monetary policy perspective either current NK models present a misleading description of the monetary transmission mechanism or policy makers need to rethink the monetary transmission channel altogether.

In this note, we show that the properties highlighted in Rupert and Šustek (2019) rely on two specific features both of which are absent in contemporary NK models that are used for monetary policy analysis by academics (for example, the literature following Christiano, Eichenbaum and Evans (2005) and Smets and Wouters (2007)), and in Central Banks (for example, Brave et al. (2012), Del Negro et al. (2013), among many others). First is that in the frictionless setting, with smooth consumption, the analysis relies on an unrealistic response of investment to a monetary policy shock - investment deviates upwards of $50 \%$ from steady state after a $1 \%$ shock to the policy rate. Depending on the persistence of the monetary shock, the (ex-ante) real interest rate can increase, decrease, or remain unchanged, and in this sense the response is not structural. None of the contemporary NK models, however, have this feature. Second is that with capital adjustment costs, Rupert and Šustek show that the real interest rate channel arises only for sufficiently high capital adjustment costs. For low costs, the real interest rate moves in the opposite direction from the monetary shock. The real interest rate response is again not structural. None of the contemporary NK models, however, consider capital adjustment costs. Instead, these models have adjustment costs on the flow of investment, or Investment Adjustment Costs (IAC) as introduced by Christiano, Eichenbaum and Evans to match 
the empirical response of investment to a monetary policy shock. ${ }^{2}$

We illustrate that in an NK model with IAC the real interest rate channel is structural, contrary to the conclusions of Rupert and Šustek (2019). The real interest rate always has the same sign as that of the monetary shock. A monetary contraction raises the real rate whereas an expansion lowers it. This response of the real interest rate does not depend on the size of IAC or the degree of persistence in the monetary shock process. In this sense, the real interest rate channel in NK models is structural. Both consumption and investment adjust to the real interest rate. Hence, the monetary transmission mechanism indeed operates through the real interest rate channel in contemporary NK models.

While we are not the first to emphasize the importance of adjustment costs for determining the sign of the real interest rate in response to a monetary policy shocks, we illustrate this point in a prototypical New-Keynesian model with investment adjustment costs which makes our results directly comparable to those in Rupert and Sustek (2019) and the contemporary literature. Previously, for example, Kimball (1995) derives analytical expressions for the real interest rate to display a liquidity effect in response to a permanent positive money supply shock in the presence of capital adjustment costs in a sticky price model. Basu and Kimball (2005) show that investment planning costs also generate a liquidity effect which is more in line with the data than capital adjustment costs. Woodford (2003) (p. 352) shows that a New-Keynesian model with firm-specific capital and capital adjustment costs can produce a liquidity effect. A recent discussion of the behavior of the real interest rate in response to a TFP shock in medium scale NK-DSGEs is presented by L'Huillier and Yoo (2019).

In Section 4.2 we lay out an NK model with endogenous capital and IAC and illustrate the real interest rate channel. We consider different parameterizations of IAC and the persistence of monetary shock to support our main

\footnotetext{
${ }^{2}$ The use of IAC in contemporary NK-DSGE models is ubiquitous.
} 
point. In Section 4.3 we conclude.

\subsection{New-Keynesian Model With Capital}

In this section we assess the New-Keynesian model with capital and investment adjustment costs. Since the model is nearly identical to the NK model in Rupert and Šustek (2019), we simply highlight the one modified equation. The law of motion for capital with IAC takes the following form,

$$
K_{t+1}=(1-\delta) K_{t}+I_{t}\left[1-\frac{\Omega}{2}\left(\frac{I_{t}}{I_{t-1}}-1\right)^{2}\right],
$$

where $K_{t}$ is the current capital stock, $I_{t}$ is current gross investment, $\delta$ is the depreciation rate, and $\Omega$ is the IAC parameter. Under this adjustment costs specification, the more the gross growth rate of investment differs from one the less new capital is produced from a unit of investment. In this setup $\Omega$ governs the magnitude of the costs associated with IAC. We describe the equilibrium conditions of the model and the log-linearized equations in the Appendix.

To minimize differences between the responses reported here and in $\mathrm{Ru}$ pert and Sustek (2019), we use the same calibration of parameter values: $\beta=0.99, \eta=1, \theta=0.7, \nu=1.5, \delta=0.025, \alpha=0.3$, and $\varepsilon=0.83 .{ }^{3}$ We calibrate the adjustment costs parameter to 5.48 which corresponds to the estimated value in Smets and Wouters (2007). However, industry level IAC estimates tend to be smaller (Groth and Khan 2010). We show that the conclusions regarding the real interest rate channel hold under smaller adjustment costs parameter specifications. The real interest rate is reported as percentage point deviation from steady state (i.e., $R_{t}-\bar{R}$ ) while con-

\footnotetext{
${ }^{3}$ We explored the importance of consumption habits for the real interest rate channel. Since they did not impact the conclusions drawn, we set $\varepsilon_{C}=0$, as in Rupert and Šustek (2019).
} 
sumption, investment, and output are reported in percentage deviation from steady state (i.e., $\frac{x_{t}-\bar{x}}{\bar{x}}$ ). Figure 4.1 displays the response of consumption, investment, the real interest rate, and output to a 1 percentage point shock to the monetary policy rule.
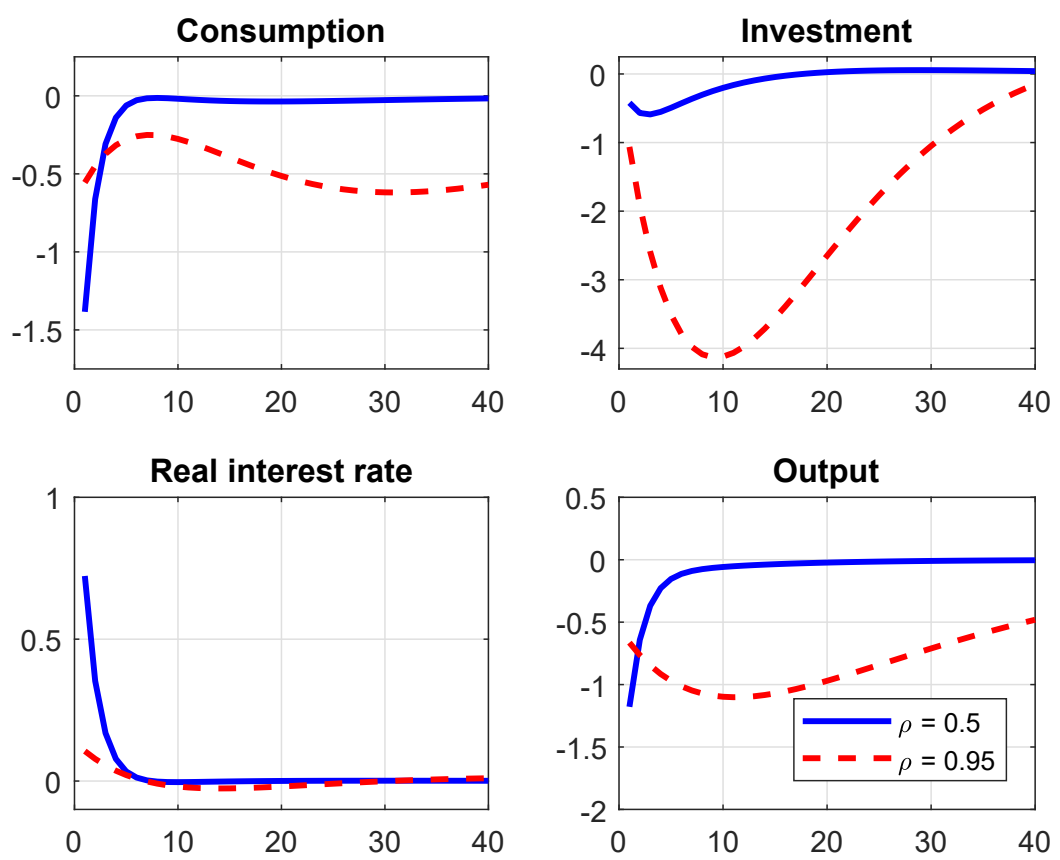

Figure 4.1: Impulse response functions to a monetary policy shock with investment adjustment costs

Notes: Investment adjustment costs parameter, $\Omega$, is calibrated to 5.48. $\rho$ is the persistence of the monetary policy shock.

The impulse response functions show that consumption, investment, and output fall in response to a positive monetary policy shock. In contrast to the ambiguity in Rupert and Šustek (2019) regarding the response of the real interest rate, when the model has frictions on the flow of investment, the real interest rate always rises in response to a positive monetary policy 
shock. This result holds under both shock persistence specifications. ${ }^{4}$ Experimenting with the model, we find that even with highly persistence shocks $(\rho=0.999)$ the real interest rate rises when IAC is present in the model. ${ }^{5}$

The IAC parameter determines the strength of the de-linkage between the real interest rate and the marginal product of capital. We document that the real interest rate channel is robust to lower IAC parameters. Figure 4.2 displays the response of consumption, investment, the real interest rate, and output to a monetary policy shock when $\Omega=2.5$ - a much smaller IAC parameter than typically estimated in the DSGE literature. ${ }^{6}$ Naturally as the adjustment costs associated with the flow of investment fall, the response of investment to a monetary policy shock becomes larger. However, the real interest rate always rises.

In the absence of costs associated with the flow of investment, capital is extremely sensitive to changes in the real interest rate which lead to large changes in investment. To illustrate this point, Figure 4.3 displays the response of consumption, investment, the real interest rate, and output to a 1 percentage point increase in $\xi_{t}$ when investment is frictionless $(\Omega=0)$. The impulse response functions reported here are identical to those in Figures 1, 3 and 4 in Rupert and Šustek (2019). Two points are worth emphasizing: First, the response of investment to a 1 percentage point shock to the monetary policy rate is unrealistic. Investment deviates from steady state by 13-53\% depending upon the persistence in the shock. ${ }^{7}$ Second, the response of the real interest rate is ambiguous. When shock persistence is low, the real interest rate rises. But even moderate amounts of persistence lead to

\footnotetext{
${ }^{4}$ We do not report impulse responses for the case where $\rho=0$, but the real interest rate also rises in this case.

${ }^{5}$ In an NK model without capital, the real interest rate always rises after a positive monetary shock (see, for example, Galí (2015), and also noted in Rupert and Šustek (2019)).

${ }^{6}$ For reference, Christiano, Motto and Rostagno (2014) find an estimate of $\Omega=10.78$.

${ }^{7}$ The response of investment to a monetary shock is not shown in Rupert and Šstek (2019).
} 

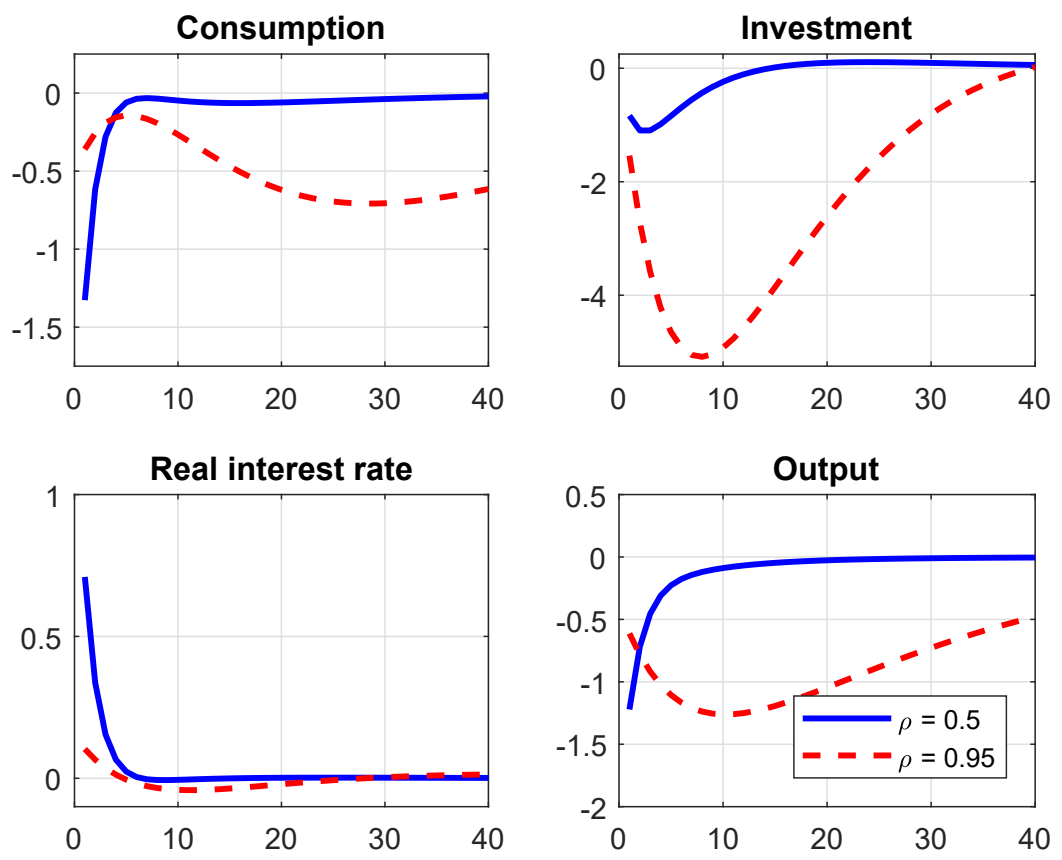

Figure 4.2: Impulse response functions to a monetary policy shock with (small) investment adjustment costs

Notes: Investment adjustment costs parameter, $\Omega$, is calibrated to 2.5 . $\rho$ is the persistence of the monetary policy shock.

a fall in the real interest rate. While the emphasis in their exercise is on the qualitative features of the model, our point is that drawing implications based on these model properties, as they do, is problematic.

\subsubsection{Long-run real interest rates and investment}

Capital is a long-lived asset. Current investment decisions depend not only on the current real rate of return, but also the full path of expected real rates of return. ${ }^{8}$ Falling short-run real interest rates and investment can be

\footnotetext{
${ }^{8}$ We thank an anonymous referee for raising this point.
} 

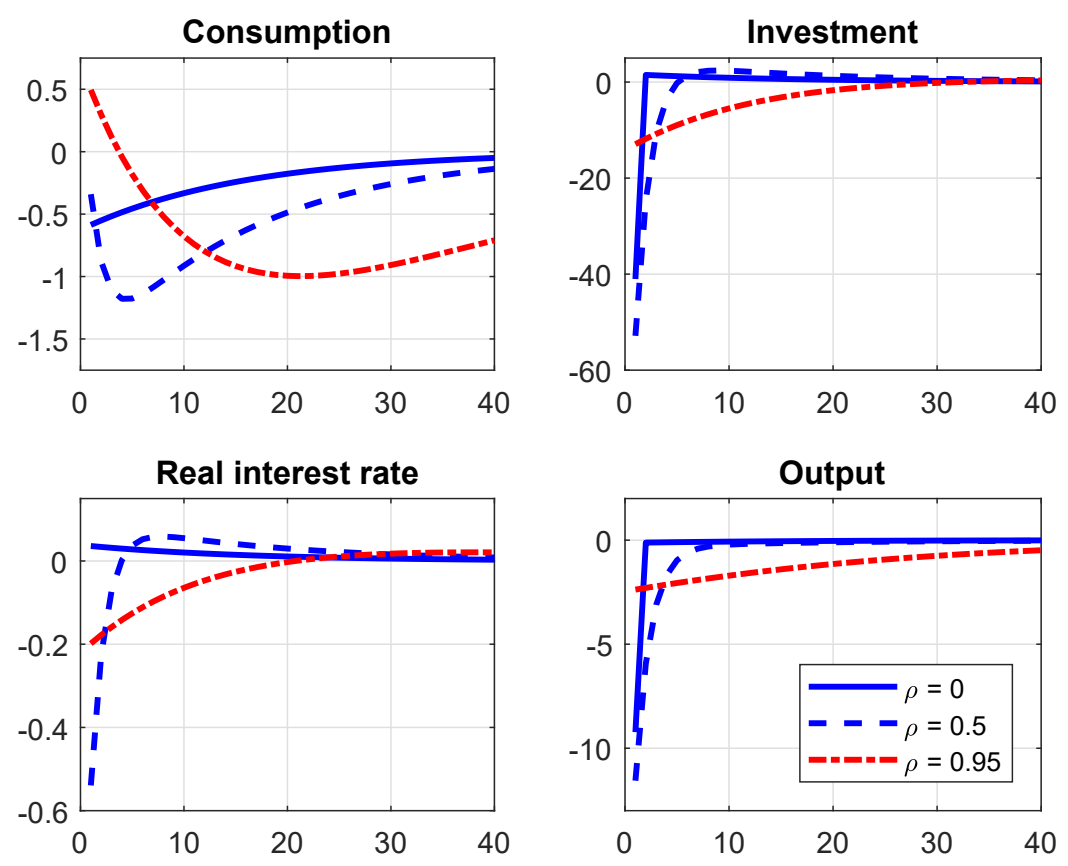

Figure 4.3: Impulse response functions to a monetary policy shock in Rupert and Šustek (2019)

Notes: Investment adjustment costs parameter, $\Omega$, is calibrated to $0 . \rho$ is the persistence of the monetary policy shock.

consistent with the real interest rate channel if the long-run real interest rate rises. ${ }^{9}$ We investigate this point under no adjustment costs, CAC, and IAC.

To define long-run real interest rate, we follow the same approach as in Rupert and Šustek (2019). By iterating the log-linearized Euler equation for bonds forward (and imposing convergence to the steady state in the absence of shocks) we obtain,

\footnotetext{
${ }^{9}$ In the absence of adjustment costs the real return on bonds is equal to the real return on capital.
} 


$$
-\hat{C}_{t}=E_{t} \sum_{t=0}^{\infty} \hat{R}_{t+j} \equiv R_{t}^{\ell}
$$

where $R_{t}^{\ell}$ is the long-run real interest rate.

Figure 4.4 reports the response of investment and the long-run real interest rate in response to a positive one percentage point monetary policy shock under alternative adjustment costs scenarios and shock persistence parameterizations.
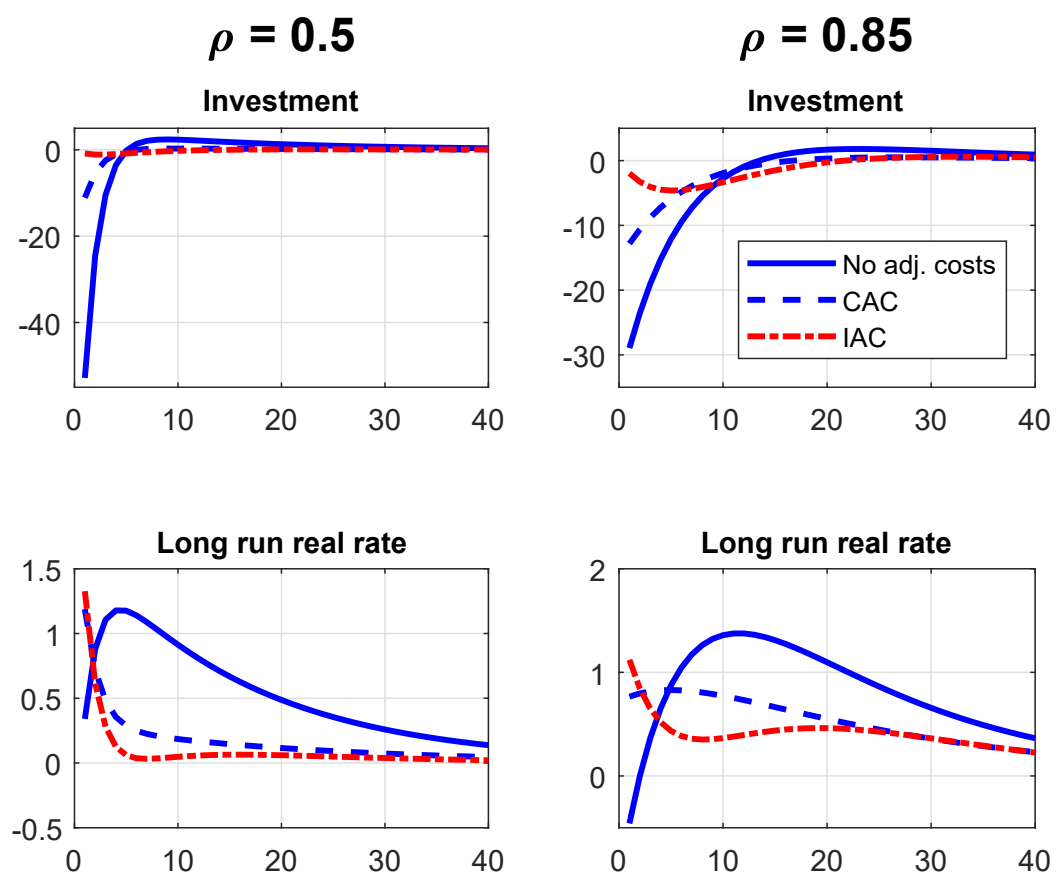

Figure 4.4: Long-run real interest rate and investment in response to a monetary policy shock under alternative adjustment costs

Notes: The left column plots the response of investment and the long-run real interest rate when the shock persistence, $\rho$, is 0.5 . The right column plots the responses when $\rho=0.85$. For capital adjustment costs we use a adjustment parameter of 0.5 and for investment adjustment costs we use a parameter of 2.5 . 
The left column in Figure 4.4 shows that the long-run real interest rate rises even when the short-run real rate falls in the no adjustment cost case after a monetary contraction, with low shock persistence. This degree of persistence is also empirically relevant. For example, the posterior mode of the monetary shock persistence parameter in Smets and Wouters (2007) (Table $1 \mathrm{~B}$ ) is 0.12 , indicating that monetary shock is of transitory nature. When the shock persistence is high (when $\rho=0.85$ ), the long-run real interest rate falls (right column). But, as mentioned above, this calibration is not supported in U.S. data.

With respect to long-run real interest rates, it is worth emphasizing two points which favor the IAC version of the model. First, with IAC, the longrun real interest rate rises under any persistence parameterization. In contrast, in the no adjustment costs case, the long run real interest rate falls if the shock is very persistent. While CAC leads to a rise in the long-run real interest under moderate and high shock persistence, the short-run real interest rate falls (as emphasized by Rupert and Šustek (2019) in their Figure 8). Only the IAC version of the model leads to a rise in both the short run and long run real interest rates under any shock persistence calibrations.

Second, IAC produces impulse responses for investment which are more in line with the empirical evidence for monetary policy shocks. Specifically, investment displays a "hump-shaped" pattern where the peak response occurs several quarters after the shock which motivates using IAC formulation (Christiano, Eichenbaum and Evans 2005). In contrast, both no adjustment costs and capital adjustment costs lead to peak responses of investment on impact which is inconsistent with the empirical evidence.

\subsection{Conclusion}

We highlight that the real interest rate channel is central to the monetary transmission mechanism in contemporary NK models. A monetary contrac- 
tion (expansion) is followed by an increase (decrease) in the real interest rate. The presence of investment adjustment costs make the real interest rate channel a structural feature in this class of models. 


\section{Bibliography}

Basu, S. and Kimball, M. S.: 2005, Investment planning costs and the effects of fiscal and monetary policy. Mimeo.

Brave, S. A., Campbell, J. R., Fisher, J. D. M. and Justiniano, A.: 2012, The Chicago Fed DSGE Model, Working Paper 02, Federal Reserve Bank of Chicago.

Christiano, L. J., Eichenbaum, M. and Evans, C. L.: 2005, Nominal rigidities and the dynamic effects of a shock to monetary policy, Journal of Political Economy 113(1), 1-45.

Christiano, L. J., Motto, R. and Rostagno, M.: 2014, Risk shocks, American Economic Review 104(1), 27-65.

Del Negro, M., Eusepi, S., Giannoni, M., Sbordone, A., Tambalotti, A., Cocci, M., Hasegawa, R. and Linder, M. H.: 2013, The FRBNY DSGE Model, Technical Report 64\%, Federal Reserve Bank of New York Staff Reports.

Galí, J.: 2015, Monetary Policy, Inflation, and the Business Cycle: An Introduction to the New Keynesian Framework and Its Applications, Princeton University Press.

Groth, C. and Khan, H.: 2010, Investment adjustment costs: An empirical assessment, Journal of Money, Credit and Banking 42(8), 1469-1494.

Kimball, M. S.: 1995, The quantitative analytics of the basic neomonetarist model, Journal of Money, Credit and Banking 27(4), 1241-1277.

L'Huillier, J.-P. and Yoo, D.: 2019, Where is the GE? consumption dynamics in DSGEs, Journal of Money, Credit and Banking 51(6), 1491-1502. 
Rupert, P. and Šustek, R.: 2019, On the mechanics of new Keynesian models, Journal of Monetary Economics 102, 53-69.

Smets, F. and Wouters, R.: 2007, Shocks and frictions in US business cycles: A Bayesian DSGE approach, American Economic Review 97(3), 586-606.

Woodford, M.: 2003, Interest and Prices: Foundations of a Theory of Monetary Policy, Princeton University Press. 
Appendices 


\section{Appendix A}

\section{Appendix to The Shifts in Lead-Lag Properties of the US Business Cycle}

\section{A.1 Cross-correlations across filters}

Table A.1 reports the baseline cross-correlations discussed in the paper. Cyclical components are obtained using the HP filter with a smoothing parameter of 1600. Table A.2 reports the cross-correlations obtained using Hamilton (2018)'s filter, with $h=8$ and $p=4$. Table A.3 reports the crosscorrelations obtained using the Baxter and King (1999) filter, examining the 6-32 quarter frequency. Table A.4 reports the cross-correlations obtained using the Christiano and Fitzgerald (2003) filter, again, examining the 6-32 quarter frequency.

\section{A.2 Standard errors of the cross-correlations}

In the paper we compute standard errors for cross-correlations using the Delta method and generalized method of moments (see, for example (Cochrane 
2005, pg. 207)),

$$
\begin{array}{r}
\rho_{i, j}(\mu)=\frac{\mu_{y x}-\mu_{x} \mu_{y}}{\left(\mu_{y}-\mu_{y}^{2}\right)^{1 / 2}\left(\mu_{x x}-\mu_{x}^{2}\right)^{1 / 2}} \\
\operatorname{var}\left(\hat{\rho_{i, j}}\right)=\frac{1}{T}\left\{\frac{\partial \rho}{\partial \mu}\right\}^{\prime} \sum_{j=-\infty}^{\infty} \operatorname{cov}\left(\mathbf{x}_{t}, \mathbf{x}_{t-j}^{\prime}\right)\left\{\frac{\partial \rho}{\partial \mu}\right\}
\end{array}
$$

where $\rho_{i, j}(\mu)$ is the standard correlation coefficient formula. The variance can be computed using (2) where $\mu=\left[\mu_{y} \mu_{x} \mu_{y y} \mu_{x x} \mu_{y x}\right]$ are the sample moments of the two variables of interest. Then $\partial \rho / \partial \mu$ is a $5 \times 1$ vector of derivatives (e.g. $\left.\partial \rho / \partial \mu_{x y}=\frac{1}{\sigma_{x} \sigma_{y}}\right)$. The variance covariance matrix is estimated using a Newey-West estimator with 10 lags.

Figures A.1-A.4 present cross-correlations discussed in the paper with their associated one standard deviation confidence bands.

\section{A.3 Literature studying business cycle cross- correlations}

As discussed in the introduction, a long literature has used cross-correlations in studying business cycles. Contributions in the case of real interest ratesoutput cross-correlations, for example, are Fiorito and Kollintzas (1994), Chari, Christiano and Eichenbaum (1995), King and Watson (1996), Beaudry and Guay (1996), Boldrin, Christiano and Fisher (2001), Mertens (2010), and Dotsey et al. (2003). For cross-correlations related to investment see Hornstein and Praschnik (1997), Gomme, Kydland and Rupert (2001), Fisher (2007), Kydland, Rupert and Sustek (2016), Khan and Rouillard (2017), Khan and Rouillard (2018), among others). For labour productivity-output and labour productivity-hours cross-correlations see Burnside and Eichenbaum (1993). In the case of net exports, terms of trade, and balance of payments cross-correlations see Backus, Kehoe and Kydland (1992), Backus, 
Kehoe and Kydland (1994), among others. Christiano, Motto and Rostagno (2014) for cross-correlations between output and investment, consumption, credit risk, and equity. Azariadis, Kaas and Wen (2016) examine crosscorrelations in unsecured firm credit to motivate their model of self-fulfilling credit cycles. Beaudry, Galizia and Portier (2017) discuss the positive correlation between their measure of capital over-accumulation prior to a recession and the subsequent severity of the recession over the period 1959-2015 in motivating their theoretical model. Barsky and Sims (2012) discuss the cross-correlations between consumer confidence and output.

\section{A.4 Replication codes}

The replication code for Smets and Wouters (2007) is available from the American Economic Review's website. The replication code for Iacoviello (2005) is available at Matteo Iacoviello's website https://www2.bc.edu/matteoiacoviello/research.htm. The replication code for Basu and Bundick (2017) is available at Brent Bundick's website http://www.brentbundick.com/research.html and Johannes Pfeifer's github page https://github.com/JohannesPfeifer/DSGE_mod. The replication code for Galí and van Rens (2020) is available from Thijs van Rens's website http://www.thijsvanrens.com/VPLP/. 


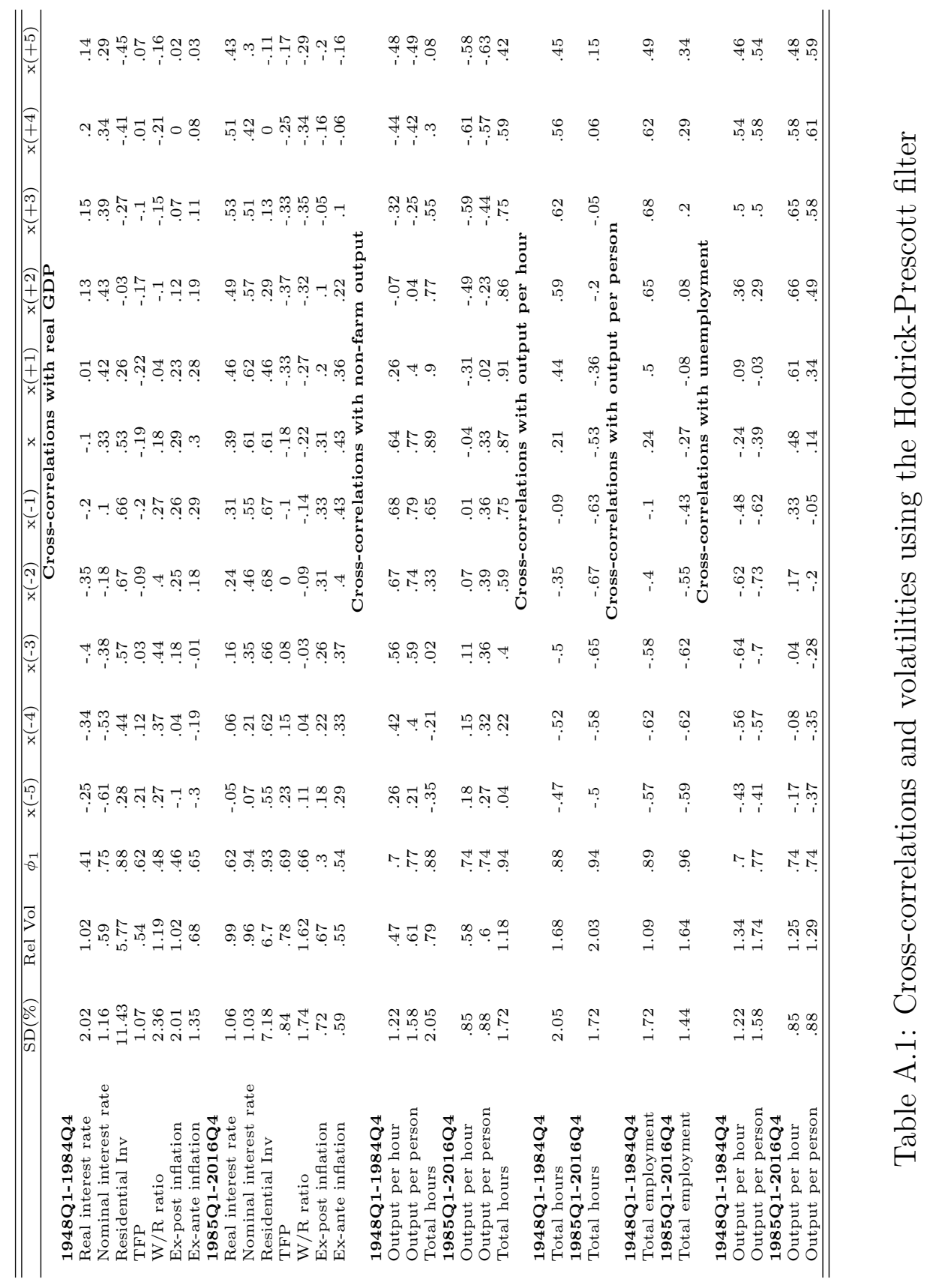




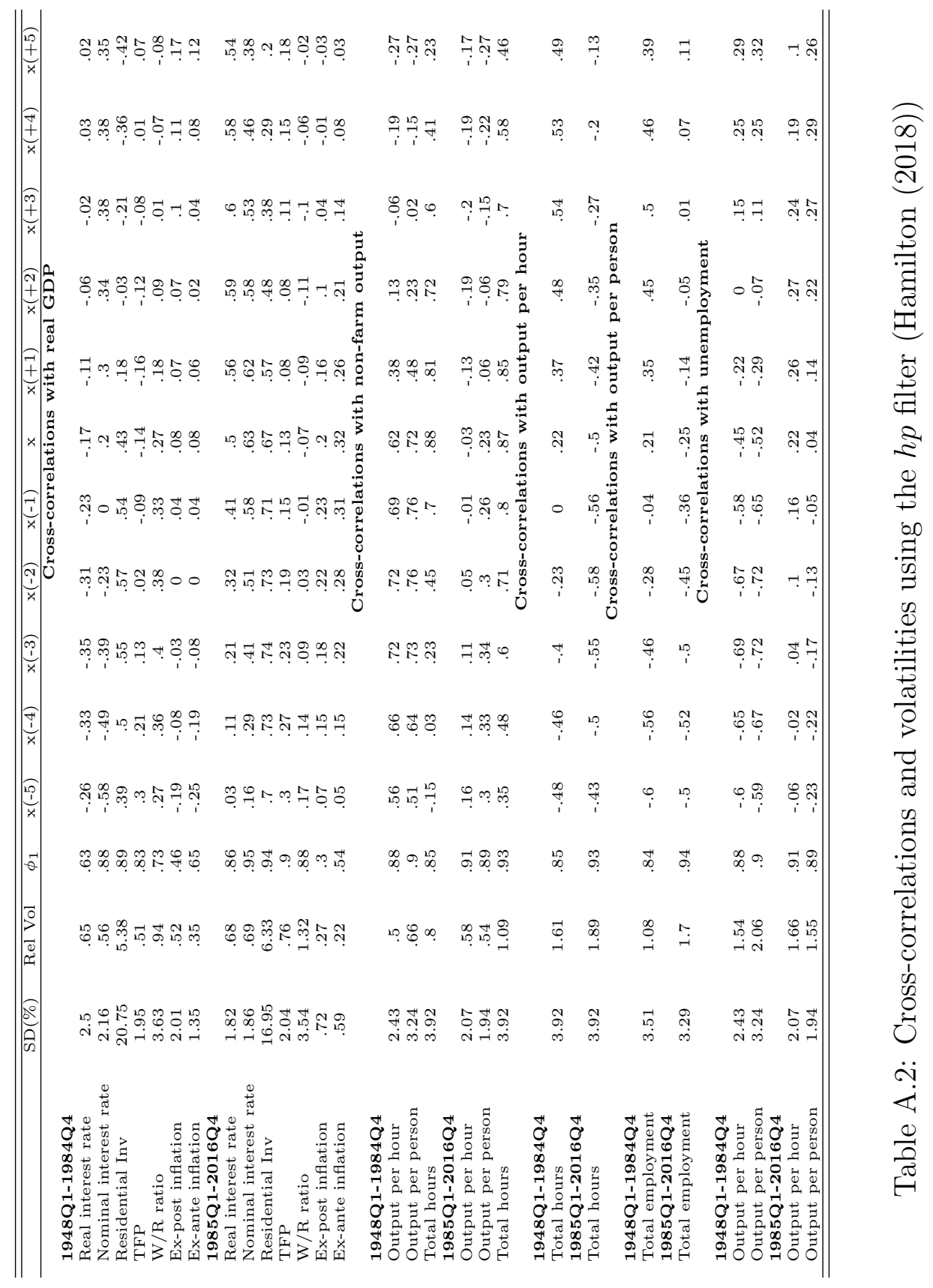




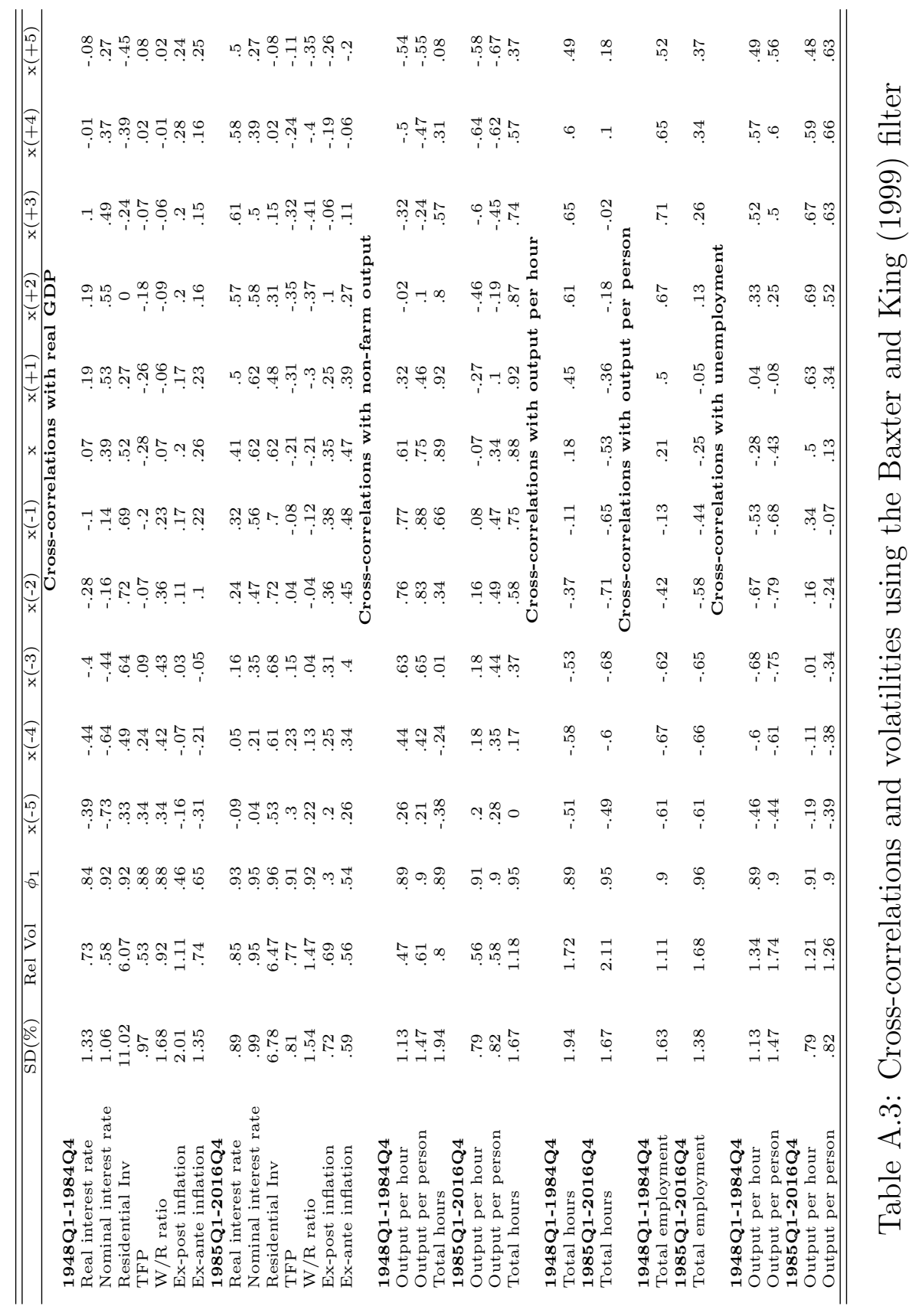




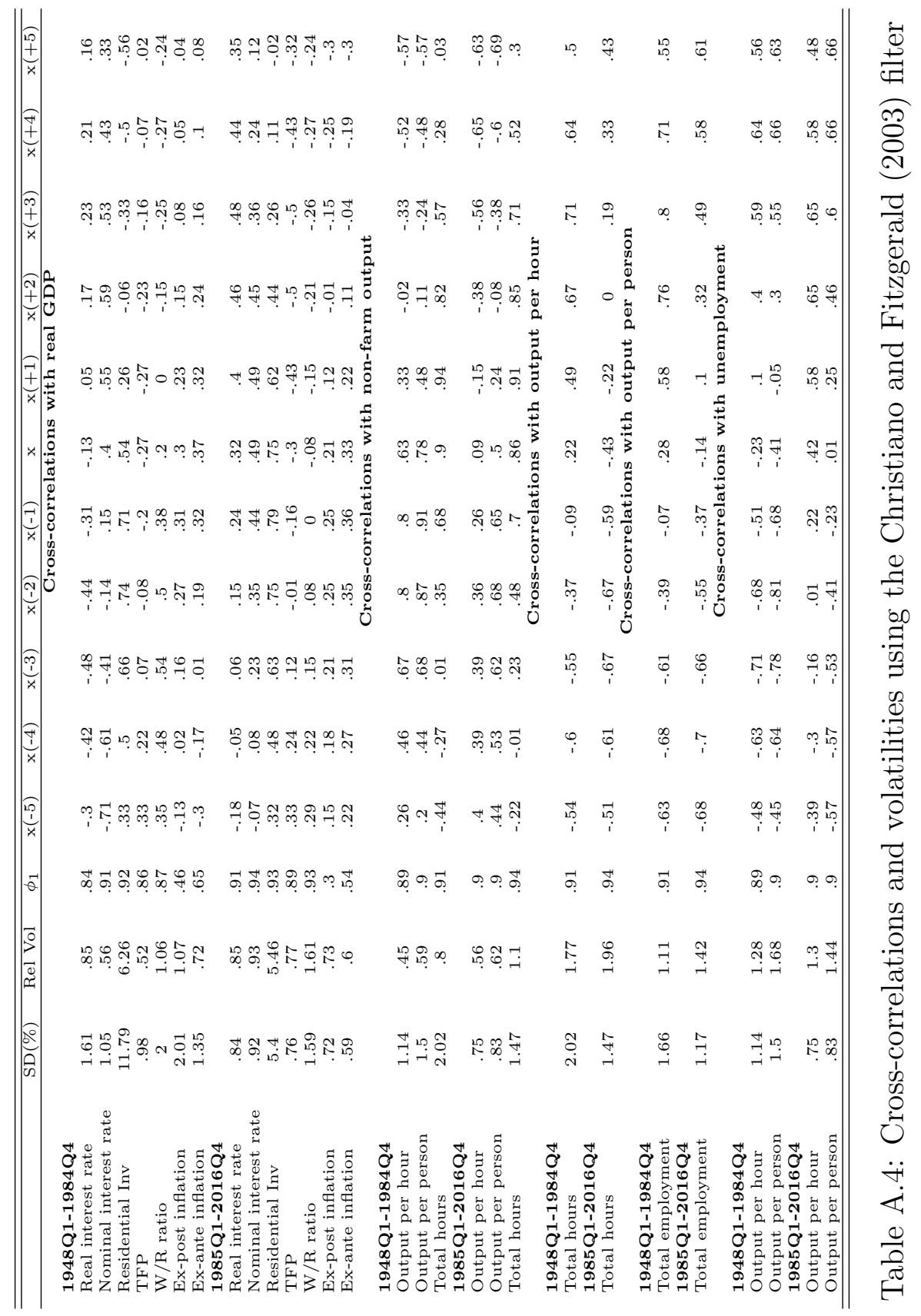




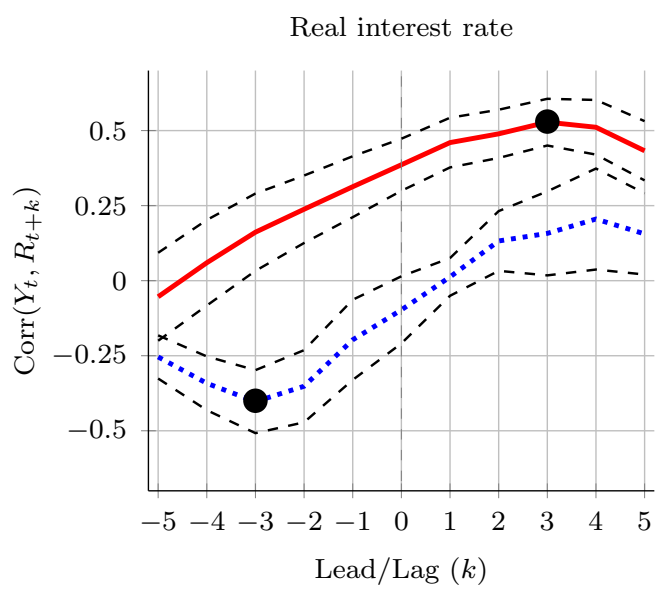

..... Pre-1985 - Post-1985

(a)

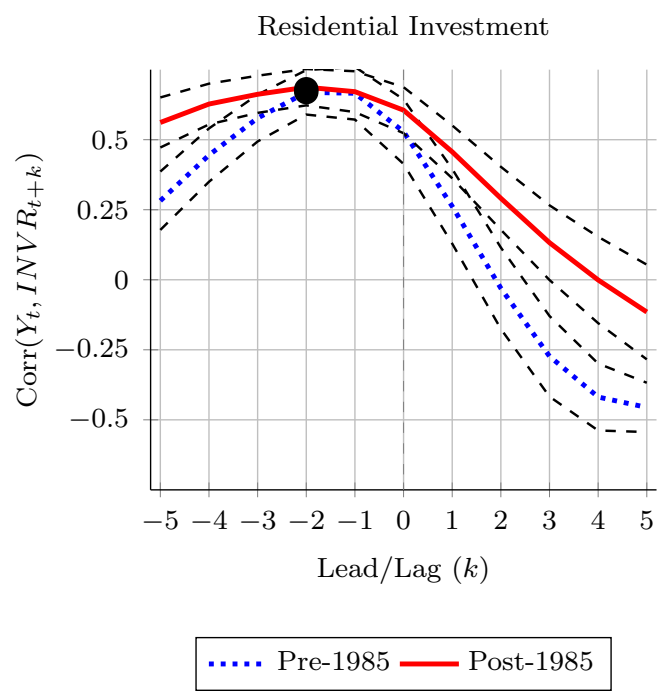

(c)

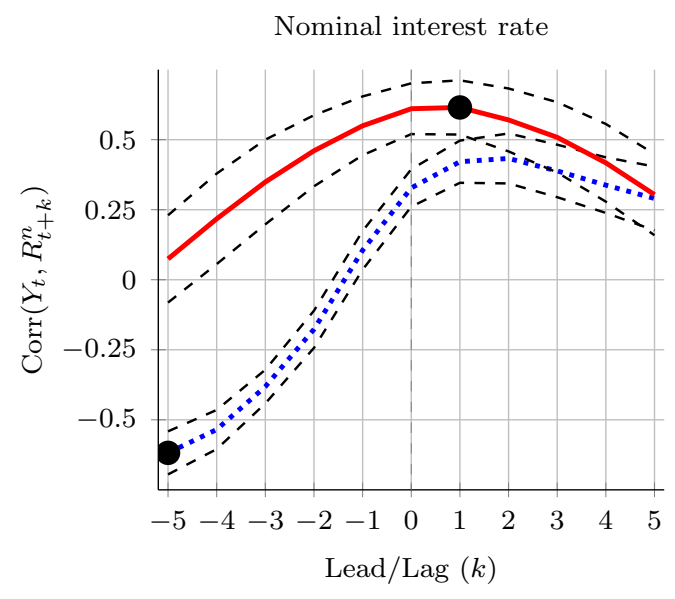

..... Pre-1985 Post-1985

(b)

Total Factor Productivity

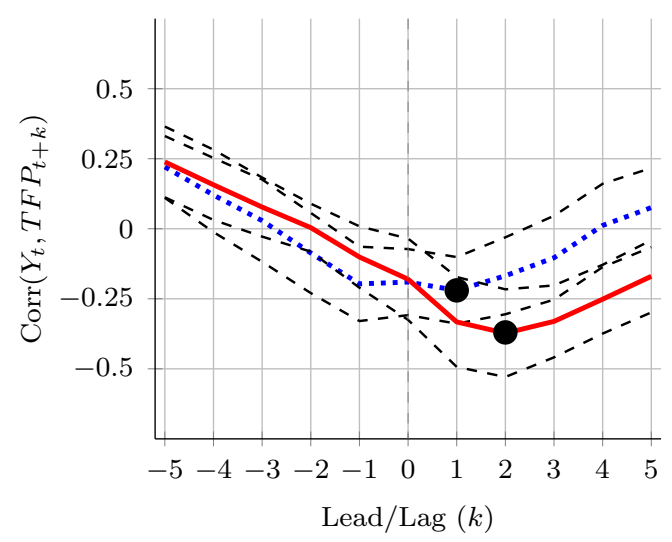

..... Pre-1985 - Post-1985

(d)

Figure A.1: Cross-correlations with 1 standard deviation confidence bands 
Wage real interest ratio

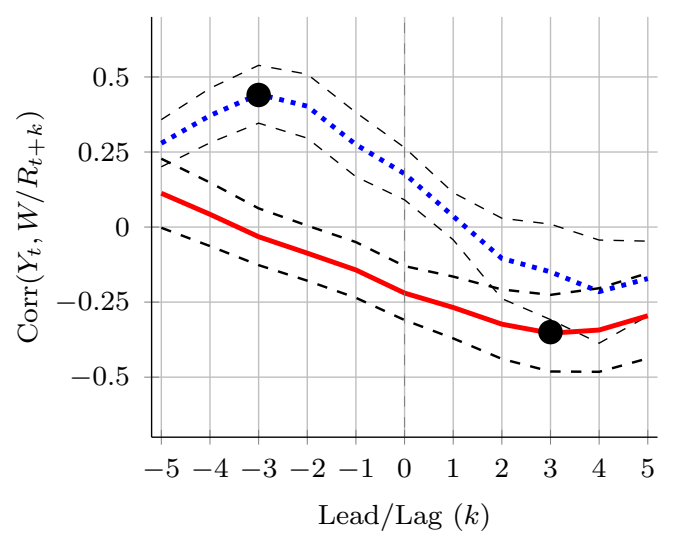

..... Pre-1985 Post-1985

(a)

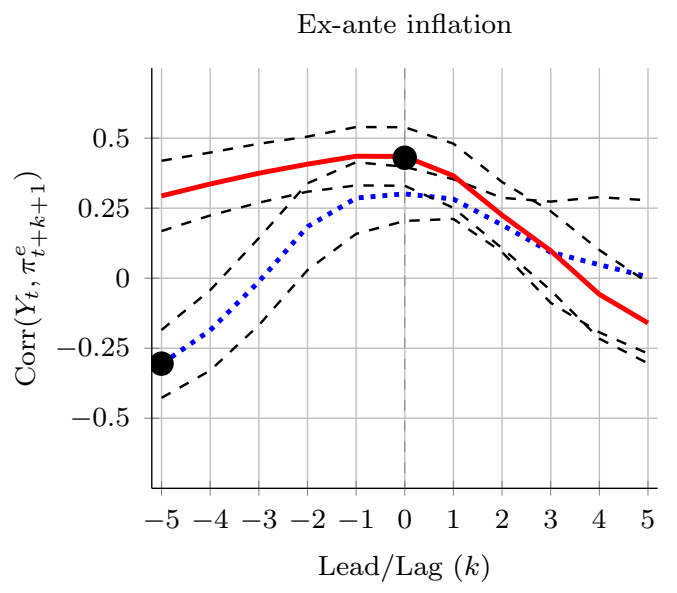

..... Pre-1985 Post-1985

(c)

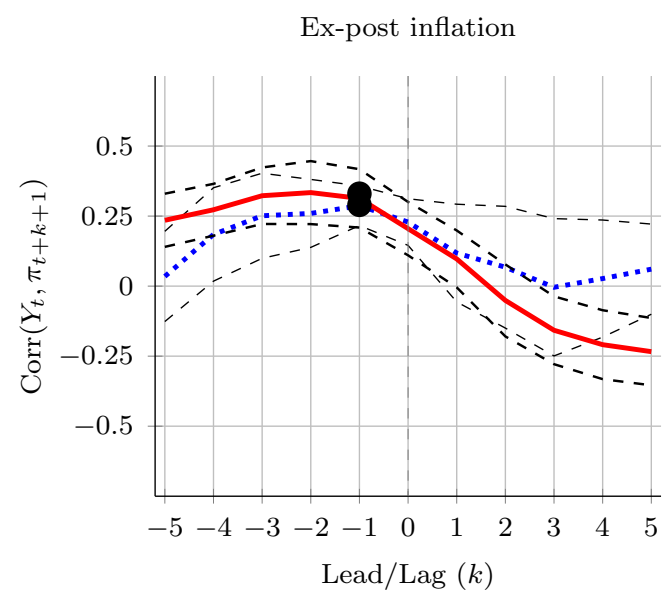

..... Pre-1985 Post-1985

(b)

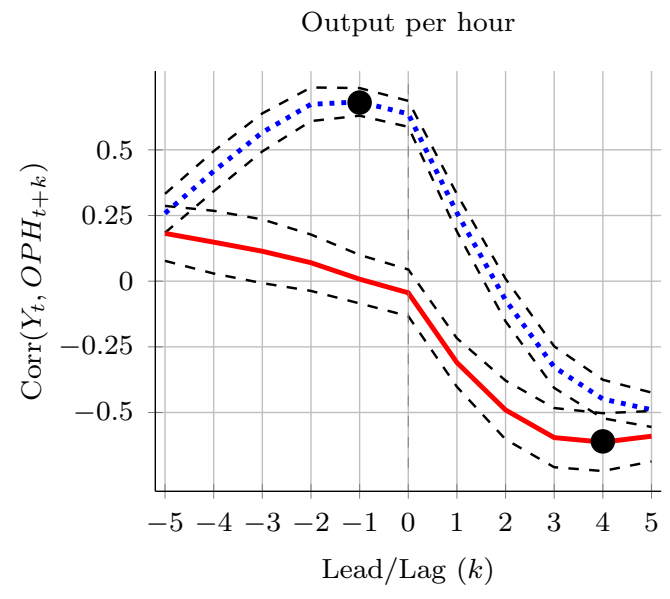

..... Pre-1985 Post-1985

(d)

Figure A.2: Cross-correlations with 1 standard deviation confidence bands 


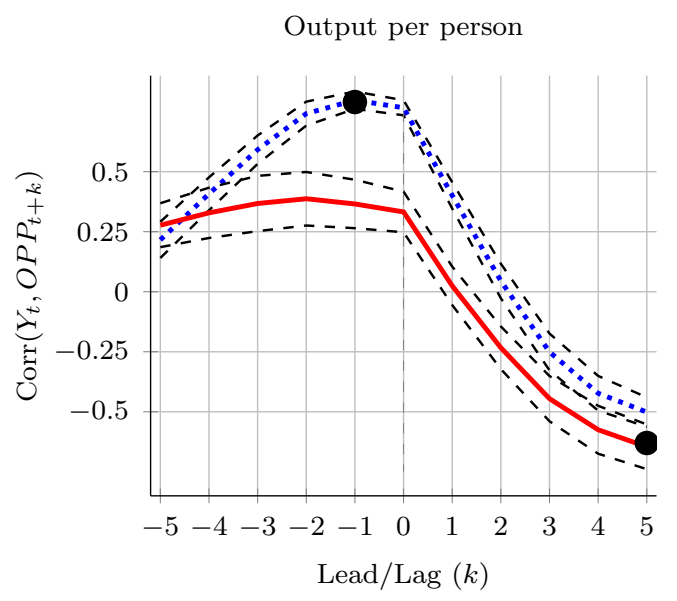

.... Pre-1985 - Post-1985

(a)

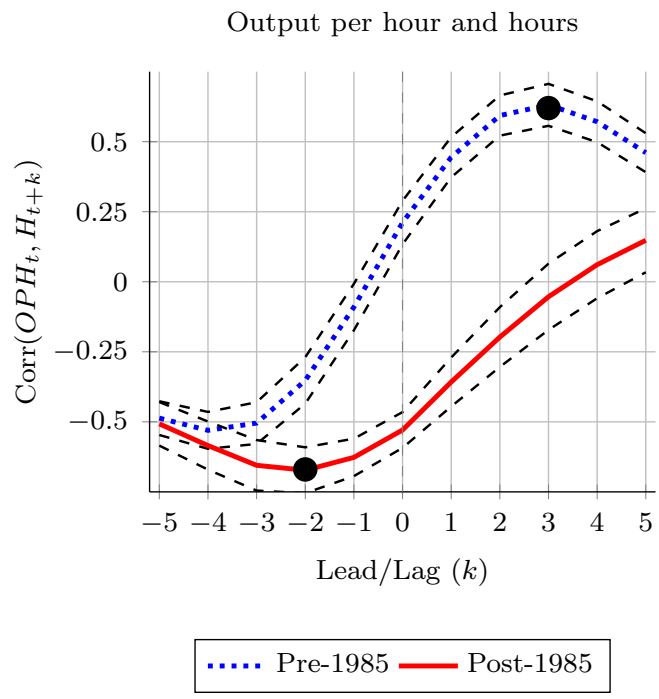

(c)

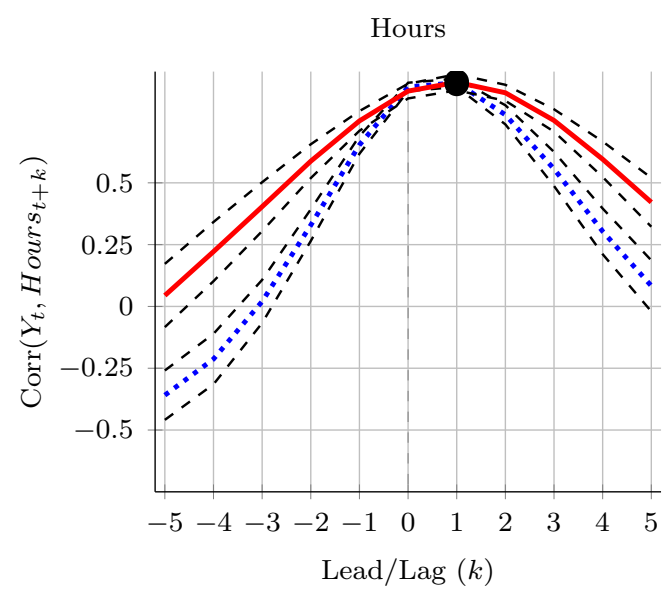

. . . . Pre-1985 Post-1985

(b)

Output per person and employment

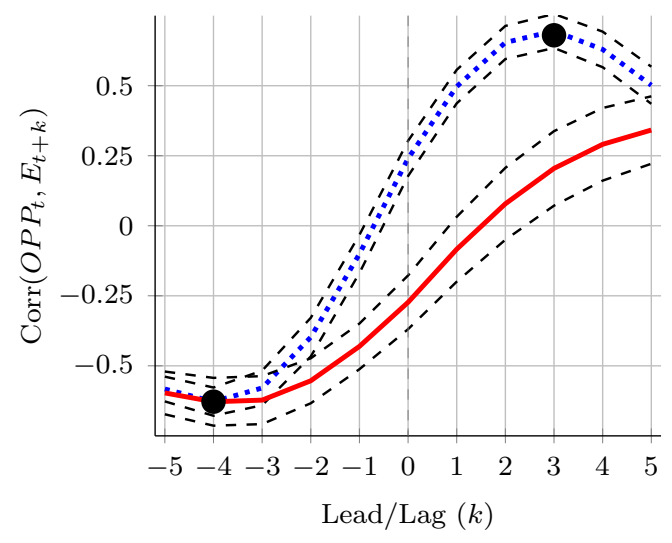

.... Pre-1985 Post-1985

(d)

Figure A.3: Cross-correlations with 1 standard deviation confidence bands 


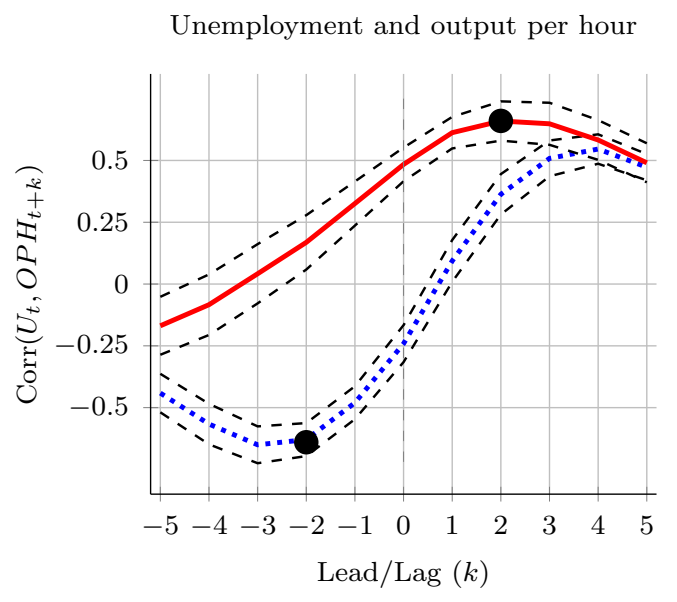

..... Pre-1985 Post-1985

(a)

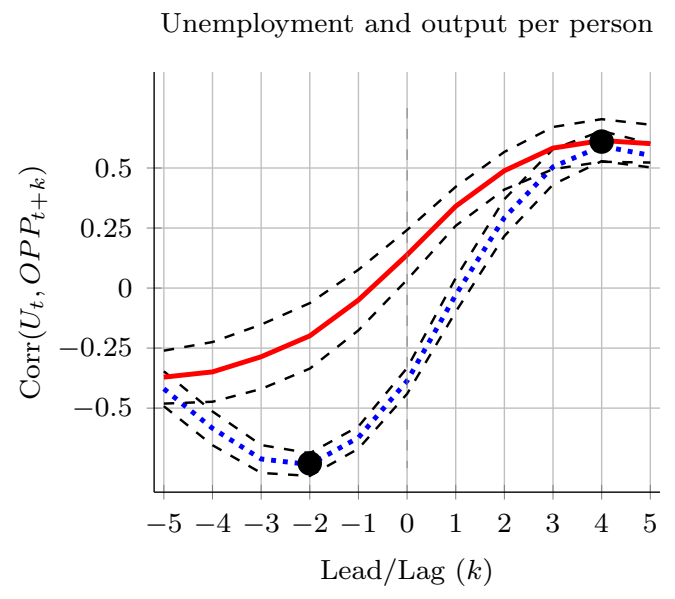

..... Pre-1985 Post-1985

(b)

Figure A.4: Cross-correlations with 1 standard deviation confidence bands 


\section{A.5 Data and Definitions}

The data series used in the paper are described below:

\begin{tabular}{lccl} 
Variable & Data source & Sample & Notes \\
\hline \hline Real GDP & FRED & $1947:$ I-2017:I & FRED code (GDPC1) \\
Nonfarm output & FRED & $1947:$ I-2017:I & FRED code (OUTNFB) \\
GDP Deflator & FRED & $1947:$ I-2017:I & FRED code (GDPDEF) \\
Federal funds rate & FRED & $1954 \mathrm{I}: 2017 \mathrm{I}$ & FRED code (FEDFUNDS) \\
3-month treasury bill & FRED & $1947 \mathrm{I}:$ 2017I & FRED code (TB3MS) \\
Total hours worked & FRED & $1947:$ I-2017:I & FRED code (HOANBS) \\
Total employment & FRED & $1947:$ I-2017:I & FRED code (PRS85006013) \\
Unemployment rate & FRED & $1948:$ I-2017:I & FRED code (UNRATE) \\
Output per person & FRED & $1947:$ I-2017:I & FRED code (PRS85006163) \\
Output per hour & FRED & $1947:$ I-2017:I & FRED code (OPHNFB) \\
Residential investment & FRED & $1947:$ I-2017:I & FRED code (A011RA3Q086SBEA) \\
Shadow federal funds rate & Wu and Xia (2016) & $1960:$ I-2015:III & No zero lower bound \\
Consumer price index & FRED & $1947:$ I-2017:I & FRED code (CPIAUCSL) \\
Core CPI & FRED & $1957:$ I-2017:I & FRED code (CPILFESL) \\
PCE Deflator & FRED & $1947:$ I-2017:I & FRED code (DPCERD3Q086SBEA) \\
Total factor productivity & Fernald (2014) & $1947:$ I-2017:I & Level 1947:I=1 \\
Forecasted inflation & SPF & $1981:$ III-2017:I & One quarter ahead forecast \\
Demographic adj. hours & Wolters $(2018)$ & $1948 \mathrm{I}: 2017 \mathrm{I}$ & Demographics purged \\
Real compensation & FRED & $1947:$ I-2017:I & FRED code (COMPRNFB) \\
\hline \hline
\end{tabular}

Table A.5: Data sources

In compiling the data sources, any variables in monthly frequency are converted to quarterly by averaging. In the paper we defined additional variables via the following formulas:

$$
\begin{array}{r}
\pi_{t}=\left(\ln \left(\text { Price }_{t}\right)-\ln \left(\text { Price }_{t-1}\right)\right) * 400 \\
r_{t}=R_{t}-\pi_{t+1} \\
\frac{W}{r}=\frac{\text { Real compensation }}{1+\text { Real interest rate }}
\end{array}
$$

Where $\pi_{t}$ is the inflation rate, $r_{t}$ is the real interest rate, $R_{t}$ is the nominal interest rate, and $W$ is the real compensation per hour, respectively. We log transform all of the variables prior to filtering, excluding interest rates and the unemployment rate. We use a smoothing parameter of $\lambda=1600$ for the Hodrick-Prescott filter. When applying the Hamilton filter, we use $h=8$ and $p=4$, Hamilton's suggested parametric specification for detrending quarterly data. 
We compute the cross-correlations as follows. Cross-covariance is defined as,

$$
\operatorname{Cov}\left\{x_{1}(t), x_{2}(t+k)\right\}=R_{12}(k)
$$

and cross-correlation is computed as,

$$
\rho_{i j}(k)=\operatorname{Corr}\left\{x_{i}(t), x_{j}(t+k)\right\}=\frac{R_{i j}(k)}{\sqrt{R_{i i}(k) R_{j j}(k)}}
$$

where $R_{i i}(k)$ and $R_{j j}(k)$ are the variances of the corresponding series.

\section{A.6 Alternative definitions of real interest rate}

The baseline real interest rate defined in the paper is the 3-month treasury bill rate minus ex-post inflation defined as the annualized log difference in the GDP deflator in $t+1$. Below we consider a variety of ex-ante and ex-post measures for the real interest rate from alternative price indexes (also we consider whether the real interest rate series is stationary or non-stationary). Table A.6 reports cross-correlations between output and the real interest rate using alternative definitions for the pre-1985 period. Table A.7 reports the real interest rate output cross-correlations for the same definitions in the post-1985 period.

Note: Ex-post measures of real interest rate are calculated using actual inflation at $t+1$. ISVAR computes expected inflation using an in-sample VAR. REVAR computes expected inflation using a recursive VAR forecast (using all information up to time $t$ to forecast inflation at time $t+1$ ). ROVAR computes expected inflation using a rolling VAR forecast where the window is 40 quarters. Finally, in brackets $(\mathrm{U})$ or $(\mathrm{F})$ indicates whether the real interest rate series was passed through the Hodrick-Prescott filter with a 
smoothing parameter of 1600 ( $\mathrm{U}$ for unfiltered and $\mathrm{F}$ for filtered). We begin the pre-1985 subsamples in 1956Q3 for all measures in this table to ensure the VAR has enough observations to generate reliable forecasts. We also consider the estimated nominal interest series from Wu and Xia (2016), which estimates the nominal interest rate in the absence of the zero lower bound (this is only relevant for the post-1985 sample). Finally, we consider expected inflation from the Survey of Profession Forecasters obtained through the Federal Reserve Bank of Philadelphia. Our measure of expected inflation is the median response for expected CPI growth in $t+1$ (CPI3 in the data). Since this data is only available from 1981:III onwards, we consider this measure for the post-1985 subsample only. 


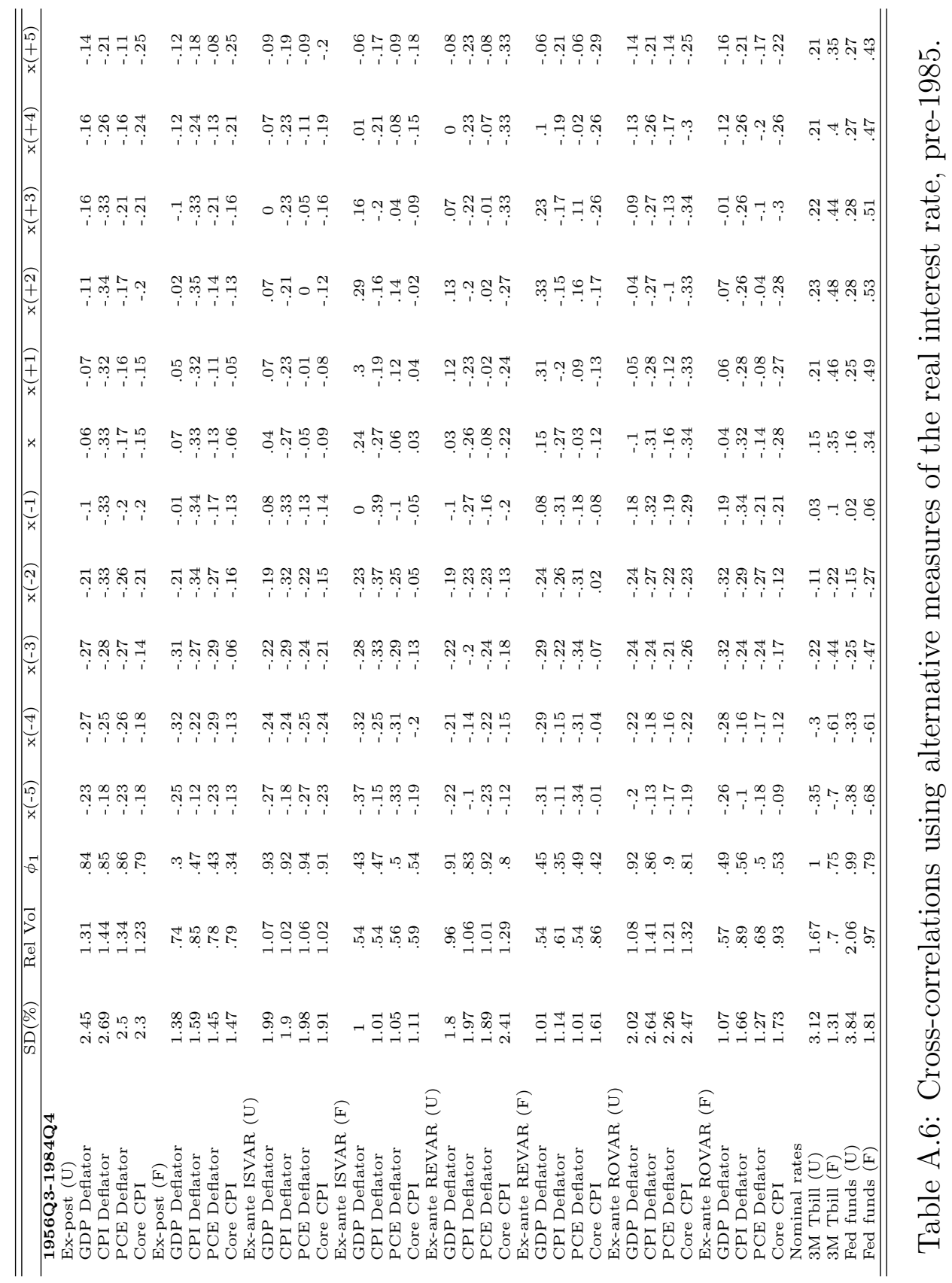




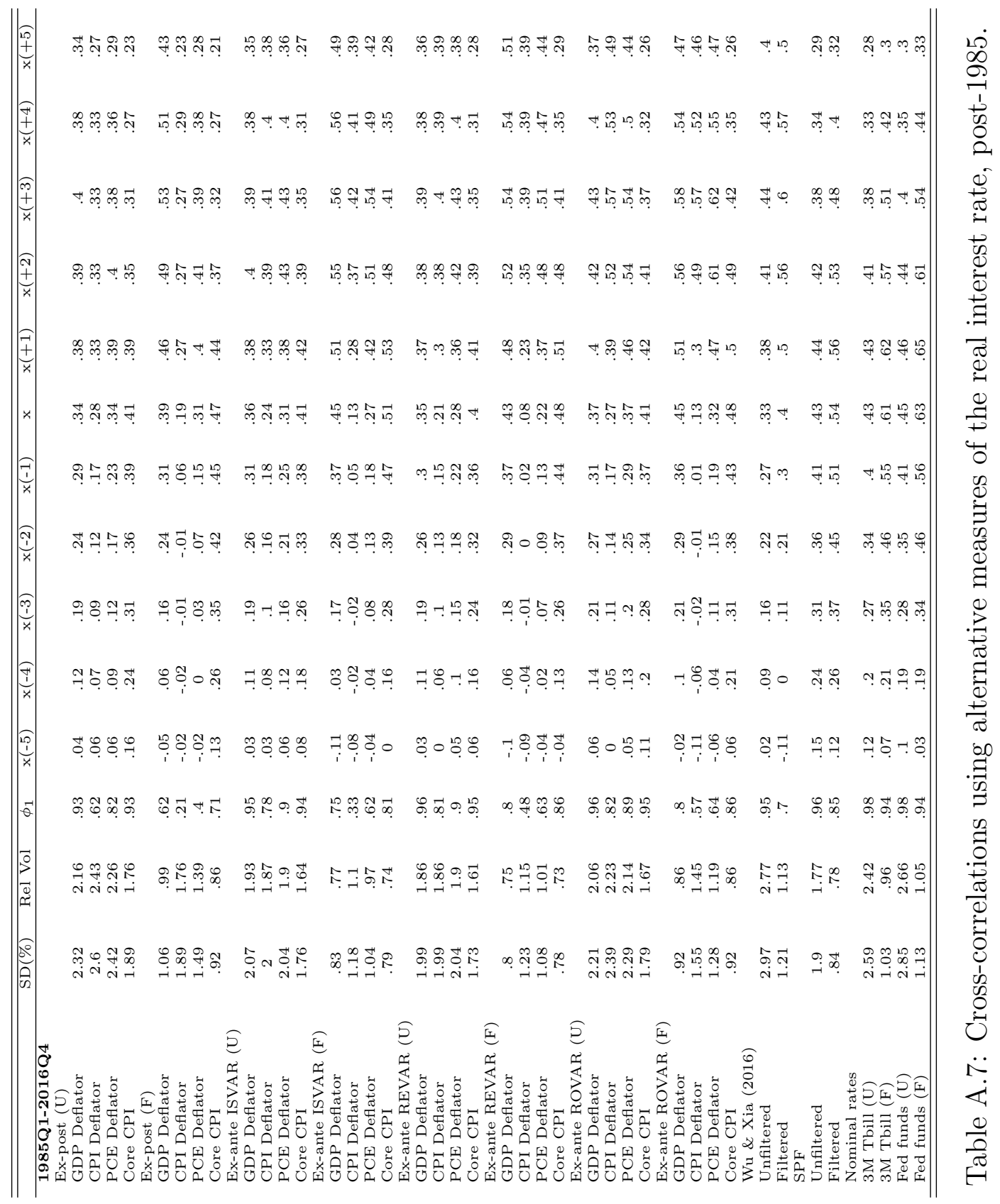




\section{A.7 Alternative sample periods}

In the paper we consider two subsamples, the pre-1985 and post-1985 periods. Below we report two alternative subsamples to assess how sensitive the shifts are to alternative subsamples. Table A.8 reports post-1985 cross-correlations and volatilities when excluding the Great Recession. This table highlights that the Positive Lagging Property reported in the paper is not driven by the nominal interest rate binding at the zero lower bound. Table A.9 reports cross-correlations and volatilities when we consider the post-1983 time period as the onset of the Great Moderation.

\section{A.8 Extending the definition of the business cycle to 8-50 quarters}

Tables A.10 and A.11 report cross-correlations when we examine the 8-50 frequency range using the Christiano and Fitzgerald (2003) and Baxter and King (1999) filters. 


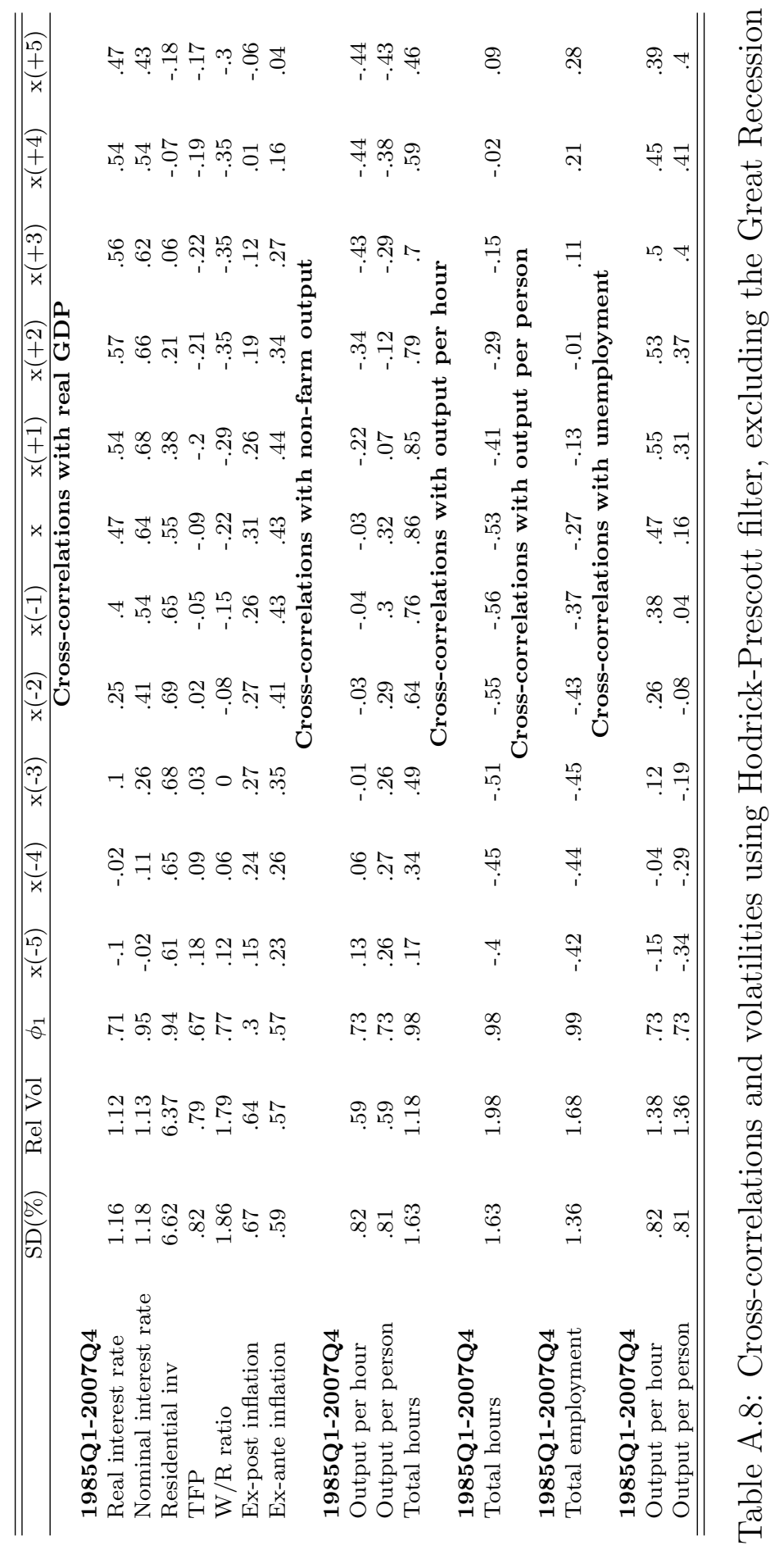




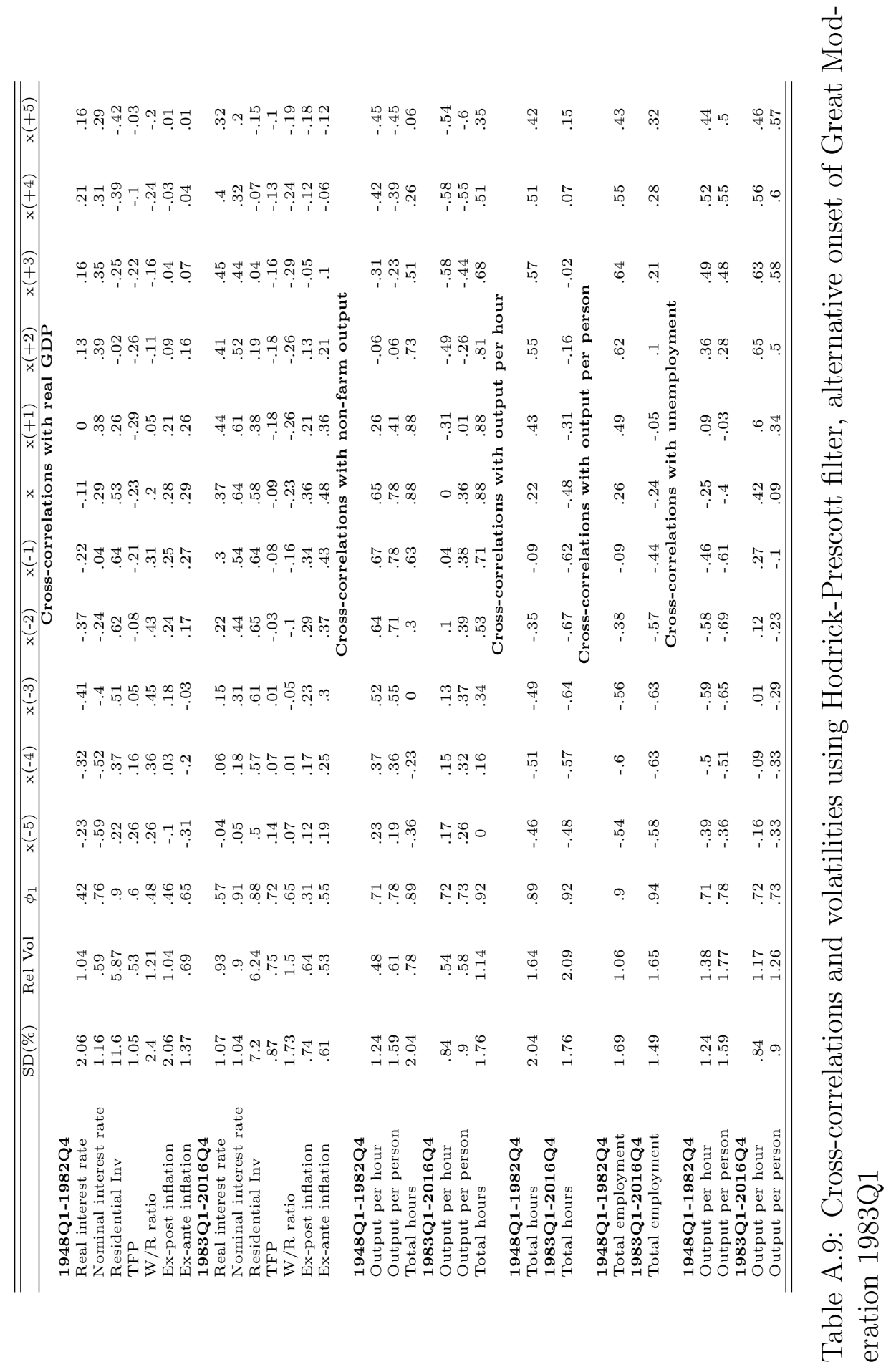




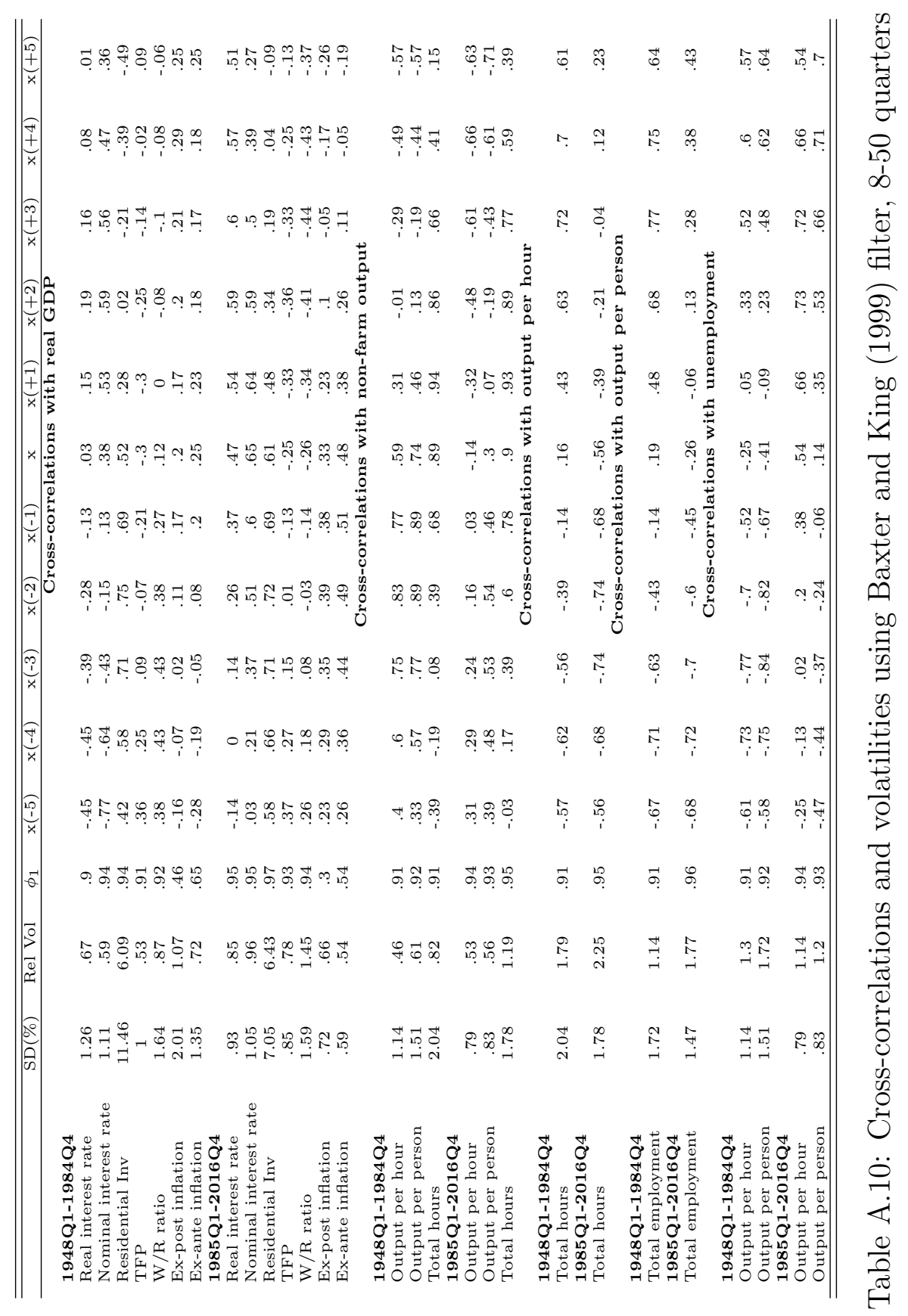




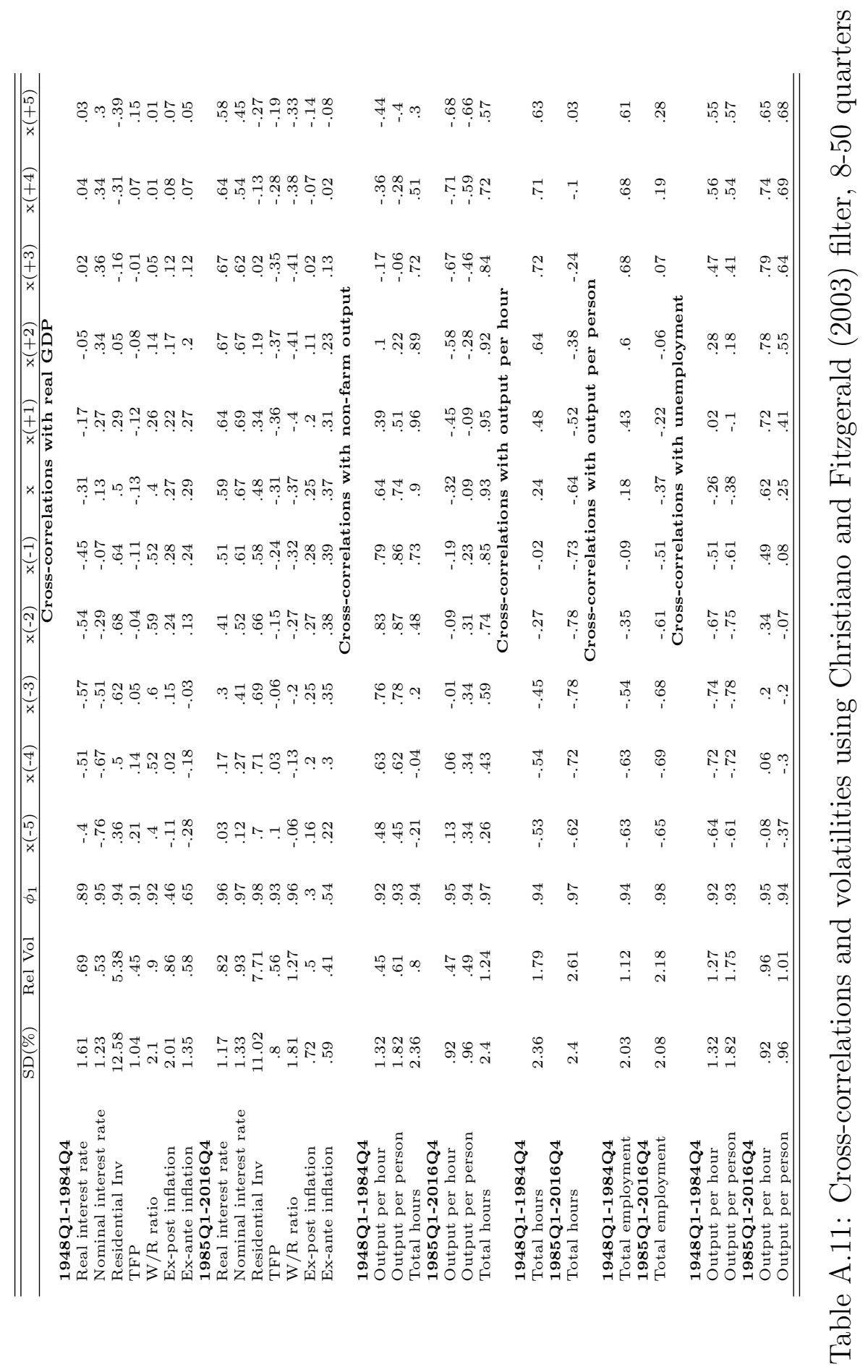




\section{A.9 Robustness to standardized volatility}

Forbes and Rigobon (2002) highlighted that correlation coefficients may be biased if significant changes in volatility occur over time. Since we are examining subsamples consisting of pre- and post Great Moderation which coincides with declining macroeconomic volatility, we provide a robustness check to ensure that the shifts we highlight are not driven by this potential bias.

To address these concerns, we follow a procedure highlighted in Stock and Watson (2002). First, we standardize the volatility of all variables such that they have a variance equal to $1 \rightarrow X_{t}=\frac{x_{t}}{\sigma_{x}^{2}}$. In Table A.12 we standardize the volatility of the entire sample and recompute the cross-correlations.

In Table A.13 we again standardize the volatility, but in this instance we standardize each subsample (1948I:1984IV and 1985I:2016IV) to have unit variance. If the shifts in cross-correlations were the result of volatility changes these patterns would differ from those discussed in the results of the paper. These results suggest that the changes in cross-correlations are not the result of changes in volatility. 


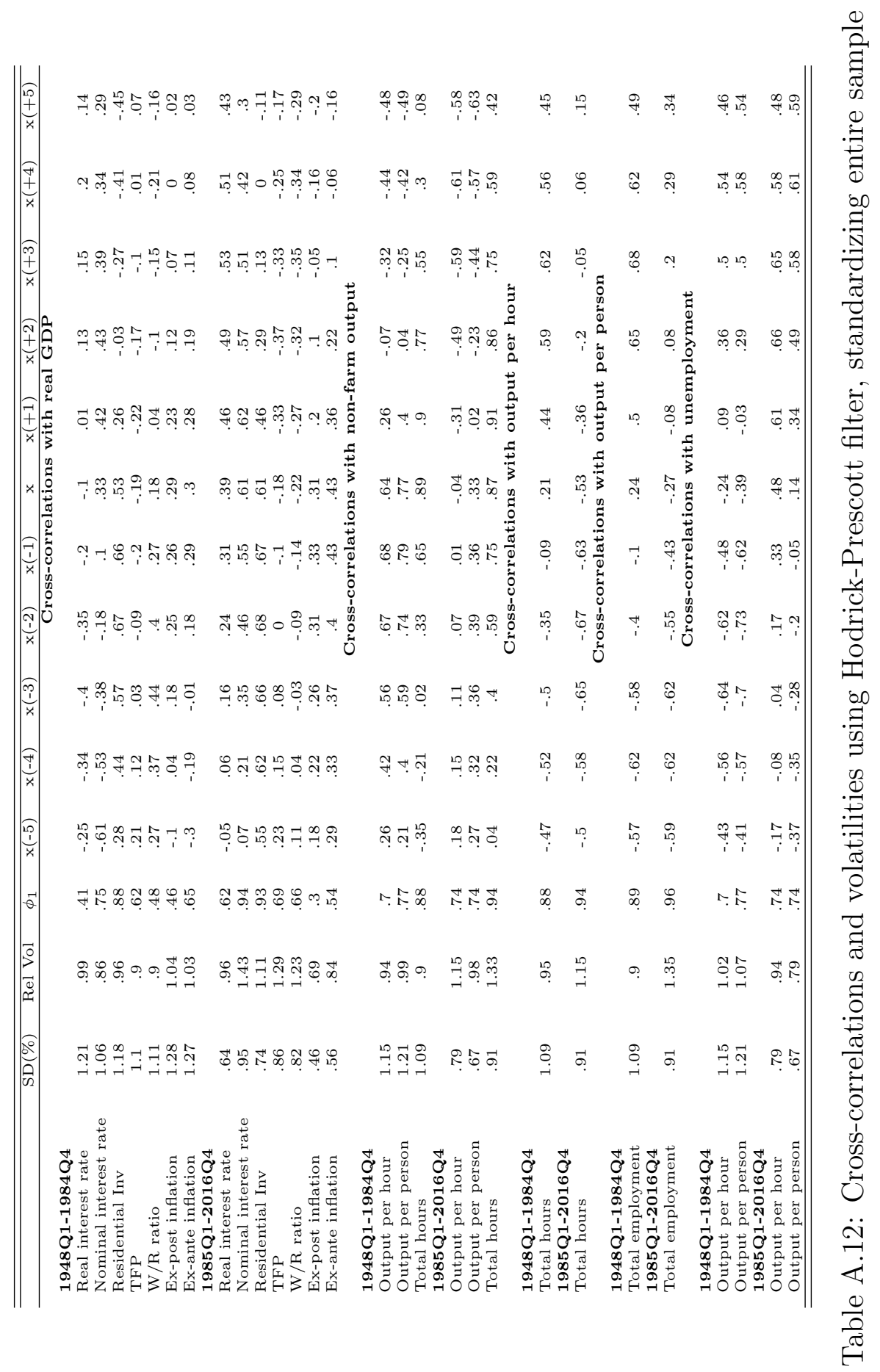




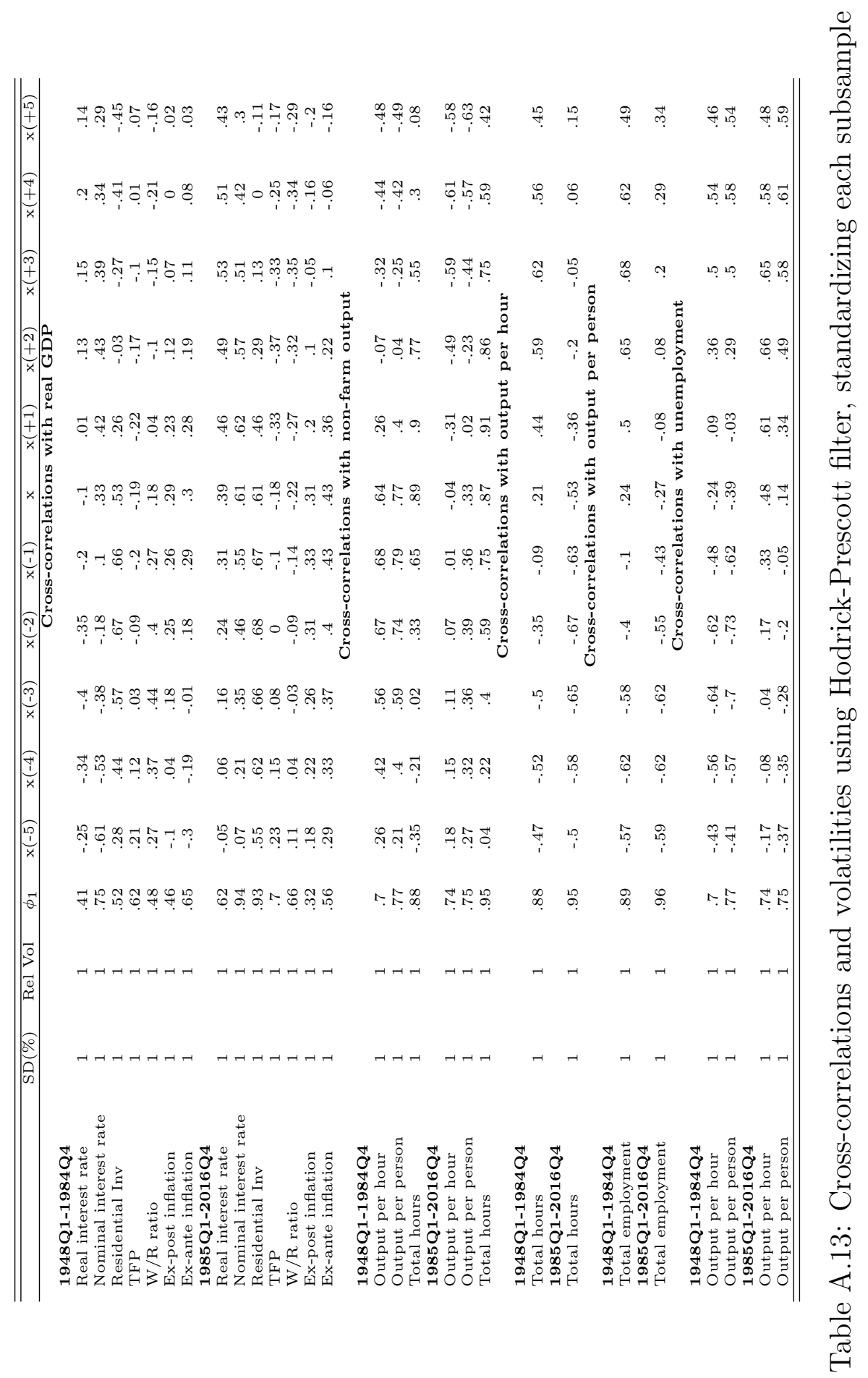




\section{A.10 Filtering on subsamples}

Table A.14 reports cross-correlations when applying the Hodrick-Prescott filter to each subsample. The baseline case in the paper applies the HP-filter to the entire sample prior to examining cross-correlations in each subsample.

\section{A.11 Demographic adjusted productivity}

Table A.15 reports cross-correlations when using demographic adjusted hours in computing output per hour. 


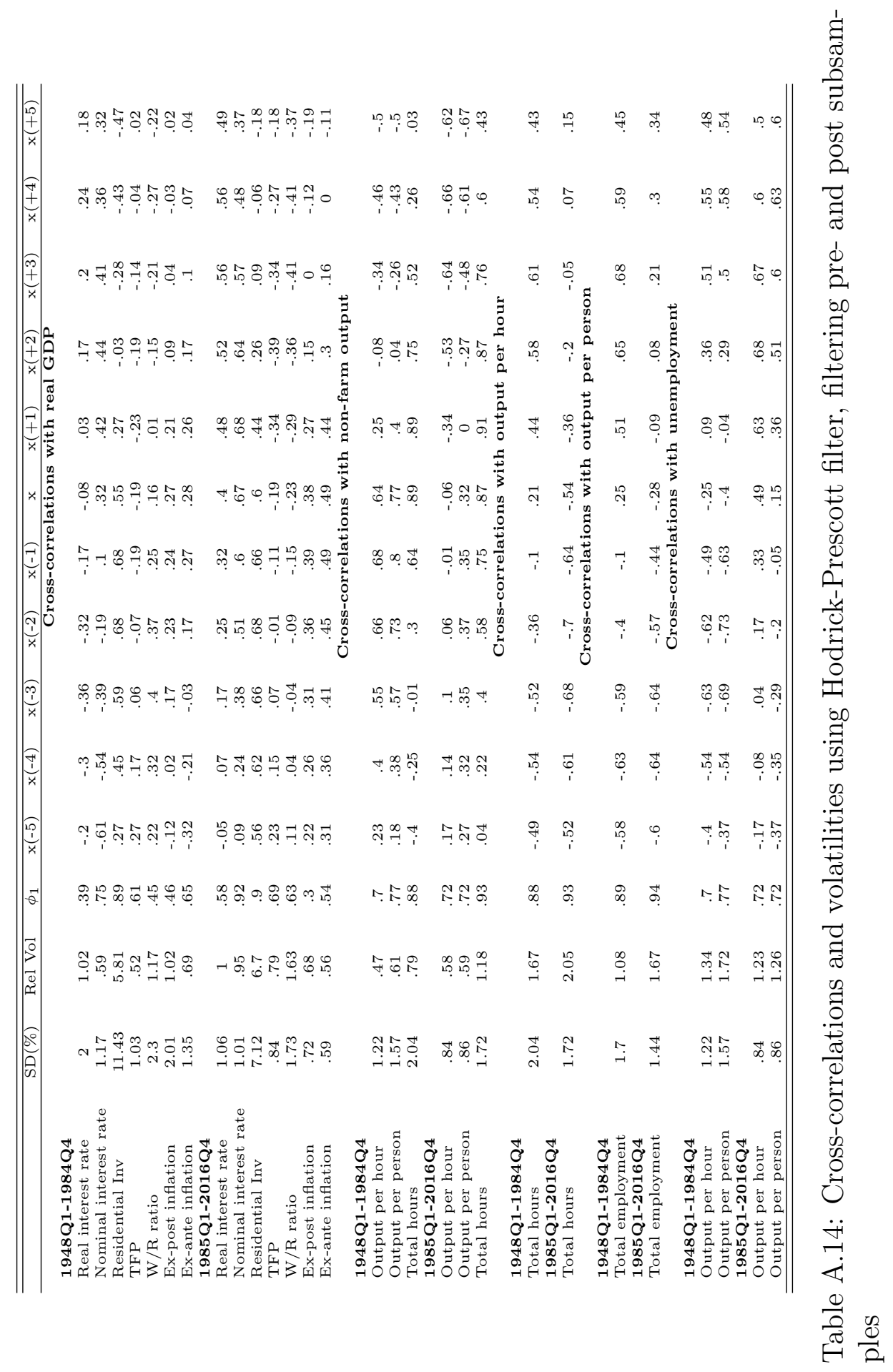




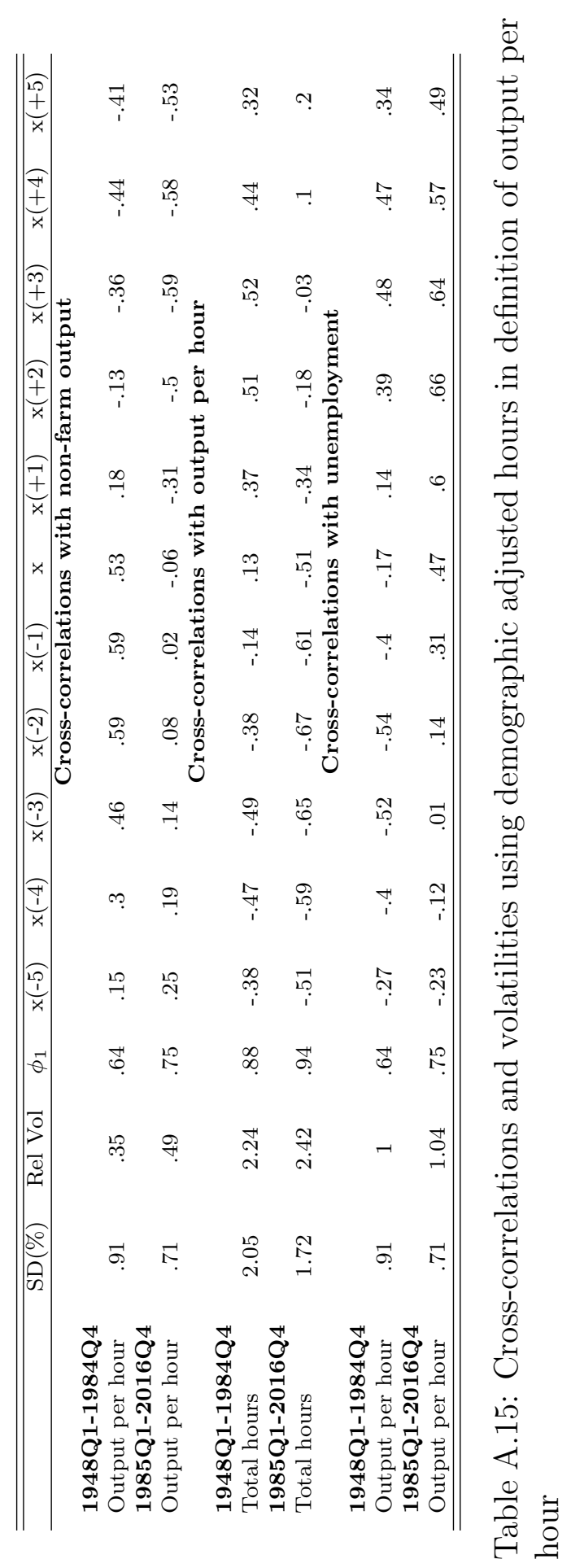




\section{A.12 Jordá, Schularick, and Taylor (2016)}

The following tables report cross-correlations by country using Jordà et al. (2016)'s dataset. We report cross-correlations for both growth rates and HP filtered data. We use real GDP per capita as our measure of output. We define credit as the total real loans per capita, which we compute by dividing total loans by the consumer price index and country population. Prior to filtering, we take the logs of both variables. We use a smoothing parameter of $\lambda=6.25$ in detrending, as suggested by Ravn and Uhlig (2002). We examine two time periods, 1948-1984 and 1985-2013.

\section{Cross-correlations for growth rates}

\begin{tabular}{lccccc}
\hline \hline & $\mathrm{x}(-2)$ & $\mathrm{x}(-1)$ & $\mathrm{x}$ & $\mathrm{x}(+1)$ & $\mathrm{x}(+2)$ \\
\hline Australia & -.14 & .14 & .5 & .21 & -.31 \\
Belgium & .17 & .47 & .23 & .21 & -.03 \\
Canada & .03 & .12 & .56 & .07 & .02 \\
Denmark & 0 & .26 & .58 & .27 & .1 \\
Finland & .1 & -.03 & .53 & .38 & -.18 \\
France & .26 & .52 & .35 & -.07 & .06 \\
Germany & .36 & .37 & .79 & .5 & .15 \\
Italy & .17 & .41 & .43 & .32 & .24 \\
Japan & .34 & .52 & .45 & .25 & .21 \\
Netherlands & -.27 & .31 & .55 & .28 & .05 \\
Norway & -.06 & .37 & .17 & -.2 & -.23 \\
Portugal & .06 & .43 & .6 & .35 & .18 \\
Spain & .31 & .44 & .65 & .44 & .3 \\
Sweden & .04 & .28 & .44 & -.02 & -.11 \\
Switzerland & .25 & .4 & .47 & -.17 & -.28 \\
UK & -.44 & .09 & .48 & -.03 & -.45 \\
USA & -.2 & .23 & .68 & -.1 & -.21 \\
\hline \hline
\end{tabular}

Table A.16: Cross-correlations between growth rate of real gdp per capita and leads/lags of real credit per capita. Data from 1948-1984. 


\begin{tabular}{lccccc}
\hline \hline & $\mathrm{x}(-2)$ & $\mathrm{x}(-1)$ & $\mathrm{x}$ & $\mathrm{x}(+1)$ & $\mathrm{x}(+2)$ \\
\hline Australia & -.48 & -.41 & .31 & .4 & .32 \\
Belgium & -.25 & .29 & .61 & .3 & .15 \\
Canada & -.42 & -.07 & .19 & .04 & -.01 \\
Denmark & -.26 & .15 & .48 & .51 & .29 \\
Finland & -.14 & .18 & .45 & .53 & .45 \\
France & -.26 & -.02 & .46 & .45 & .09 \\
Germany & .24 & .19 & .02 & .04 & -.07 \\
Italy & -.09 & .19 & .59 & .36 & .37 \\
Japan & .44 & .34 & .36 & .4 & .32 \\
Netherlands & .47 & .54 & .47 & .39 & .15 \\
Norway & -.37 & -.11 & .35 & .51 & .36 \\
Portugal & -.14 & .08 & .3 & .33 & .25 \\
Spain & .04 & .41 & .66 & .6 & .45 \\
Sweden & -.27 & -.03 & .38 & .46 & .37 \\
Switzerland & .14 & .37 & .47 & .39 & .06 \\
UK & -.04 & .29 & .59 & .81 & .65 \\
USA & .08 & .32 & .65 & .42 & .13 \\
\hline \hline
\end{tabular}

Table A.17: Cross-correlations between growth rate of real gdp per capita and leads/lags of real credit per capita. Data from 1985-2013.

\section{Cross-correlations for HP filtered data}

\begin{tabular}{lccccc}
\hline \hline & $\mathrm{x}(-2)$ & $\mathrm{x}(-1)$ & $\mathrm{x}$ & $\mathrm{x}(+1)$ & $\mathrm{x}(+2)$ \\
\hline Australia & -.29 & .14 & .57 & .21 & -.44 \\
Belgium & .16 & .5 & .28 & .09 & -.28 \\
Canada & -.07 & .12 & .53 & .04 & -.15 \\
Denmark & -.31 & .13 & .6 & .23 & -.13 \\
Finland & -.03 & .12 & .6 & .38 & -.26 \\
France & .18 & .47 & .12 & -.52 & -.44 \\
Germany & -.19 & -.08 & .63 & .24 & -.3 \\
Italy & -.31 & .2 & .41 & .28 & .1 \\
Japan & -.1 & .33 & .38 & .06 & -.04 \\
Netherlands & -.39 & .32 & .68 & .29 & -.19 \\
Norway & -.02 & .52 & .35 & -.07 & -.18 \\
Portugal & -.33 & .23 & .51 & .26 & .04 \\
Spain & -.03 & .25 & .52 & .13 & -.17 \\
Sweden & -.16 & .36 & .42 & -.23 & -.43 \\
Switzerland & .28 & .48 & .44 & -.21 & -.47 \\
UK & -.6 & .07 & .59 & .13 & -.37 \\
USA & -.25 & .34 & .8 & 0 & -.35 \\
\hline \hline
\end{tabular}

Table A.18: Cross-correlations between HP filtered real gdp per capita and leads/lags of HP filtered real credit per capita. Data from 1948-1984. 


\begin{tabular}{lccccc}
\hline \hline & $\mathrm{x}(-2)$ & $\mathrm{x}(-1)$ & $\mathrm{x}$ & $\mathrm{x}(+1)$ & $\mathrm{x}(+2)$ \\
\hline Australia & -.66 & -.52 & .34 & .63 & .32 \\
Belgium & -.28 & .34 & .74 & .4 & .04 \\
Canada & -.36 & .18 & .47 & .25 & -.04 \\
Denmark & -.37 & .08 & .54 & .64 & .33 \\
Finland & -.29 & .13 & .49 & .56 & .36 \\
France & -.36 & .04 & .66 & .66 & .13 \\
Germany & .24 & .21 & -.01 & -.07 & -.16 \\
Italy & -.44 & -.04 & .43 & .12 & .07 \\
Japan & -.02 & -.24 & -.33 & -.03 & .09 \\
Netherlands & .44 & .51 & .3 & .09 & -.17 \\
Norway & -.45 & -.09 & .54 & .82 & .5 \\
Portugal & -.19 & .15 & .52 & .56 & .39 \\
Spain & -.02 & .52 & .77 & .51 & .11 \\
Sweden & -.33 & -.02 & .46 & .53 & .31 \\
Switzerland & .15 & .48 & .55 & .31 & -.23 \\
UK & -.6 & -.12 & .48 & .85 & .52 \\
USA & .03 & .42 & .78 & .47 & -.05 \\
\hline \hline
\end{tabular}

Table A.19: Cross-correlations between HP filtered real gdp per capita and leads/lags of HP filtered real credit per capita. Data from 1985-2013. 


\section{Bibliography}

Azariadis, C., Kaas, L. and Wen, Y.: 2016, Self-fulfilling credit cycles, Review of Economic Studies 83, 1364-1405.

Backus, D. K., Kehoe, P. J. and Kydland, F. E.: 1992, International real business cycles, American Economic Review 100(4), 745-775.

Backus, D. K., Kehoe, P. J. and Kydland, F. E.: 1994, Dynamics of the trade balance and the terms of trade: The J-curve?, American Economic Review 84(1), 84-103.

Barsky, R. B. and Sims, E. R.: 2012, Information, animal spirits, and the meaning of innovations in consumer confidence, American Economic Review 102(4), 1343-77.

Basu, S. and Bundick, B.: 2017, Uncertainty shocks in a model of effective demand, Econometrica 85(3), 937-958.

Baxter, M. and King, R. G.: 1999, Measuring business cycles: Approximate band-pass filters for economic time series, The Review of Economics and Statistics 81(4), 575-593.

Beaudry, P., Galizia, D. and Portier, F.: 2017, Reconciling Hayek's and Keynes' views of recessions, Review of Economic Studies 01, 1-38.

Beaudry, P. and Guay, A.: 1996, What do interest rates reveal about the functioning of real business cycle models?, Journal of Economic Dynamics and Control 20, 1661-1682.

Boldrin, M., Christiano, L. J. and Fisher, J. D. M.: 2001, Habit persistence, asset returns, and the business cycle, American Economic Review 91(1), 149-166. 
Burnside, C. and Eichenbaum, M. S.: 1993, Factor hoarding and the propagation of business cycle shocks, Working Paper 4675, NBER.

Chari, V. V., Christiano, L. J. and Eichenbaum, M.: 1995, Inside money, outside money, and short-term interest rates, Journal of Money, Credit and Banking 27(4), 1354-1386.

Christiano, L. J. and Fitzgerald, T. J.: 2003, The band pass filter, International Economic Review 44(2), 435-465.

Christiano, L. J., Motto, R. and Rostagno, M.: 2014, Risk shocks, American Economic Review 104(1), 27-65.

Cochrane, J. H.: 2005, Asset Pricing, Princeton University Press.

Dotsey, M., Lantz, C. and Scholl, B.: 2003, The behavior of the real rate of interest, Journal of Money, Credit and Banking 35(1), 91-110.

Fernald, J. G.: 2014, A quarterly, utilization-adjusted series on total factor productivity, Working Paper 2012-19, Federal Reserve Bank of San Francisco.

Fiorito, R. and Kollintzas, T.: 1994, Stylized facts of business cycles in the $\mathrm{g} 7$ from a real business cycle perspective, European Economic Review 38(2), 235-269.

Fisher, J.: 2007, Why Does Household Investment Lead Business Investment over the Business Cycle, Journal of Political Economy 115(1), 141-68.

Forbes, K. and Rigobon, R.: 2002, No contagion, only interdependence: Measuring stock market comovements, Journal of Finance 57(5), 2223-2261.

Galí, J. and van Rens, T.: 2020, The Vanishing Procyclicality of Labour Productivity, The Economic Journal 131(633), 302-326. 
Gomme, P., Kydland, F. and Rupert, P.: 2001, Home production meets time to build, Journal of Political Economy 109, 1115-131.

Hamilton, J. D.: 2018, Why you should never use the hodrick-prescott filter, The Review of Economics and Statistics 100(5), 831-843.

Hornstein, A. and Praschnik, J.: 1997, Intermediate inputs and sectoral comovement in the business cycle, Journal of Monetary Economics 40, 573595.

Iacoviello, M.: 2005, House prices, borrowing constraints, and monetary policy in the business cycle, American Economic Review 95(3), 739-764.

Jordà, Ò., Schularick, M. and Taylor, A. M.: 2016, Macrofinancial history and the new business cycle facts, NBER Macroeconomics Annual 2016, Volume 31, NBER Chapters, National Bureau of Economic Research, Inc, pp. 213-263.

Khan, H. and Rouillard, J.-F.: 2017, Why does Household Investment Lead Business Investment Over the Business Cycle: Comment, Carleton Economics Paper 17-04, Carleton University and University of Sherbrooke.

Khan, H. and Rouillard, J.-F.: 2018, Household borrowing constraints and residential investment dynamics, Journal of Economic Dynamics and Control 95, 1-18.

King, R. G. and Watson, M. W.: 1996, Money, Prices, Interest Rates and the Business Cycle, The Review of Economics and Statistics 78(1), 35-53.

Kydland, F., Rupert, P. and Sustek, R.: 2016, Housing dynamics over the business cycle, International Economic Review 57(4), 1149-1177.

Mertens, E.: 2010, Structural shocks and the comovements between output and interest rates, Journal of Economic Dynamics and Control 34, 11711186. 
Ravn, M. O. and Uhlig, H.: 2002, On adjusting the Hodrick-Prescott filter for the frequency of observations, Review of Economics and Statistics 84(2), 371-375.

Smets, F. and Wouters, R.: 2007, Shocks and frictions in US business cycles: A Bayesian DSGE approach, American Economic Review 97(3), 586-606.

Stock, J. H. and Watson, M. W.: 2002, Macroeconomic forecast using diffusion indexes, Journal of Business \& Economic Statistics 20(2).

Wolters, M. H.: 2018, How the baby boomers' retirement wave distorts model-based output gap estimates, Journal of Applied Econometrics 33(5), 680-689.

Wu, J. C. and Xia, F. D.: 2016, Measuring the macroeconomic impact of monetary policy at the zero lower bound, Journal of Money, Credit and Banking 48(2-3), 253-291. 


\section{Appendix B}

\section{Appendix to Monetary policy uncertainty and the cyclicality of interest rates}

\section{B.1 Proofs of Propositions}

\section{Proposition 1}

Let $\mathbf{K}^{\prime}$ be a submatrix of the Kalman gain associated with predetermined variables and $\mathbf{K}^{\prime \prime}$ a submatrix of the Kalmain gain associated with exogenous variables (i.e., shocks). As $\sigma_{\eta_{\pi}} \rightarrow \infty$ and $\sigma_{\eta_{y}} \rightarrow \infty, \mathbf{K}^{\prime} \rightarrow 0$. Let $\mathbf{X}_{t \mid t}^{\prime}$ be the time $t$ expectation of predetermined variables. Then in response to a demand shock from the steady state (i.e., $\mathbf{X}_{0}=\mathbf{0}$ ), it is straightforward to show that predetermined variables evolve according to,

$$
\mathbf{X}_{t \mid t}^{\prime}=\mathbf{X}_{t \mid t-1}^{\prime}+\mathbf{K}^{\prime}\left(\mathbf{Z}_{t}-\mathbf{Z}_{t \mid t-1}\right)
$$

Since $\mathbf{X}_{1 \mid 0}=\mathbf{0}$ and $\mathbf{K}^{\prime}=\mathbf{0}$, it is straightforward to iterate equation (B.1) to show that $\mathbf{X}_{t \mid t}^{\prime}=0$ for all $t$. Next, note that the rational expectations 
equilibria (REE) solution is independent of the noise shocks. Then it can be shown that,

$$
\mathbf{X}_{2, t \mid t}=\mathbf{G}^{\star} \mathbf{X}_{1, t \mid t}=\mathbf{G}^{\prime \star} \mathbf{X}_{1, t \mid t}^{\prime} .
$$

Then it is straightforward to show by substituting (B.1) into (B.2) that $\mathbf{X}_{2, t \mid t}=\mathbf{0}$ for all $t$. The monetary policy rule can be represented as a function of expected predetermined variables and current values of output and inflation (this representation was used in (2.25)),

$$
i_{t}=\mathbf{F}_{1} \mathbf{X}_{1, t \mid t}+\mathbf{F}_{2} \mathbf{X}_{2, t \mid t} .
$$

It has been shown above that both $\mathbf{X}_{1, t \mid t}$ and $\mathbf{X}_{2, t \mid t}$ are null matrices for all $t$, then the nominal interest rate is equal to zero for all $t$ in response to a demand shock. Since the nominal rate is zero for all $t$, the $\operatorname{Cov}\left(y_{t}, i_{t}\right)=0$ and the associated conditional correlation $\operatorname{Corr}\left(y_{t}, i_{t}\right)=0$. Additionally, since the ex-post real interest rate is given by $r_{t}=i_{t}-\pi_{t+1}$, a fixed nominal interest rate implies that real interest rate is entirely determined by $-\pi_{t+1}$. A positive demand shock introduces a positive output gap and increases inflation. Then the conditional correlation between output and the real interest rate is determined entirely by $\operatorname{Corr}\left(y_{t},-\pi_{t+1}\right)$ which belongs to interval $(0,-1]$. 


\section{B.2 Derivation of the economic model}

The model is a relatively standard 3 equation New Keynesian model. I describe the derivation of the log linearized model below.

\section{B.2.1 Households}

There are an infinite number of identical households distributed over the

unit interval. This representative household has the following maximization problem,

$$
\operatorname{Max}_{c_{t+\tau}, l_{t+\tau}, b_{t+\tau}} E_{t} \sum_{\tau=0}^{\infty} \beta^{\tau} b_{t+\tau}\left[\log \left(c_{t+\tau}-h \bar{c}_{t+\tau-1}\right)-v \frac{l_{t+\tau}^{1+\eta}}{1+\eta}\right]
$$

where $\beta \in(0,1)$ is the discount factor, $c_{t}$ is consumption in period $t, h$ is the external habit formation parameter which is proportional to past aggregate consumption, $l_{t}$ is labour supplied in period $t$, and $\eta$ governs the elasticity of labour supplied. The representative household faces the following budget constraint,

$$
b_{t}+c_{t}=\left(\frac{1+i_{t-1}}{1+\pi_{t}}\right) b_{t-1}+w_{t} l_{t}+\Pi_{t}
$$

The maximization problem yields the following first order conditions,

$$
\begin{array}{r}
\lambda_{t}=\frac{b_{t}}{c_{t}-h c_{t-1}} \\
1=\beta E_{t}\left[\left(\frac{\lambda_{t+1}}{\lambda_{t}}\right)\left(\frac{1+i_{t}}{1+\pi_{t+1}}\right)\right] \\
b_{t} v l_{t}^{\eta}=\lambda_{t} w_{t}
\end{array}
$$




\section{B.2.2 Final goods firms}

Final goods firms operate in a perfectly competitive environment and package intermediate goods into a final aggregate good, $y_{t}$, sold at price $p_{t}$. Their maximization problem is given by,

$$
\operatorname{Max}_{y_{t}(i)} p_{t} y_{t}-\int_{0}^{1} p_{t}(i) y_{t}(i) d i
$$

where,

$$
y_{t}=\left(\int_{0}^{1} y_{t}(i)^{\frac{\epsilon_{t}-1}{\epsilon_{t}}} d i\right)^{\frac{\epsilon_{t}}{\epsilon_{t}-1}}
$$

where $p_{t}(i)$ and $y_{t}(i)$ are prices and quantities of intermediate goods, and $\epsilon_{t}$ is the elasticity of substitution between intermediate goods. The maximization problem yields the standard downward sloping demand function for intermediate firm $i$ 's input, which is a function of its relative price and the price elasticity of demand,

$$
y_{t}(i)=\left(\frac{p_{t}(i)}{p_{t}}\right)^{-\epsilon} y_{t}
$$

and implies an aggregate price index given by,

$$
p_{t}=\left(\int_{0}^{1} p_{t}(i)^{1-\epsilon}\right)^{\frac{1}{1-\epsilon}}
$$




\section{B.2.3 Intermediate goods firms}

There is a continuum of intermediate goods producer on the unit interval $i \in[0,1]$ who produce goods using a constant returns to scale technology and minimize costs subject to meeting demand. In this setup, wages are common to all firms. The minimization problem is given by,

$$
\begin{array}{r}
\operatorname{Min}_{l_{t}(i)} w_{t} l_{t}(i)-\Phi \quad \text { subject to } \\
a_{t} l_{t}(i) \geq\left(\frac{p_{t}(i)}{p_{t}}\right)^{-\epsilon} y_{t}
\end{array}
$$

which yields a nominal marginal cost equation given by,

$$
\chi_{t}=\frac{w_{t}}{a_{t}}
$$

Intermediate goods producers operate in a monopolistically competitive environment and set prices for the good they produce. Prices are fixed for a stochastic number of periods following Calvo (1983). In each period intermediate goods firms have a probability to adjust their price given by $\theta$. Thus optimal price setting takes into account not only the current optimal price, but the possibility that the firm may not be able to adjust its price for a long time. A firm setting its price optimally in period $t$ then maximizes real profits given by the following,

$$
\operatorname{Max}_{p_{t}(i)} E_{t} \sum_{\tau=0}^{\infty} \theta^{\tau}\left\{\Lambda_{t, t+\tau}\left(\frac{p_{t}}{p_{t+\tau}}\right)\left(p_{t}(i)\left(\frac{p_{t}(i)}{p_{t+\tau}}\right)^{-\epsilon} y_{t+\tau}-\chi_{t+\tau}\left(\frac{p_{t}(i)}{p_{t+\tau}}\right)^{-\epsilon} y_{t+\tau}\right)\right\}
$$


where $\Lambda_{t, t+\tau}$ is a stochastic discount factor given by $\Lambda_{t, t+\tau}=\beta^{\tau}\left(\frac{u^{\prime}\left(c_{t}\right)}{u^{\prime}\left(c_{t+\tau}\right)}\right)$. The firms optimal price is given by,

$$
p_{t}(i)=\left(\frac{\epsilon}{\epsilon-1}\right) \frac{E_{t} \sum_{\tau=0}^{\infty} \theta^{\tau} \Lambda_{t, t+\tau} \chi_{t+\tau}^{R} p_{t+\tau}^{\epsilon} y_{t+\tau}}{E_{t} \sum_{\tau=0}^{\infty} \theta^{\tau} \Lambda_{t, t+\tau} p_{t+\tau}^{\epsilon-1} y_{t+\tau}}
$$

where $\chi_{t+\tau}^{R} \equiv \frac{\chi_{t+\tau}}{p_{t+\tau}}$ is the real marginal cost in each period $t+\tau$.

\section{B.2.4 Monetary policy}

Monetary policy is conducted according to the following Taylor type rule,

$$
\frac{i_{t}}{i^{\star}}=\left(\frac{i_{t-1}}{i^{\star}}\right)^{\rho_{i}}\left[\left(\frac{\pi_{t}}{\pi^{\star}}\right)^{\alpha_{\pi}}\left(\frac{Y_{t}}{Y_{t}^{F}}\right)^{\alpha_{y}}\right]^{1-\rho_{i}} \epsilon_{t}^{m}
$$

where $\rho_{i}$ is the degree of interest rate smoothing, $i^{\star}$ is the steady state nominal interest rate, and $\epsilon^{m}$ is a monetary policy shock.

\section{B.2.5 Equilibrium and Log-linearization}

In equilibrium, goods market clearing imposes that all output is consumed, $y_{t}=c_{t}$. Then the intertemporal IS equation becomes,

$$
\left.\widetilde{y}_{t}=\frac{h}{1+h} \widetilde{y}_{t-1}+\frac{1}{1+h} E_{t} \widetilde{y}_{t+1}-\frac{1-h}{1+h} \widetilde{i}_{t}-E_{t} \widetilde{\pi}_{t+1}\right)+\frac{1-h}{1+h} \widetilde{v}_{t}^{y}\left(1-\rho_{y}\right)
$$

where $\frac{1-h}{1+h} \widetilde{v}_{t}^{y}\left(1-\rho_{y}\right) \equiv \frac{1-h}{1+h}\left(\widetilde{b}_{t}-E_{t} \widetilde{b}_{t+1}\right)$. Output fluctuations are represented in percentage deviations from steady state (i.e., $\frac{x_{t}-\bar{x}}{x}$ ), while fluctuations in interest rates and inflation are represented in percentage point deviation from 
steady state (i.e., $x_{t}-\bar{x}$ ). The optimal pricing equation given in (B.17) can be rewritten as in the typical NKPC form. First let,

$$
X_{1, t}=E_{t} \sum_{\tau=0}^{\infty}(\beta \theta)^{\tau} c_{t+\tau}^{-1} \chi_{t+\tau}^{R} p_{t+\tau}^{\epsilon} y_{t+\tau}
$$

and rewrite in the following manner,

$$
X_{1, t}=c_{t}^{-1} \chi_{t}^{R} p_{t}^{\epsilon} y_{t}+\beta \theta X_{1, t+1}
$$

Similarly, the denominator of the optimal price setting equation can be written as,

$$
X_{2, t}=c_{t}^{-1} p_{t}^{\epsilon-1} y_{t}+\beta \theta X_{2, t+1}
$$

The optimal price reset equation can then be written as,

$$
p_{t}(i)=\left(\frac{\epsilon}{\epsilon-1}\right) p_{t} \frac{x_{1, t}}{x_{2, t}}
$$

where $x_{1, t}=\frac{X_{1, t}}{p_{t}^{\epsilon}}$ and $x_{2, t}=\frac{X_{2, t}}{p_{t}^{\epsilon-1}}$. The optimal price reset equation can be written in terms of inflation by dividing both sides by $p_{t-1}$,

$$
1+\pi_{t}^{\#}=\left(\frac{\epsilon}{\epsilon-1}\right)\left(1+\pi_{t}\right) \frac{x_{1, t}}{x_{2, t}},
$$

where $\pi^{\#}$ is the inflation based on the optimal price change. Log-linearizing the above equation, it is straightforward to show that, 


$$
\tilde{\pi}_{t}^{\#}=\widetilde{\pi}_{t}+\widetilde{x}_{1, t}-\widetilde{x}_{2, t}
$$

where, in a zero inflation steady state, $\widetilde{x}_{1, t}$ and $\widetilde{x}_{2, t}$ are given by,

$$
\begin{array}{r}
\widetilde{x}_{1, t}=(1-\beta \theta) \widetilde{\chi}_{t}^{R}+\beta \theta \widetilde{x}_{1, t+1}+\beta \theta \epsilon \widetilde{\pi}_{t+1}, \\
\widetilde{x}_{2, t}=\beta \theta \widetilde{x}_{2, t+1}+\beta \theta(\epsilon-1) \widetilde{\pi}_{t+1} .
\end{array}
$$

Substituting (B.26) and (B.27) into (B.25) and using the identity that $\widetilde{\pi}_{t}^{\#}=$ $\frac{1}{1-\theta} \widetilde{\pi}_{t}$, we arrive at the following,

$$
\begin{array}{r}
\frac{\theta}{1-\theta} \pi_{t}=(1-\beta \theta) \widetilde{\chi}_{t}^{R}+\beta \theta \underbrace{\left(\widetilde{x}_{1, t+1}-\widetilde{x}_{2, t+1}\right)}_{\frac{\theta}{1-\theta} E_{t} \widetilde{\pi}_{t+1}}+\beta \theta \widetilde{\pi}_{t+1}, \\
\pi_{t}=\frac{(1-\beta \theta)(1-\theta)}{\theta} \widetilde{\chi}_{t}^{R}+\beta E_{t} \widetilde{\pi}_{t+1} .
\end{array}
$$

As a final step I rewrite the NKPC in terms of deviations of output its flexible price level. This can be done by log linearizing the intratemporal condition given in (B.8) and the production function given in (B.14) and substituting these two into the log linearized marginal cost condition given in (B.15). After making these substitutions, one can arrive at the following,

$$
\widetilde{\chi}_{t}=\frac{\eta(1-\varphi)(1-h)+1}{(1-h)} \widetilde{y}_{t}-\frac{h}{1-h} \widetilde{y}_{t-1}-(1+\eta) \widetilde{a}_{t},
$$

and in the scenario where prices are completely flexible, marginal costs are constant. This yields the following, 


$$
\tilde{a}_{t}=\frac{\eta(1-\varphi)(1-h)+1}{(1-h)(1+\eta)} \tilde{y}_{t}^{F}-\frac{h}{(1-h)(1+\eta)} \tilde{y}_{t-1}^{F} .
$$

Substituting (B.30) and (B.31) into (B.29) yields a standard New Keynesian Phillips Curve relating inflation to the current and past output gap and expected future inflation,

$$
\pi_{t}=\kappa_{1}\left(\tilde{y}_{t}-\tilde{y}_{t}^{F}\right)-\kappa_{2}\left(\tilde{y}_{t-1}-\tilde{y}_{t-1}^{F}\right)+\beta E_{t} \pi_{t+1}
$$

where,

$$
\begin{array}{r}
\kappa_{1}=\frac{(1-\beta \theta)(1-\theta)}{\theta} \frac{\eta(1-\varphi)(1-h)+1}{1-h} \\
\kappa_{2}=\frac{(1-\beta \theta)(1-\theta)}{\theta} \frac{h}{1-h}
\end{array}
$$

Lastly, log linearizing the Taylor rule yields the following,

$$
\widetilde{i}_{t}=\rho_{i} \tilde{i}_{t-1}+\left(1-\rho_{i}\right)\left\{\alpha_{\pi} \widetilde{\pi}_{t}+\alpha_{y}\left(\widetilde{y}_{t}-\widetilde{y}_{t}^{F}\right)\right\}+v_{t}^{R}
$$

In summary, the model dynamics are represented by the following equations, 


$$
\begin{gathered}
\widetilde{y}_{t}=\frac{h}{1+h} \widetilde{y}_{t-1}+\frac{1}{1+h} E_{t} \widetilde{y}_{t+1}-\frac{1-h}{1+h}\left(\widetilde{i}_{t}-E_{t} \widetilde{\pi}_{t+1}\right)+\frac{1-h}{1+h} \widetilde{v}_{t}^{y}\left(1-\rho_{y}\right) \\
\pi_{t}=\kappa_{1}\left(\tilde{y}_{t}-\tilde{y}_{t}^{F}\right)-\kappa_{2}\left(\tilde{y}_{t-1}-\tilde{y}_{t-1}^{F}\right)+\beta E_{t} \pi_{t+1}+v_{t}^{\pi} \\
\widetilde{i}_{t}=\rho_{i} \widetilde{i}_{t-1}+\left(1-\rho_{i}\right)\left\{\alpha_{\pi} \widetilde{\pi}_{t}+\alpha_{y}\left(\widetilde{y}_{t}-\widetilde{y}_{t}^{F}\right)\right\}+v_{t}^{m}
\end{gathered}
$$

where I also admit for potential supply disturbances in the NKPC given by $v_{t}^{\pi}$. 


\section{B.3 Model setup and solution}

In the following I describe the matrices that make up the following matrix form representation of the model and are used to solve the filtering problem of the central bank. The matrix form of the model is given by,

$$
\mathbf{A}_{0}\left[\begin{array}{c}
\mathbf{X}_{1, t+1} \\
E_{t} \mathbf{X}_{2, t+1}
\end{array}\right]=\mathbf{A}_{1}\left[\begin{array}{l}
\mathbf{X}_{1, t} \\
\mathbf{X}_{2, t}
\end{array}\right]+\mathbf{A}_{2}\left[\begin{array}{l}
\mathbf{X}_{1, t \mid t} \\
\mathbf{X}_{2, t \mid t}
\end{array}\right]+\left[\begin{array}{c}
\mathbf{C}_{1} \\
0
\end{array}\right] \boldsymbol{\epsilon}_{t+1}
$$

where $\mathbf{X}_{1, t}$ is the vector of predetermined variables, $\mathbf{X}_{2, t}$ is the vector of forward looking (or jump) variables, and $\boldsymbol{\epsilon}_{t+1}$ is the vector of structural shocks and measurement errors. $\mathbf{X}_{1, t \mid t}$ and $\mathbf{X}_{2, t \mid t}$ are the expected values of the vectors of predetermined variables and jump variables conditional on information at time $t$. To keep notation compact I include the measurement errors in the vector $\mathbf{X}_{1, t}$. These vectors are given by the following,

Based on the above the model can be written in a more compact notation given by,

$$
\left[\begin{array}{c}
\mathbf{X}_{1, t+1} \\
E_{t} \mathbf{X}_{2, t+1}
\end{array}\right]=\mathbf{A}^{1}\left[\begin{array}{l}
\mathbf{X}_{1, t} \\
\mathbf{X}_{2, t}
\end{array}\right]+\mathbf{A}^{2}\left[\begin{array}{l}
\mathbf{X}_{1, t \mid t} \\
\mathbf{X}_{2, t \mid t}
\end{array}\right]+\mathbf{C} \boldsymbol{\epsilon}_{t+1},
$$

where $\mathbf{A}^{1}=\mathbf{A}_{0}^{-1} \mathbf{A}_{1}, \mathbf{A}^{2}=\mathbf{A}_{0}^{-1} \mathbf{A}_{2}$, and $\mathbf{C}=\mathbf{A}_{0}^{-1}\left[\begin{array}{ll}\mathbf{C}_{1} & \mathbf{0}\end{array}\right]^{\prime}$. The solution to the model is then a simple application of the methods shown in Svensson and Woodford (2003). As they show, under the assumption of symmetric partial information the estimation of the partially observed state and the computation of the rational expectations equilibrium can be separated. Thus a linear mapping exists relating the predetermined state variables to the forward looking variables and one can use standard methods of eliminating bubbles to find this solution given by, 


$$
\mathbf{X}_{2, t \mid t}=\mathbf{G}^{\star} \mathbf{X}_{1, t \mid t}
$$

In this paper I use a simple fixed point iteration to solve for the matrix $\mathbf{G}^{\star}$ which satisfies the following

$$
\mathbf{G}=\left(\mathbf{G} \mathbf{A}_{12}-\mathbf{A}_{22}\right)^{-1}\left(\mathbf{A}_{21}-\mathbf{G} \mathbf{A}_{11}\right)
$$

where $\mathbf{A}=\mathbf{A}^{1}+\mathbf{A}^{2}$ and subscripts indicate rows and columns of the predetermined variables and jump variables (e.g., $A_{11}$ are the first $n_{1}$ rows and $n_{1}$ columns of matrix $\mathrm{A}$ and $n_{1}$ is equal to the number of predetermined variables). The model dynamics can then be described by the following system of equations, ${ }^{1}$

$$
\begin{array}{r}
\mathbf{X}_{1, t+1}=\mathbf{H X}_{1, t}+\mathbf{J} \mathbf{X}_{1, t \mid t}+\mathbf{C}_{1} \boldsymbol{\epsilon}_{t+1} \\
\mathbf{X}_{1, t \mid t}=\mathbf{X}_{1, t \mid t-1}+\mathbf{K}\left(\mathbf{Z}_{t}-\mathbf{Z}_{t \mid t-1}\right) \\
\mathbf{Z}_{t}=\mathbf{L} \mathbf{X}_{t}+\mathbf{M} \mathbf{X}_{t \mid t}
\end{array}
$$

where

\footnotetext{
${ }^{1}$ Note that since I carry the measurement error shocks in the state vector, one could alternatively depict the observation equation with an error term. Instead, in this case the matrix $L$ picks the observable and its measurement error from the state vector.
} 


$$
\begin{array}{r}
\mathbf{H}=\mathbf{A}_{11}^{1}-\mathbf{A}_{12}^{1}\left(\mathbf{A}_{22}^{1}\right)^{-1} \mathbf{A}_{21}^{1} \\
\mathbf{J}=\mathbf{A}_{12}^{1}\left[\left(\mathbf{A}_{22}^{1}\right)^{-1} \mathbf{A}_{21}^{1}+\mathbf{G}^{\star}\right]+\mathbf{A}_{11}^{2}+\mathbf{A}_{12}^{2} \mathbf{G}^{\star} \\
\mathbf{L}=\mathbf{D}_{1}^{1}-\mathbf{D}_{2}^{1}\left(\mathbf{A}_{22}^{1}\right)^{-1} \mathbf{A}_{21}^{1} \\
\mathbf{M}=\mathbf{D}_{2}^{1}\left[\left(\mathbf{A}_{22}^{1}\right)^{-1} \mathbf{A}_{21}^{1}+\mathbf{G}^{\star}\right] \\
\mathbf{K}=\mathbf{P L}^{\prime}\left(\mathbf{L} \mathbf{P} \mathbf{L}^{\prime}+\boldsymbol{\sigma}_{v v}^{2}\right)^{-1}
\end{array}
$$

The matrix $\mathbf{P}$ is the covariance matrix for the prediction errors which can be solved as the solution to a Riccati equation (see equation (25) in Svensson and Woodford (2003) for this formula). These equilibrium dynamics can be represented in a more compact fashion (which I use in the code) given by the following,

$$
\underbrace{\left[\begin{array}{c}
\mathbf{X}_{1, t+1} \\
\mathbf{X}_{1, t+1 \mid t+1}
\end{array}\right]}_{\tilde{\mathbf{X}}_{t+1}}=\underbrace{\left[\begin{array}{cc}
\mathbf{H} & \mathbf{J} \\
\mathbf{K L H} & (\mathbf{H}+\mathbf{J})-\mathbf{K L H}
\end{array}\right]}_{\tilde{\mathbf{A}}} \underbrace{\left[\begin{array}{c}
\mathbf{X}_{1, t} \\
\mathbf{X}_{1, t \mid t}
\end{array}\right]}_{\tilde{\mathbf{X}}_{t}}+\underbrace{\left[\begin{array}{c}
\mathbf{C}_{1} \\
\mathbf{K L} \mathbf{C}_{1}
\end{array}\right]}_{\tilde{\mathbf{C}}} \boldsymbol{\epsilon}_{t+1}
$$

and the forward looking variables can be obtained using,

$$
\mathbf{X}_{2, t}=\mathbf{G}^{1} \mathbf{X}_{1, t}+\mathbf{G}^{2} \mathbf{X}_{1, t \mid t}
$$

where,

$$
\begin{array}{r}
\mathbf{G}^{1}=-\left(\mathbf{A}_{22}^{1}\right)^{-1} \mathbf{A}_{21}^{1} \\
\mathbf{G}^{2}=\mathbf{G}^{\star}-\mathbf{G}^{1}
\end{array}
$$

and from the definition of the rational expectations equilibrium, the expected 
value of the forward looking variables is given by,

$$
\mathbf{X}_{2, t \mid t}=\mathbf{G}^{\star} \mathbf{X}_{1, t \mid t}
$$

\section{B.3.1 Computing impulse response functions}

Based on the notation given in equation (B.51), it is straightforward to compute impulse response functions by iterating the state space forward. For example, the state space at a given time $t$ for a structural shock at time $t_{0}$ can be computed from

$$
\tilde{\mathbf{X}}_{t}=\tilde{\mathbf{A}}^{t-1} \tilde{\mathbf{C}} \boldsymbol{\epsilon}_{t_{0}}
$$

and the corresponding values for the forward looking variables and expected forward looking variables can be found using equations (B.52) and (B.55). 


\section{B.4 Data and Estimation}

\section{B.4.1 Data}

To estimate the structural parameters of the model I use data from the Federal Reserve Bank of St. Louis database. The exact FRED codes are below in parentheses. These variables include:

- Gross Domestic Product (GDP).

- Gross Domestic Product Implicit Price Deflator (GDPDEF).

- Effective Federal Funds rate (FEDFUNDS). This measure is converted to quarterly frequency by taking averages.

- Population Level (CNP160V).

It is well known that the population series used is problematic due to irregular updating from census population measures. This causes spikes in the series unrelated to business cycles. To avoid introducing spurious dynamics into my per capita real GDP measure, I use a smoothed value of this population series which is obtained by fitting an HP-filtered trend with a smoothing parameter, $\lambda=10,000$, as suggested by Pfeifer (2020). I use the following variable construction,

$$
\begin{array}{r}
Y_{t}=\log \left(\frac{G D P}{G D P D E F * P O P^{H P}}\right) * 100, \\
\pi_{t}=\log \left(\frac{G D P D E F_{t}}{G D P D E F_{t-1}}\right) * 100, \\
i_{t}=\frac{F E D F U N D S}{4} .
\end{array}
$$

Since I am not explicitly modeling any non-stationary factors I detrend output using a one-sided HP filter with a smoothing parameter, $\lambda=1600$ (Stock and Watson 1999, pg. 301). 
In the empirical section of the paper I make use of data from the RealTime Data Set for Macroeconomists from the Federal Reserve Bank of Philadelphia. I use first release data for real GDP/GNP under the heading NIPA Product Side - Real and inflation data from the Price Index for GNP/GDP under the Price Level Indices heading. Both of these variables can be obtained in Excel format from https://www.philadelphiafed.org/research-anddata/real-time-center/real-time-data/data-files/first-second-third.

The second source of data used in the empirical investigation of noise uses data from the Federal Reserve's Greenbook. This data is also available from the Federal Reserve Bank of Philadelphia at https://www.philadelphiafed.org/researchand-data/real-time-center/greenbook-data/. Again, I use measures for Real GDP and GDP Price inflation.

\section{B.4.2 Estimation}

To estimate the posterior mode of the model I use a simulated annealing algorithm as in Goffe et al. (1994). The algorithm combines grid search with random movements in the parameter space which allows for movements parameter vector which are not always improvements in the likelihood. I initialize the temperature to 5 and set $N_{t}=5$ and $N_{s}=20$. The temperature convergence criterion is set to $1 \mathrm{e}-8$. The algorithm is described below.

After obtaining posterior mode estimates of the structural parameters, I simulate the posterior distributions of the parameters using the RandomWalk Metropolis Hastings algorithm with 2 million replications (S in algorithm below). The algorithm is described below.

In Table B.1 I report the model predicted standard deviations of inflation, output, and the nominal interest rate in the pre-1979 and post-1983 periods.

In Table B.2 I report the unconditional variance decomposition of output, inflation, and the nominal interest rate in the pre-1979 and post-1983 periods. 

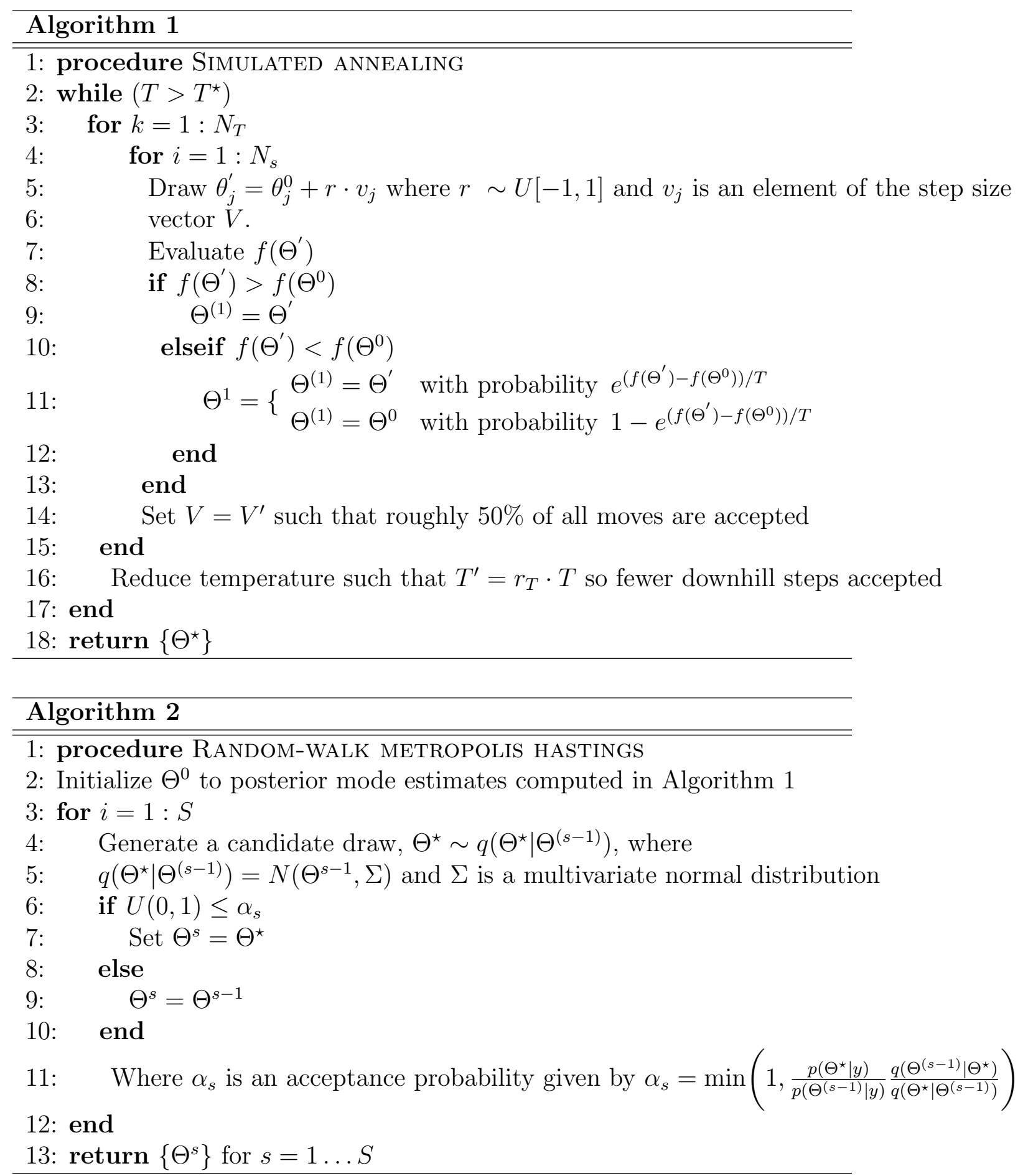


\begin{tabular}{l|lll}
\hline Pre-1979 & Output & Inflation & Nominal rate \\
Data & 1.7258 & 0.6755 & 0.6062 \\
Model & 3.0081 & 0.4881 & 0.6109 \\
& & & \\
Post-1983 & & & \\
Data & 1.3406 & 0.2211 & 0.6131 \\
Model & 1.4114 & 0.2540 & 0.4714 \\
\hline
\end{tabular}

Notes: Output in the data is real GDP detrended using a one-sided HodrickPrescott filter.

Table B.1: Data and model standard deviations

\begin{tabular}{l|cccccc} 
& \multicolumn{7}{c}{ Pre-1979 } \\
Moment $\downarrow /$ Shock $\rightarrow$ & Tech. & Cost push & Preference & MP & Inf. noise & Output noise \\
\hline Output & 0.0001 & 0.0277 & 0.6842 & 0.0303 & 0.2311 & 0.0265 \\
Inf. & 0.0031 & 0.8675 & 0.0553 & 0.0040 & 0.0598 & 0.0103 \\
Nom. rate & 0.0002 & 0.0599 & 0.1890 & 0.1231 & 0.5067 & 0.1211 \\
& & \multicolumn{7}{c}{ Post-1983 } \\
Moment $\downarrow /$ Shock $\rightarrow$ & Tech. & Cost push & Preference & MP & Inf. noise & Output noise \\
\hline Output & 0.0002 & 0.0316 & 0.4603 & 0.0375 & 0.3940 & 0.0765 \\
Inf. & 0.0086 & 0.7870 & 0.0888 & 0.0048 & 0.0623 & 0.0485 \\
Nom. rate & 0.0001 & 0.0218 & 0.4287 & 0.0754 & 0.2732 & 0.2008 \\
\hline
\end{tabular}

Table B.2: Unconditional variance decomposition 


\section{B.5 Additional results}
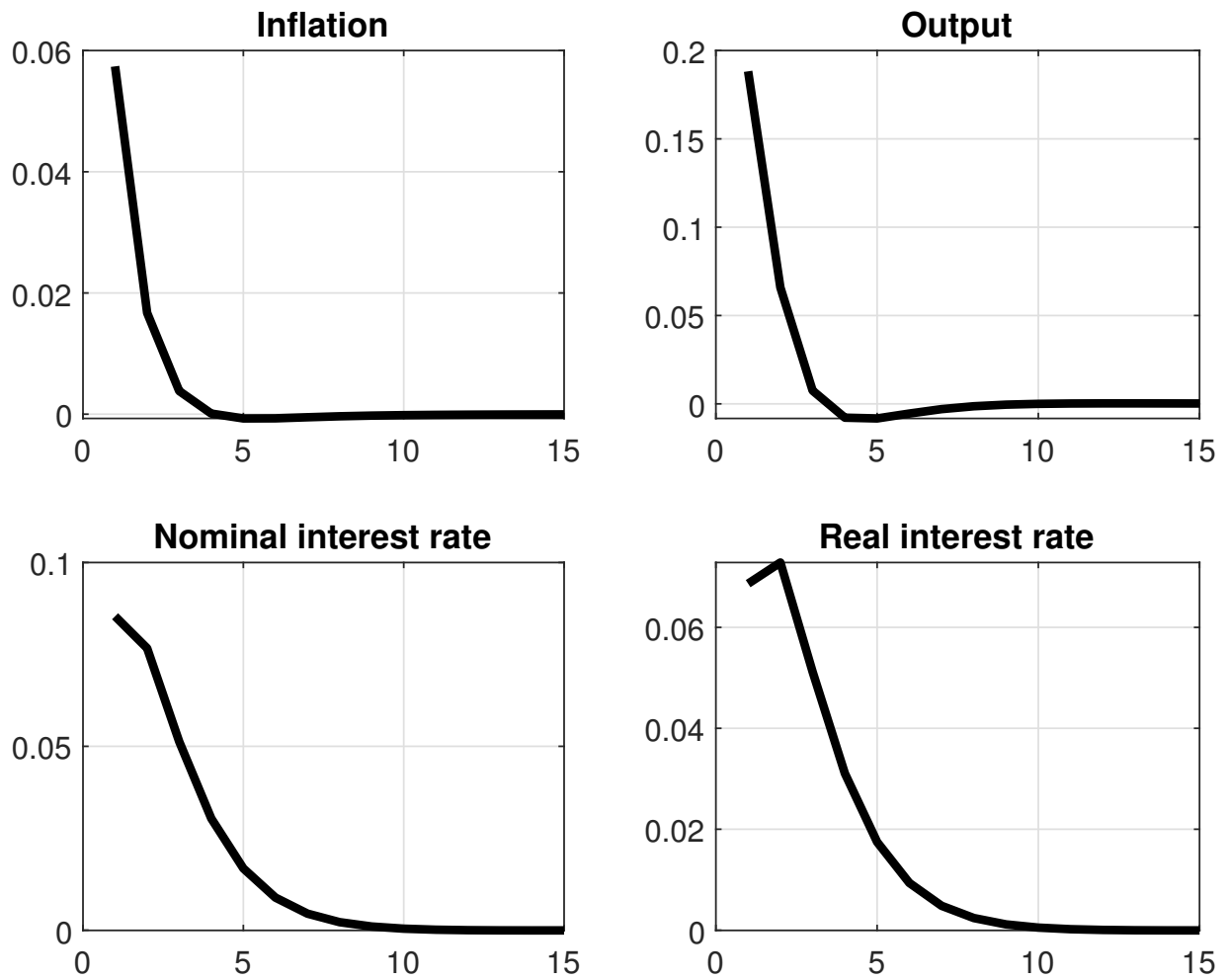

Figure B.1: Output noise shock

Notes: The IRF in this figure uses the estimated structural parameters from the pre-1979 estimation. The real interest rate reported here is the ex-post real interest rate, consistent with the focus in the empirical section of the paper. The impulse response function is computed using a one standard deviation output noise shock. 


\section{Bibliography}

Calvo, G. A.: 1983, Staggered prices in a utility-maximizing framework, Journal of Monetary Economics 12(3), 383-398.

Goffe, W., Ferrier, G. and Rogers, J.: 1994, Global optimization of statistical functions with simulated annealing, Journal of Econometrics 60(1), 65 99.

Pfeifer, J.: 2020, A Guide to Specifying Observation Equations for the Estimation of DSGE Models, Technical report.

Stock, J. H. and Watson, M. W.: 1999, Forecasting inflation, Journal of Monetary Economics 44(2), 293-335.

Svensson, L. E. and Woodford, M.: 2003, Indicator variables for optimal policy, Journal of Monetary Economics 50(3), 691 - 720. 


\section{Appendix $\mathrm{C}$}

\section{Appendix to Has the US Business Cycle Become More Asymmetric?}

\section{C.1 Data Sources}

The data used in this paper were obtained from the Federal Reserve Economic Data database (FRED) maintained by the Federal Reserve Bank of St. Louis. The data were obtained on December 8, 2018. Nominal variables are converted to real using each series corresponding deflator. The series used in the paper and their corresponding FRED codes are described below:

Non-durable consumption and services are added together after deflating each series with its respective price deflator. 


\begin{tabular}{lcc} 
Variable & Sample & FRED code \\
\hline \hline GDP & $1947:$ I-2018:II & GDP \\
GDP Deflator & $1947: I-2018: I I$ & GDPDEF \\
Personal Consumption Expenditures (PCE) & 1947:I-2018:II & PCEC \\
PCE Implicit Price Deflator & $1947: I-2018: I I$ & DPCERD3Q086SBEA \\
PCE: Durable Goods & $1947: I-2018: I I$ & PCDG \\
PCE: Durable Goods Deflator & $1947: I-2018: I I$ & DDURRD3Q086SBEA \\
PCE: Nondurable Goods & $1947: I-2018: I I$ & PCND \\
PCE: Nondurable Goods Deflator & $1947: I-2018: I I$ & DNDGRD3Q086SBEA \\
PCE: Services & $1947: I-2018: I I$ & PCESV \\
PCE: Services Deflator & $1947: I-2018: I I$ & DSERRD3Q086SBEA \\
Gross Private Investment & $1947: I-2018: I I$ & GPDI \\
Gross Private Investment Deflator & $1947: I-2018: I I$ & A006RD3Q086SBEA \\
Residential Investment & $1947: I-2018: I I$ & PRFI \\
Residential Investment Deflator & $1947: I-2018: I I$ & A011RD3Q086SBEA \\
Non-residential Investment & $1947: I-2018: I I$ & PNFI \\
Non-residential Investment Deflator & $1947: I-2018: I I$ & A008RD3Q086SBEA \\
\hline
\end{tabular}

Table C.1: Data sources

\section{C.2 Bai and Ng (2005) Standard Errors for Sample Skewness}

To compute standard errors for skewness coefficients in the paper I use the correction suggested by Bai and Ng (2005). Under Corollary 1, when testing for $\tau=0$, one only needs to test the sampling properties of,

$$
\frac{1}{\sqrt{T}} \sum_{t=1}^{T} \mathbf{Z}_{t}=\frac{1}{\sqrt{T}} \sum_{t=1}^{T}\left[\begin{array}{c}
\left(X_{t}-\mu\right)^{3} \\
\left(X_{t}-\mu\right)
\end{array}\right]
$$

where $\boldsymbol{\Gamma}=\lim _{T \rightarrow \infty} \mathrm{E}\left(\mathbf{Z} \mathbf{Z}^{\prime}\right)$. $\boldsymbol{\Gamma}$ is estimated using a Newey-West approximation where the number of lags is chosen according to the rule-of-thumb $T^{1 / 4}$. This leads to the following result, 


$$
\sqrt{T} \hat{\tau} \rightarrow \mathrm{N}\left(0, \frac{\alpha_{2} \boldsymbol{\Gamma}_{22} \alpha_{2}^{\prime}}{\sigma^{6}}\right)
$$

where $\alpha_{2}=\left[1,-3 \sigma^{2}\right]$. Then the empirical standard error is given by $s(\hat{\tau})=$ $\left(\frac{\alpha_{2} \boldsymbol{\Gamma}_{22} \alpha_{2}}{\sigma^{6}}\right)^{1 / 2}$. The difference between this standard error and the typical sample skewness standard error is the normalizing constant in the denominator.

\section{C.3 Additional Results}

\begin{tabular}{lcccc} 
& \multicolumn{2}{c}{ Hamilton Filtered } & \multicolumn{2}{c}{ Growth Rates } \\
& Q-stat & P-value & Q-stat & P-value \\
\hline GDP & 602.57 & 0.00 & 57.05 & 0.00 \\
Consumption & 614.71 & 0.00 & 42.19 & 0.00 \\
Durable Consumption & 609.37 & 0.00 & 21.21 & 0.02 \\
Non-durable and Services & 565.48 & 0.00 & 116.09 & 0.00 \\
Gross Private Investment & 645.51 & 0.00 & 36.44 & 0.00 \\
Fixed Investment & 633.60 & 0.00 & 112.44 & 0.00 \\
Non-residential Investment & 602.05 & 0.00 & 104.25 & 0.00 \\
$\begin{array}{l}\text { Residential Investment } \\
\text { N }\end{array}$ & 639.28 & 0.00 & 114.59 & 0.00 \\
\hline
\end{tabular}

Table C.2: Ljung-Box test results

Note: Ljung-Box test results were performed allowing for autocorrelation up to lag 10. 


\begin{tabular}{lcccccc} 
& Deepness (HP) & P-value & Decision & Deepness (BN) & P-value & Decision \\
\hline \hline GDP & -0.487 & 0.775 & Do Not Reject & 1.036 & 0.121 & Do Not Reject \\
Cons. & 0.677 & 0.145 & Do Not Reject & 1.029 & 0.085 & Reject \\
D. Cons. & 1.985 & 0.058 & Reject & 3.134 & 0.025 & Reject \\
ND S. Cons. & -0.108 & 0.639 & Do Not Reject & 0.269 & 0.287 & Do Not Reject \\
GPI & 2.114 & 0.035 & Reject & 2.757 & 0.079 & Reject \\
NR. Inv. & -0.054 & 0.530 & Do Not Reject & 1.403 & 0.035 & Reject \\
R. Inv. & -0.036 & 0.555 & Do Not Reject & 2.465 & 0.011 & Reject \\
\hline
\end{tabular}

Table C.3: Changing business cycle asymmetry: Alternative filters

Note: The hypothesis test is $H_{0}: \hat{\tau_{1}}-\hat{\tau_{2}}<0$ and $H_{A}: \hat{\tau_{1}}-\hat{\tau_{2}} \geq 0$. The test is comparing deepness and steepness from 1949:4-1983:4 to 1984:1-2018:2. P-values are bootstrapped using a moving-block bootstrap with 9999 replications.

\begin{tabular}{|c|c|c|c|c|c|c|}
\hline & Steepness (MA) & P-value & Decision & Steepness (YoY) & P-value & Decision \\
\hline GDP & 1.765 & 0.092 & Reject & 1.799 & 0.110 & Do Not Reject \\
\hline Cons. & 1.161 & 0.049 & Reject & 1.144 & 0.052 & Reject \\
\hline D. Cons. & 2.975 & 0.008 & Reject & 2.533 & 0.019 & Reject \\
\hline ND S. Cons. & 0.465 & 0.174 & Do Not Reject & 0.452 & 0.181 & Do Not Reject \\
\hline GPI & 3.727 & 0.072 & Reject & 5.015 & 0.107 & Do Not Reject \\
\hline NR. Inv. & 1.847 & 0.029 & Reject & 1.550 & 0.039 & Reject \\
\hline R. Inv. & 2.704 & 0.003 & Reject & 3.537 & 0.003 & Reject \\
\hline
\end{tabular}

Table C.4: Changing business cycle asymmetry: Alternative growth rates

Note: The hypothesis test is $H_{0}: \hat{\tau_{1}}-\hat{\tau_{2}}<0$ and $H_{A}: \hat{\tau_{1}}-\hat{\tau_{2}} \geq 0$. The test is comparing deepness and steepness from 1949:4-1983:4 to 1984:1-2018:2. P-values are bootstrapped using a moving-block bootstrap with 9999 replications. 


\begin{tabular}{|c|c|c|c|}
\hline & Sample & Deepness & Steepness \\
\hline \multirow[t]{4}{*}{ GDP } & 1949.3-2018.2 & -14.51 & -0.05 \\
\hline & $1949.3-1983.4$ & -6.11 & -0.29 \\
\hline & $1984.1-2007.4$ & -4.87 & -0.05 \\
\hline & $1984.1-2018.2$ & -14.42 & -0.23 \\
\hline \multirow[t]{4}{*}{ Cons. } & 1949.3-2018.2 & -10.84 & -0.21 \\
\hline & $1949.3-1983.4$ & -8.79 & -0.57 \\
\hline & $1984.1-2007.4$ & -3.33 & -0.02 \\
\hline & $1984.1-2018.2$ & -11.13 & -0.05 \\
\hline \multirow[t]{4}{*}{ D. Cons. } & $1949.3-2018.2$ & -541.82 & -5.54 \\
\hline & 1949.3-1983.4 & -422.16 & -2.47 \\
\hline & 1984.1-2007.4 & -226.53 & -1.74 \\
\hline & $1984.1-2018.2$ & -527.37 & -6.30 \\
\hline \multirow[t]{4}{*}{ ND S. Cons. } & 1949.3-2018.2 & -2.67 & -0.01 \\
\hline & $1949.3-1983.4$ & -1.41 & -0.06 \\
\hline & $1984.1-2007.4$ & -0.97 & -0.01 \\
\hline & $1984.1-2018.2$ & -3.82 & -0.02 \\
\hline \multirow[t]{4}{*}{ GPI } & $1949.3-2018.2$ & -1407.72 & -17.18 \\
\hline & 1949.3-1983.4 & -639.57 & -25.83 \\
\hline & $1984.1-2007.4$ & -210.15 & -2.81 \\
\hline & $1984.1-2018.2$ & -2171.47 & -22.13 \\
\hline \multirow[t]{4}{*}{ NR. Inv. } & 1949.3-2018.2 & -369.58 & -6.82 \\
\hline & 1949.3-1983.4 & -115.40 & -6.58 \\
\hline & 1984.1-2007.4 & -362.00 & -2.35 \\
\hline & $1984.1-2018.2$ & -640.94 & -8.67 \\
\hline \multirow[t]{4}{*}{ R. Inv. } & $1949.3-2018.2$ & -3627.71 & -44.14 \\
\hline & 1949.3-1983.4 & 912.05 & -60.75 \\
\hline & $1984.1-2007.4$ & -1735.93 & -19.10 \\
\hline & 1984.1-2018.2 & -6856.03 & -40.54 \\
\hline
\end{tabular}

Table C.5: 3rd central moments: Pre- and post-1984 


\begin{tabular}{lcccccc} 
& Deepness & P-value & Decision & Steepness & P-value & Decision \\
\hline \hline GDP & 1.629 & 0.021 & Reject & 2.715 & 0.001 & Reject \\
Cons. & 0.822 & 0.122 & Do Not Reject & -0.584 & 0.645 & Do Not Reject \\
D. Cons. & 1.351 & 0.062 & Reject & 1.501 & 0.185 & Do Not Reject \\
ND S. Cons. & 0.960 & 0.071 & Reject & -0.148 & 0.559 & Do Not Reject \\
GPI & 2.122 & 0.007 & Reject & 2.604 & 0.056 & Reject \\
NR. Inv. & 1.134 & 0.038 & Reject & 3.199 & 0.012 & Reject \\
R. Inv. & 3.432 & 0.003 & Reject & 2.279 & 0.012 & Reject \\
\hline
\end{tabular}

Table C.6: Changing business cycle asymmetry: Pre- and post-1985

Note: The hypothesis test is $H_{0}: \hat{\tau_{1}}-\hat{\tau_{2}}<0$ and $H_{A}: \hat{\tau_{1}}-\hat{\tau_{2}} \geq 0$. The test is comparing deepness and steepness from 1949:4-1984:4 to 1985:1-2018:2. P-values are bootstrapped using a moving-block bootstrap with 9999 replications. 


\section{Bibliography}

Bai, J. and Ng, S.: 2005, Tests for skewness, kurtosis, and normality for time series data, Journal of Business \& Economic Statistics 23, 49-60. 


\section{Appendix D}

\section{Appendix to The real interest rate channel $i s$ structural in contemporary New-Keynesian models: A Note}

\section{D.1 The Model}

\section{D.1.1 Households}

The household problem is given by,

$$
\operatorname{Max} \sum_{t=0}^{\infty} \beta^{t}\left\{\log \left(C_{t}-\varepsilon_{C} C_{t-1}\right)-\frac{L_{t}^{1+\eta}}{1+\eta}\right\}
$$

subject to the following budget constraint and law of motion for capital which includes investment adjustment costs (IAC) and capital adjustment $\operatorname{costs}(\mathrm{CAC})^{1}$,

\footnotetext{
${ }^{1}$ We consider IAC and CAC in isolation by setting $\Omega$ or $\kappa$ equal to 0 .
} 


$$
\begin{array}{r}
W_{t} L_{t}+R_{t}^{k} K_{t}+\left(\frac{1+i_{t-1}}{1+\pi_{t}}\right) B_{t-1}=C_{t}+I_{t}+B_{t}, \\
K_{t+1}=(1-\delta) K_{t}+I_{t}\left[1-\frac{\Omega}{2}\left(\frac{I_{t}}{I_{t-1}}-1\right)^{2}\right]-\frac{\kappa}{2}\left(K_{t+1}-K_{t}\right)^{2},
\end{array}
$$

yielding the following equilibrium conditions,

$$
\begin{array}{r}
\lambda_{t}=\frac{1}{C_{t}-\varepsilon_{C} C_{t-1}}-E_{t}\left\{\frac{\beta \varepsilon_{C}}{C_{t+1}-\varepsilon_{C} C_{t}}\right\}, \\
L_{t}^{\eta}=\lambda_{t} W_{t}, \\
1=\beta E_{t}\left\{\left(\frac{\lambda_{t+1}}{\lambda_{t}}\right)\left(\frac{1+i_{t}}{1+\pi_{t+1}}\right)\right\}, \\
q_{t}\left(1+\kappa\left(K_{t+1}-K_{t}\right)=\beta E_{t}\left\{\left(\frac{\lambda_{t+1}}{\lambda_{t}}\right)\left(R_{t+1}^{k}+\left(1-\delta+\kappa\left(K_{t+2}-K_{t+1}\right)\right) q_{t+1}\right)\right\},\right. \\
1=q_{t}\left[1-\frac{\Omega}{2}\left(\frac{I_{t}}{I_{t-1}}-1\right)^{2}-\Omega\left(\frac{I_{t}}{I_{t-1}}-1\right)\left(\frac{I_{t}}{I_{t-1}}\right)\right]+\beta \Omega E_{t}\left\{q_{t+1}\left(\frac{\lambda_{t+1}}{\lambda_{t}}\right)\left(\frac{I_{t+1}}{I_{t}}-1\right)\left(\frac{I_{t+1}}{I_{t}}\right)^{2}\right\},
\end{array}
$$

where $\lambda$ is the Lagrange multiplier on the budget constraint and $q$ is the ratio of the Lagrange multipliers on the law of motion for capital and the budget constraint.

\section{D.1.2 Intermediate firms}

Intermediate firms use a constant returns to scale technology and minimize costs subject to meeting demand. Wages and rental rates are common to all firms,

$$
\begin{gathered}
\operatorname{Min} R_{t}^{k} K_{t}+W_{t} L_{t} \quad \text { s.t. } \\
K_{t}(i)^{\alpha} L_{t}(i)^{1-\alpha} \geq\left(\frac{P_{t}(i)}{P_{t}}\right)^{\frac{1}{\varepsilon-1}} Y_{t}
\end{gathered}
$$

which yields the optimal mix of capital and labour in production and marginal 
cost,

$$
\begin{array}{r}
\frac{W_{t}}{R_{t}^{k}}=\left(\frac{1-\alpha}{\alpha}\right)\left(\frac{K_{t}}{L_{t}}\right), \\
\chi_{t}=\left(\frac{R_{t}^{k}}{\alpha}\right)^{\alpha}\left(\frac{W_{t}}{1-\alpha}\right)^{1-\alpha} .
\end{array}
$$

Letting $\theta$ denote the probability that a firm cannot adjust its prices, the firm chooses $P_{t}(j)$ taking into account it may not be able to change its price for a very long time and maximizes real profit,

$\operatorname{Max} E_{t} \sum_{s=0}^{\infty}(\beta \theta)^{s}\left(\frac{U^{\prime}\left(C_{t+s}\right)}{U^{\prime}\left(C_{t}\right)}\right)\left(\frac{P_{t}(j)}{P_{t+s}}\left(\frac{P_{t}(j)}{P_{t+s}}\right)^{\frac{1}{\varepsilon-1}} Y_{t+s}-\frac{\chi_{t+s}}{P_{t+s}}\left(\frac{P_{t}(j)}{P_{t+s}}\right)^{\frac{1}{\varepsilon-1}} Y_{t+s}\right)$

which yields the standard New-Keynesian Phillips Curve,

$$
\pi_{t}=\beta E_{t} \pi_{t+1}+\Psi \hat{\chi}_{t}
$$

where $\Psi=\frac{(1-\beta \theta)(1-\theta)}{\theta} \frac{1-\alpha}{1-\alpha+\frac{\alpha}{1-\varepsilon}}$.

\section{D.1.3 Final goods firms}

The final goods sector is perfectly competitive and aggregates intermediate inputs to produce final goods. The final goods problem is given by,

$$
\operatorname{Max} P_{t} Y_{t}-\int_{0}^{1} P_{t}(i) Y_{t}(i)
$$

where $Y_{t}=\left(\int_{0}^{1} Y_{t}(i)^{\varepsilon}\right)^{\frac{1}{\varepsilon}}$, which yields the standard downward sloping de- 
mand function for intermediate firm $i$ 's input,

$$
Y_{t}(i)=\left(\frac{P_{t}(i)}{P_{t}}\right)^{\frac{1}{\varepsilon-1}} Y_{t}
$$

that states that the demand for input $i$ is a function of its relative price and price elasticity of demand.

\section{D.1.4 Monetary policy rule and market clearing con- ditions}

Following Rupert and Šustek (2019), we set the weight on the output gap to 0 in the Taylor rule,

$$
i_{t}=i+\nu \pi_{t}+\xi_{t},
$$

where $\xi_{t}$ is an $\mathrm{AR}(1)$ process with varying degrees of persistence given by,

$$
\log \xi_{t}=\rho_{m} \log \xi_{t-1}+\epsilon_{t}, \quad \rho_{m} \in(0,1), \epsilon \sim N\left(0, \sigma_{m}^{2}\right)
$$

Lastly, the aggregate resource constraint states that all output is either invested or consumed,

$$
Y_{t}=C_{t}+I_{t}
$$

\section{D.1.5 Solving for the steady state}

To solve for the steady state, we starting by normalizing steady state output to 1 . The firm first order condition for capital then yields, 


$$
R^{k}=\frac{\alpha}{K}
$$

combining this with the steady state Euler equation for capital, we can solve for steady state capital as,

$$
K=\left(\frac{\alpha}{\frac{1}{\beta}-1+\delta}\right)
$$

From here it is straightforward to solve for steady levels of labour, consumption and investment.

\section{D.1.6 Log-linearizing the model}

Log-linearizing the optimality conditions and the capital law of motion yields the following system of equations ${ }^{2}$,

\footnotetext{
${ }^{2}$ Recall that $\hat{x_{t}}=\frac{x_{t}-x}{x}$ for all variables excluding the nominal interest rate and return on capital, which are expressed in percentage point deviations (i.e., $x_{t}=x_{t}-x$ ).
} 


$$
\begin{aligned}
& \left(1-\varepsilon_{C}\right)\left(1-\beta \varepsilon_{C}\right) \hat{\lambda}_{t}=\theta \hat{C}_{t-1}-\left(1+\beta \varepsilon_{C}^{2}\right) \hat{C}_{t}+\beta \varepsilon_{C} E_{t} \hat{C}_{t+1} \\
& \hat{\lambda}_{t}+\hat{W}_{t}=\frac{\eta}{1-\alpha} \hat{Y}_{t}-\frac{\alpha \eta}{1-\alpha} \hat{K}_{t} \\
& \hat{\lambda}_{t}=E_{t} \hat{\lambda}_{t+1}+\hat{i}_{t}-E_{t} \pi_{t+1} \\
& \hat{L}_{t}=\frac{1}{1-\alpha} \hat{Y}_{t}-\frac{\alpha}{1-\alpha} \hat{K}_{t} \\
& \hat{R}_{t}^{k}=R^{k}\left(\hat{L}_{t}-\hat{K}_{t}+\hat{W}_{t}\right) \\
& \hat{\chi}_{t}=\hat{W}_{t}+\frac{\alpha}{1-\alpha} \hat{Y}_{t}-\frac{\alpha}{1-\alpha} \hat{K}_{t} \\
& \pi_{t}=\Psi \hat{\chi}_{t}+\beta E_{t} \pi_{t+1} \\
& \hat{i}_{t}^{n}=v \pi_{t}+\xi_{t} \\
& \hat{Y}_{t}=\frac{C}{Y} \hat{C}_{t}+\frac{I}{Y} \hat{I}_{t} \\
& \delta \hat{I}_{t}=\hat{K}_{t+1}-(1-\delta) \hat{K}_{t} \\
& \hat{q}_{t}=\Omega(1+\beta) \hat{I}_{t}-\Omega \hat{I}_{t-1}-\beta \Omega \hat{I}_{t+1} \\
& \hat{q}_{t}+\kappa K\left(\hat{K}_{t+1}-\hat{K}_{t}\right)=E_{t} \hat{\lambda}_{t+1}-\hat{\lambda}_{t}+E_{t} \hat{R}_{t+1}^{k}+(1-\delta) E_{t} \hat{q}_{t+1}+\kappa K\left(\hat{K}_{t+2}-\hat{K}_{t+1}\right)
\end{aligned}
$$




\section{D.2 Dynare Codes}

All results in the paper can be recreated using the following Dynare code (parameters for persistence of shock and adjustment costs will need to be changed to match each figures specification). Alternatively, it is possible to download files to recreate the exact figures in the paper from www.joshuabrault.com/research. ${ }^{3}$

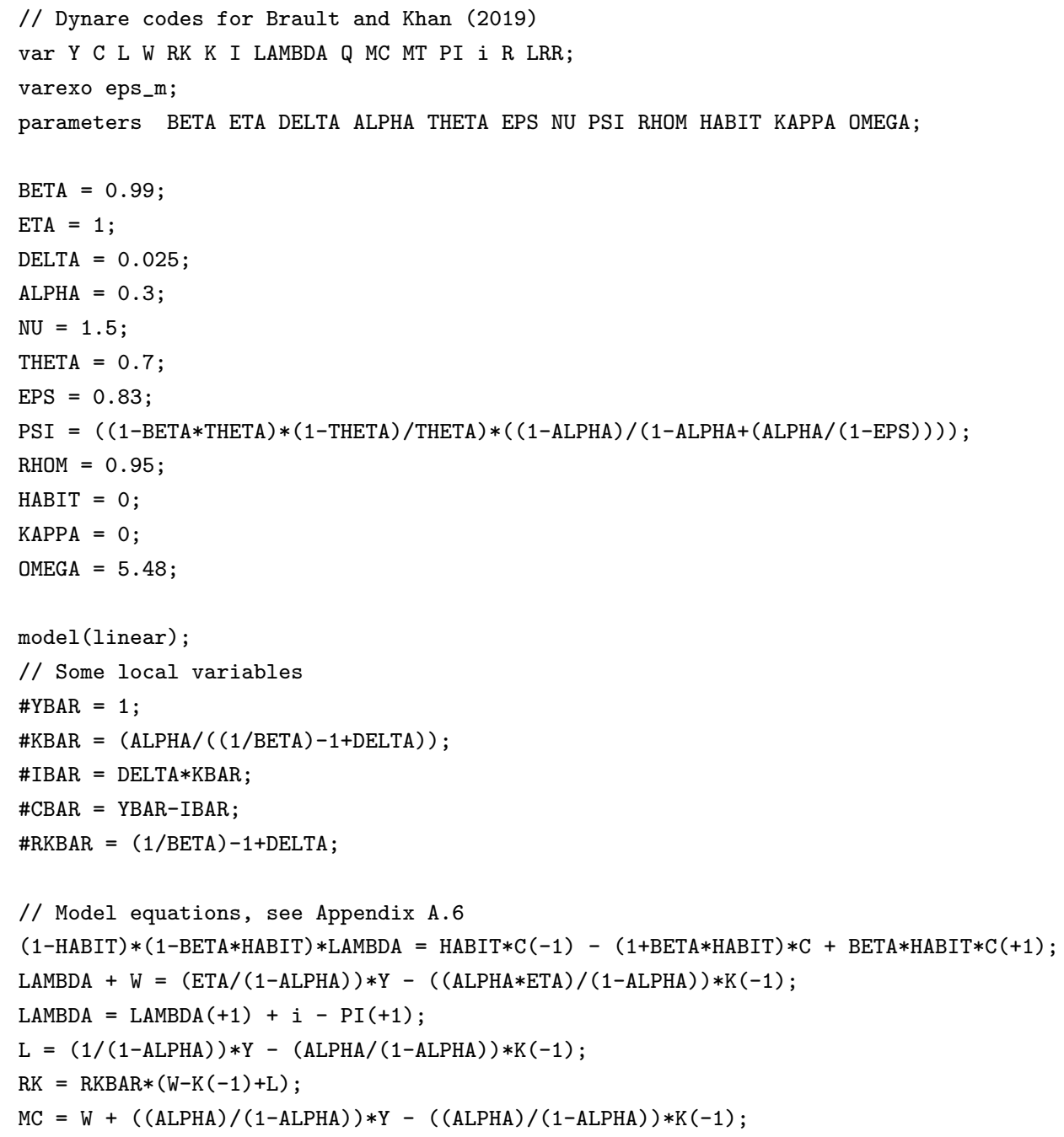

\footnotetext{
${ }^{3}$ All computations were done using Matlab 2018b and Dynare 4.5.7 (Adjemian et al. (2011)). In Dynare, capital is a predetermined variable which implies it must show up as dated $t-1$. As is customary, we lead capital by 1 period.
} 


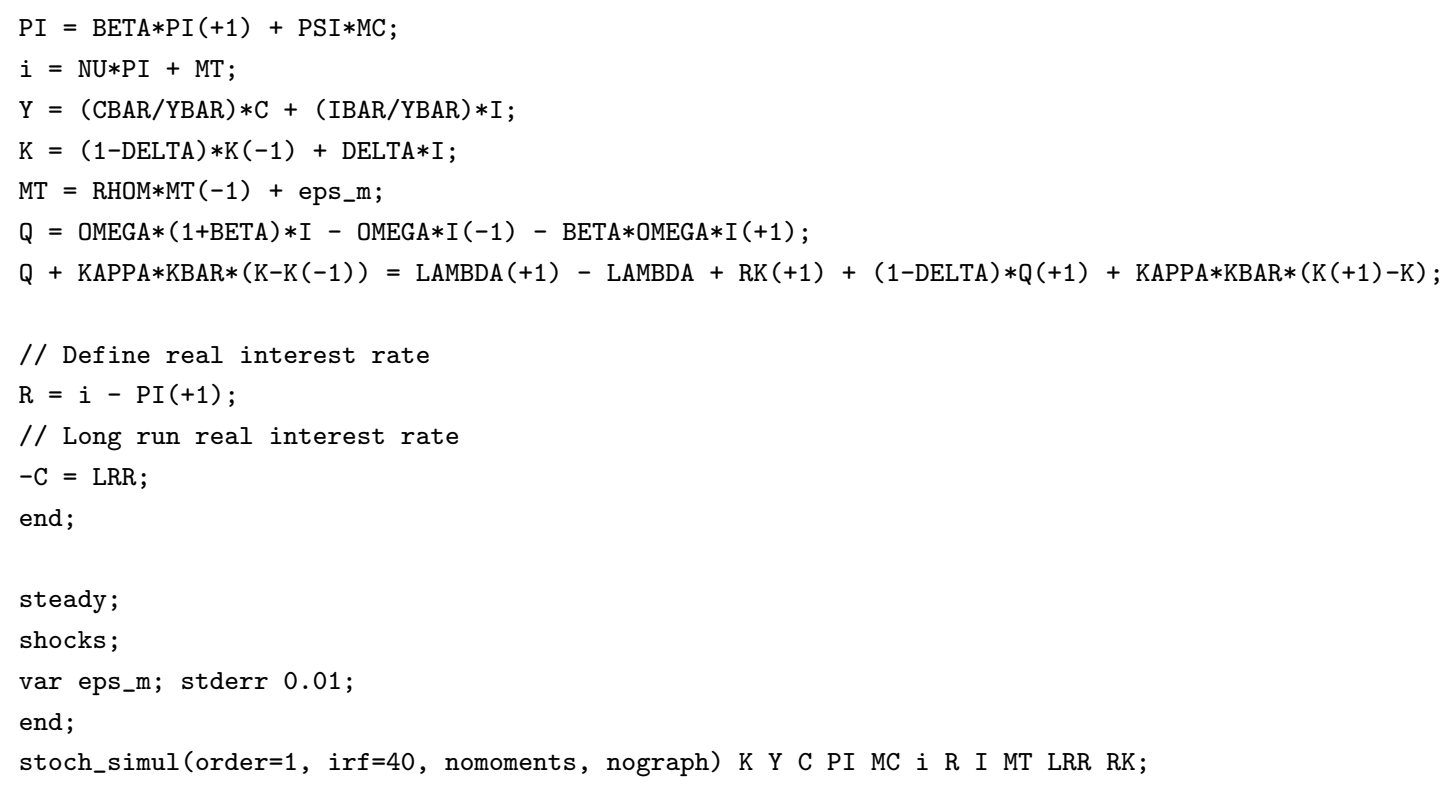




\section{Bibliography}

Adjemian, S., Bastani, H., Juillard, M., Karamé, F., Maih, J., Mihoubi, F., Perendia, G., Pfeifer, J., Ratto, M. and Villemot, S.: 2011, Dynare: Reference Manual Version 4, Dynare Working Papers 1, CEPREMAP.

Rupert, P. and Šustek, R.: 2019, On the mechanics of new Keynesian models, Journal of Monetary Economics 102, 53-69. 